\author{
Juliana Ferrari Mancio
}

\title{
Variação sazonal das correntes na plataforma continental interna e média de São Paulo: forçantes e respostas
}

\begin{abstract}
Dissertação apresentada ao Instituto Oceanográfico da Universidade de São Paulo, como parte dos requisitos para obtenção do título de Mestre em Ciências, Programa de Oceanografia, área de Oceanografia Física
\end{abstract}

Orientador:

Prof. Dr. Belmiro Mendes de Castro Filho

São Paulo

2019 


\title{
UNIVERSIDADE DE SÃO PAULO INSTITUTO OCEANOGRÁFICO
}

\section{Variação sazonal das correntes na plataforma continental interna e média de São Paulo: forçantes e respostas}

\author{
Juliana Ferrari Mancio
}

Dissertação apresentada ao Instituto Oceanográfico da Universidade de São Paulo, como parte dos requisitos para obtenção do título de Mestre em Ciências, Programa de Oceanografia, área de Oceanografia Física

Julgada em 1

VERSÃO CORRIGIDA 
À minha família, e a todos os perseverantes cientistas brasileiros.

"it always seems impossible until it is done"

NELSON MANDELA 


\section{Sumário}

Resumo ........................ $\mathrm{i}$

Abstract ..................... i

Lista de Figuras .................... . . . i

Lista de Tabelas . . . . . . . . . . . . . . . . . viii

1 Introdução 1

1.1 Plataforma Continental Sudeste . . . . . . . . . . . . . . . . 1

1.2 Sistemas atmosféricos na Plataforma Continental Sudeste . . . . . . . . . 7

1.3 A circulação na Plataforma Continental Sudeste . . . . . . . . . . . . . . 9

1.4 Hipótese e objetivos . . . . . . . . . . . . . . . . . . . . . . . 13

2 Métodos e dados $\quad 14$

2.1 Modelo numérico . . . . . . . . . . . . . . . . . . . . . . . . 14

2.2 Experimentos numéricos . . . . . . . . . . . . . . . . 20

2.3 Dados . . . . . . . . . . . . . . . . . . . . 22

3 Resultados e discussão $\quad 25$

3.1 Validação do modelo . . . . . . . . . . . . . . . . 25

3.2 Campos horizontais de temperatura e salinidade . . . . . . . . . . . . . 29

3.3 Campos horizontais de correntes sazonais . . . . . . . . . . . . . 34

3.3.1 Resposta das correntes à entrada de frente fria . . . . . . . . . . . 43

3.4 Transpote paralelo à costa . . . . . . . . . . . . . . . . . 57

3.5 Nível médio do mar . . . . . . . . . . . . . . . . . . . . . . 67

4 Conclusões $\quad 83$

Referências Bibliográficas . . . . . . . . . . . . . . 86 


\section{Agradecimentos}

Ao Instituto Oceanográfico da USP, por toda a infraestrutura oferecida para a realização deste mestrado.

Ao U. S. Office of Naval Research Global, pela bolsa concedida.

À secretaria de pós graduação, Daniel, Ana Paula e Letícia, pelo trabalho prestado.

Ao professor Dr. Belmiro Castro, pela orientação e pelas aulas ministradas.

Ao professor Dr. Ilson Silveira, pelas aulas ministradas, pelas conversas e por me aceitar como "anexo" ao LaDO.

Ao professor Dr. Luiz Miranda, pelas aulas ministradas e por tantas histórias inspiradoras.

Ao professor Marcelo Dottori, por me receber na sua sala, e pelas conversas oceanográficas e não oceanográficas.

Aos professores Polito e Olga, pelas conversas e conselhos pelos corredores.

Ao Laboratório de Hidrodinâmica Costeira pela acolhida nestes anos. Pelos colegas e amigos aqui criados. Em especial aos técnicos do laboratório, Carine e José Roberto, por estarem sempre com as portas abertas para ajudar a sanar as minhas dúvidas; Dalton, Danilo e Paulinha, por tantas ajudas e conversas neste tempo dividindo uma sala; Potranca pelas conversas descontraídas e momentos de desabafo no pouco tempo em que dividimos a mesa; Rafinha pelas dicas salvadoras na reta final. Pela amizade ali criada.

Ágata, Cauê e Igor, pela amizade criada na salinha de confinamento durante as (quase) intermináveis listas de DFG. Por todos "tu consegue", "vai da tudo certo", "eu te ajudo". À Laura, pela amizade, pelo ano dividido em SP, pelo suporte emocional, pelas discussões oceanográficas (e não oceanográficas) via whatsapp.

Aos meus pais e meu irmão, pela base, pela certeza de ter sempre pra onde voltar.

Ao Cauê, pela parceria, pelas noites viradas fazendo listas de exercício, formatando trabalhos, pelas discussões acadêmicas do café da manhã ao jantar. Por topar a loucura de casar no meio do mestrado e do doutorado. Por estar sempre presente. Por seguir sempre lado a lado. Por nunca deixar cair.

A todos que de uma forma ou outra se fizerem presentes neste período. Hoje saio uma pessoa muito diferente da que chegou aqui em 2017.

Muito obrigada. 


\section{Resumo}

A Plataforma Continental de São Paulo situa-se na região central da Plataforma Continental Sudeste. É uma plataforma larga, cuja ciruculação é dirigida em resposta às forçantes de vento, maré, variação de densidade e da Corrente do Brasil. Entretanto, a sazonalidade do papel relativo destas forçantes sobre a circulação costeira, assim como o papel das forçantes em anos com circulação atmosférica anômala, não são muito bem compreendidos. Este trabalho tem como objetivo estudar esta resposta referente às três primeiras forçantes, considerando a variação sazonal e duas situações atomosféricas diferentes: normal e ENSO (La Niña). Foram realizados experimentos numéricos através da suíte ECOM. Foram simulados os campos horizontais de temperatura, salinidade e velocidade, e calculados os transportes barotrópico e baroclínico, paralelos à linha de costa nas sessões transversais em frente à Ubatuba, Santos e Cananéia, até a isóbata de $100 \mathrm{~m}$. Não foram observados padrões bem definidos de variação da circulação horizontal entre o ano neutro e o ano de La Niña, sendo que as principais diferenças encotradas estão relacionadas à sazonalidade das forçantes. Já o transporte de volume foi maior em todos experimentos de La Niña.

Palavras chave: Plataforma Continental,transporte de volume, nível médio do mar, La Niña, modelagem numérica, ECOM. 


\begin{abstract}
The Sao Paulo Continental Shelf (SPCS) is part of the southeast Brazilian Coast, which is located between the latitudes of $19^{\circ} \mathrm{S}$ and $34^{\circ} \mathrm{S}$. It is a wide shelf, where the circulation is mainly driven by the winds, the tides, the density variations, and the Brazil Current. However, the seasonal variation of those forcing mechanisms is not completely understood, as well as the interannual variations related to atmospheric anomalies as the ENSO. The aim of this study was to understand the SPCS seasonal circulation in response to those forcing mechanism. The seasonal circulation variability was analyzed during two years, one "normal" year, with no atmospheric anomalies, and an ENSO - La Nina year. The numerical experiments were conducted using the ECOM model. The alongshelf barotropic and baroclinic seasonal transports were calculated, showing that the LN experiment showed greater values.
\end{abstract}

Key words: Continental Shelf, volume transport, sea level, La Niña, numerical modeling, ECOM. 


\section{Lista de Figuras}

1.1 Localização da Plataforma Continental Sudeste, com a topografia em metros. Fonte: Laboratório de Hidrodinâmica Costeira. . . . . . . . . . . . . . . . 2

1.2 Representação esquemática das regiões da Plataforma Continental de São Paulo: Plataforma Continental Interna (PCI), Plataforma Continental Média (PCM) e Plataforma Continental Externa (PCE). Estão representadas também as frentes que limitam estas regiões: a Frente Térmica profunda e a Frente Halina Superfícial. Além disso, encontram-se também representadas as três massas de água da região, com suas principais características, sendo $S$ salinidade e T temperatura: Água Costeira (AC), Água Tropical (AT) e Água Central do Atlantico Sul (ACAS) $($ Silva 2019). . . . . . . . . . . . . . . . . . . .

1.3 Representação gráfica de um modelo conceitual de frente fria durante o inverno, no sudeste do Brasil. Y aponta para o norte geográfico e X aponta para o leste geográfico. (Stech e Lorenzzetti 1992) . . . . . . . . . . . . . . . . 8

1.4 Exemplo de uma frente fria na costa do Brasil, em 10 de agosto de 1996 (Rodrigues, Franco, e Sugahara 2004). . . . . . . . . . . . . . . . . . . . 9

1.5 Divisão da PCSE e as forçantes atuantes em cada uma das sub divisões (Gregorio 2014). . . . . . . . . . . . . . . . . . . . . . . 10

2.1 Grade de diferenças finitas utilizada no Laboratório de Hidrodinâmica Costeira no modelo operacional da Plataforma Continental Sudeste. Topografia em metros. As radiais coloridas representam as sessões perpendiculares à costa em frente a Ubatuba (azul), Santos (vermelho) e Cananéia (preto). . . . . . . . . . 15

2.2 Sistema de coordenadas vertical sigma $(\sigma)$. Z é a profundidade local em metros, H é topografia e $\eta$ é a variação do nível médio do mar. . . . . . . . . . . . . . 16 
2.3 Localização do fundeio de correntógrafos $\mathrm{C} 2$ e do ponto de grade do modelo ECOM, selecionado para validação dos experimentos numéricos. . . . . . . . 23

3.1 Série temporal das componentes da velocidade perpendicular e paralela à costa. Profundidade utilizada no modelo para o skill: 13.40 m. Valor médio do skill é de 0.78 para a componente paralela à costa da velocidade, e 0.33 para a componente perpendicular à costa. Em preto estão os dados, e em azul, o resultado do modelo. . . . . . . . . . . . . . . . . . . . . . 26

3.2 Série temporal das componentes da velocidade perpendicular e paralela à costa. Profundidade utilizada no modelo para o skill: $9.3 \mathrm{~m}$. Valor médio do skill é de 0.68 para a componente paralela à costa da velocidade, e 0.43 para a componente perpendicular à costa. Em preto estão os dados e, em azul, o resultado do modelo. . . . . . . . . . . . . . . . . . .

3.3 Série temporal das componentes da velocidade perpendicular e paralela à costa. Profundidade utilizada no modelo para o skill: $14.3 \mathrm{~m}$. Valor médio do skill é de 0.73 para a componente paralela à costa da velocidade, e 0.33 para a componente perpendicular à costa. Em preto estão os dados, e em azul, o resultado do modelo. . . . . . . . . . . . . . . . . . . . . . . . . 28

3.4 Campo horizontal de Temperatura $\left({ }^{\circ} \mathrm{C}\right)$ e Salinidade. Figuras $(A)$ e $(C)$ representam a superfície, e figuras $(B)$ e $(D)$ representam o fundo. Figuras obtidas para o outono, após integração do modelo por 10 dias em modo prognóstico. . . 30

3.5 Campo horizontal de Temperatura $\left({ }^{\circ} \mathrm{C}\right)$ e Salinidade. Figuras $(A)$ e $(C)$ representam a superficie, e figuras $(B)$ e $(D)$ representam o fundo. Figuras obtidas para o inverno, após integração do modelo por 10 dias em modo prognóstico. . .

3.6 Campo horizontal de Temperatura $\left({ }^{\circ} \mathrm{C}\right)$ e Salinidade. Figuras $(A)$ e $(C)$ representam a superficie, e figuras $(B)$ e $(D)$ representam o fundo. Figuras obtidas para o primavera, após integração do modelo por 10 dias em modo prognóstico.

3.7 Campo horizontal de Temperatura $\left({ }^{\circ} \mathrm{C}\right)$ e Salinidade. Figuras $(A)$ e $(C)$ representam a superfície, e figuras $(B)$ e $(D)$ representam o fundo. Figuras obtidas para o verão, após integração do modelo por 10 dias em modo prognóstico. ..

3.8 Campo horizontal de velocidade média na camada superficial. Experimento de outono. Anos de La Niña (LN) e de ano neutro (AN). Intensidade representada pela cor, em $\mathrm{m} \mathrm{s}^{-1}$, e direção representada pelos vetores normalizados. . . . . . 35 
3.9 Campo horizontal de velocidade média na camada de fundo. Experimento de outono. Anos de La Niña (LN) e de ano neutro (AN). Intensidade representada pela cor, em $\mathrm{m} \mathrm{s}^{-1}$, e direção representada pelos vetores normalizados. . . . . . 36

3.10 Campo horizontal de velocidade média na camada de superfície. Experimento de inverno. Anos de La Niña (LN) e de ano neutro (AN). Intensidade representada pela cor, em $\mathrm{m} \mathrm{s}^{-1}$, e direção representada pelos vetores normalizados. . .

3.11 Campo horizontal de velocidade média na camada de fundo. Experimento de inverno. Anos de La Niña $(L N)$ e de ano neutro (AN). Intensidade representada pela cor, em $\mathrm{m} \mathrm{s}^{-1}$, e direção representada pelos vetores normalizados. . . . . . 38

3.12 Campo horizontal de velocidade média na camada de superfície. Experimento de primavera. Anos de La Niña $(L N)$ e de ano neutro (AN). Intensidade representada pela cor, em $\mathrm{m} \mathrm{s}^{-1}$, e direção representada pelos vetores normalizados. . 39

3.13 Campo horizontal de velocidade média na camada de fundo. Experimento de primavera. Anos de La Niña (LN) e de ano neutro (AN). Intensidade representada pela cor, em $\mathrm{m} \mathrm{s}^{-1}$, e direção representada pelos vetores normalizados. . .

3.14 Campo horizontal de velocidade média na camada de superfície. Experimento de verão. Anos de La Niña (LN) e de ano neutro (AN). Intensidade representada pela cor, em $\mathrm{m} \mathrm{s}^{-1}$, e direção representada pelos vetores normalizados. . . . . .

3.15 Campo horizontal de velocidade média na camada de fundo. Experimento de verão. Anos de La Niña ( $L N)$ e de ano neutro (AN). Intensidade representada pela cor, em $\mathrm{m} \mathrm{s}^{-1}$, e direção representada pelos vetores normalizados. . . . . .

3.16 Vento a $10 \mathrm{~m}$ da superfície no dia 23/09/2010. Experimento de primavera, no ano de La Niña. Período Pré Frontal. Intensidade representada pela cor, em $m s^{-1}$, e direção representada pelos vetores normalizados. . . . . . . . . . . . 44

3.17 Vento a $10 \mathrm{~m}$ da superfície no dia 25/09/2010. Experimento de primavera, no ano de La Niña. Frente Fria. Intensidade representada pela cor, em $\mathrm{m} \mathrm{s}^{-1}$, e direção representada pelos vetores normalizados. . . . . . . . . . . . . . . . 45

3.18 Vento a $10 \mathrm{~m}$ da superfície, no dia 26/09/2010. Experimento de primavera, no ano de La Niña. Pós Frente Fria. Intensidade representada pela cor, em $\mathrm{m} \mathrm{s}^{-1}$, e direção representada pelos vetores normalizados. . . . . . . . . . . . . . . 46 
3.19 Campo instantâneo de corrente. Experimento de primavera, no ano de LN. Intensidade representada pela cor, em $\mathrm{m} \mathrm{s}^{-1}$, e direção representada pelos vetores normalizados. Figuras $(A),(C)$ e $(E)$ representam a superfície; $(B),(D)$ e $(F)$ representam o fundo. Figuras $(A)$ e (B) são do dia 23/09/2010,0 (C) e (D) são do dia 25/09/2010 e (E) e (F) são do dia 26/09/2010. . . . . . . . . . . . . . . 48

3.20 Vento a $10 \mathrm{~m}$ da superfície no dia 01/06/2010. Experimento de outono, ano de La Niña. Passagem de frente fria. Intensidade representada pela cor, em $\mathrm{m} \mathrm{s}^{-1}$, e direção representada pelos vetores normalizados. . . . . . . . . . . . . . 50

3.21 Campo instantâneo de corrente. Experimento de outono, ano de LN. Intensidade representada pela cor, em $\mathrm{m} \mathrm{s}^{-1}$, e direção representada pelos vetores normalizados. Figuras $(A),(C)$ e $(E)$ representam a superfície; $(B),(D)$ e $(F)$ representam o fundo. Figuras (A) e (B) são do dia 30/05/2010, (C) e (D) são do dia 01/06/2010 e (E) e (F) são do dia 03/06/2010. . . . . . . . . . . . . . . .

3.22 Campo instantâneo de corrente. Experimento de inverno, no AN. Intensidade representada pela cor, em $\mathrm{m} \mathrm{s}^{-1}$, e direção representada pelos vetores normalizados. Figuras $(A),(C)$ e $(E)$ representam a superfície; $(B),(D)$ e $(F)$ representamo fundo. Figuras $(A)$ e (B) são do dia 04/08/2012, (C) e (D) são do dia 06/08/2012 $e(E) e(F)$ são do dia $08 / 08 / 2012 \ldots \ldots \ldots$

3.23 Transporte de volume paralelo à costa em Sv. Em preto o transporte total, em vermelho o transporte barotrópico e em azul o transporte baroclínico. (A) Ubatuba; (B) Santos; (C) Cananéia. Experimento de outono, ano de La Nña. . . . . 57

3.24 Transporte de volume paralelo à costa em Sv. Transporte total, barotrópico e baroclínico em preto, vermelho e azul, respectivamente. (A) Ubatuba; (B) Santos; (C) Cananéia. Experimento de outono, no ano neutro. . . . . . . . . . 58

3.25 Transporte de volume paralelo à costa em Sv. Transporte total, barotrópico e baroclínico em preto, vermelho e azul, respectivamente. (A) Ubatuba; (B) Santos; (C) Cananéia. Experimento de inverno, no ano de La Niña. . . . . . . . 59

3.26 Transporte de volume paralelo à costa em Sv. Transporte total, barotrópico e baroclínico em preto, vermelho e azul, respectivamente. (A) Ubatuba; (B) Santos; (C) Cananéia. Experimento de inverno, no ano neutro. . . . . . . . . . 
3.27 Transporte de volume paralelo à costa em Sv. Transporte total, barotrópico e baroclínico em preto, vermelho e azul, respectivamente. (A) Ubatuba; (B) Santos; (C) Cananéia. Experimento de primavera, no ano de La Niña. . . . . . 61

3.28 Transporte de volume paralelo à costa em Sv. Transporte total, barotrópico e baroclínico em preto, vermelho e azul, respectivamente. (A) Ubatuba; (B) Santos; (C) Cananéia. Experimento de primavera, no ano neutro. . . . . . . . 62

3.29 Transporte de volume paralelo à costa em Sv. Transporte total, barotrópico e baroclínico em preto, vermelho e azul, respectivamente. (A) Ubatuba; (B) Santos; (C) Cananéia. Experimento de verão, no ano de La Niña. . . . . . . . . 63

3.30 Transporte de volume paralelo à costa em SV. Transporte total, barotrópico e baroclínico em preto, vermelho e azul, respectivamente. (A) Ubatuba; (B) Santos; (C) Cananéia. Experimento de verão, no ano neutro. . . . . . . . . . . . . . . 64

3.31 Transporte de volume médio paralelo à costa (Sv). Em azul, experimento de La Niña e em laranja, Ano Neutro, para Ubatuba, Santos e Cananéia, para as 4 estações do ano. . . . . . . . . . . . . . . . . . . . . . . 66

3.32 Nivel médio do mar em metros. (A) radial de Ubatuba até isóbata de 100 m; (B) radial de Santos até isóbata de 100 m; (C) radial de Cananéia até isóbata de 100 m. Experimento de outono, no ano neutro. . . . . . . . . . . . . . . . .

3.33 Nivel médio do mar em metros. (A) radial de Ubatuba até isóbata de 100 m; (B) radial de Santos até isóbata de 100 m; (C) radial de Cananéia até isóbata de 100 m. Experimento de outono, no ano de La Niña. . . . . . . . . . . . . . . 68

3.34 Nível médio do mar, referente à maré, em metros. (A) radial de Ubatuba até isóbata de $100 \mathrm{~m} ;($ B) radial de Santos até isóbata de $100 \mathrm{~m} ;$ (C) radial de Cananéia até isóbata de $100 \mathrm{~m}$. Experimento de outono, ano de La Niña. . . . .

3.35 Nível médio do mar, sem maré, em metros. (A) radial de Ubatuba até isóbata de 100 m; (B) radial de Santos até isóbata de 100 m; isóbata de 100 m; (C) radial de Cananéia até isóbata de 100 m. Experimento de outono, ano de La Niña. . . 70

3.36 Nível médio do mar em metros. (A) radial de Ubatuba até isóbata de 100 m; (B) radial de Santos até isóbata de 100 m; (C) radial de Cananéia até isóbata de 100 m. Experimento de inverno, no ano neutro. . . . . . . . . . . . . . 7 
3.37 Nível médio do mar em metros. (A) radial de Ubatuba até isóbata de 100 m; (B) radial de Santos até isóbata de 100 m; (C) radial de Cananéia até isóbata de 100 m. Experimento de inverno, ano de La Niña. . . . . . . . . . . . . . . . . 72

3.38 Nivel médio do mar, referente à maré, em metros. (A) radial de Ubatuba até isóbata de $100 \mathrm{~m}$; (B) radial de Santos até isóbata de $100 \mathrm{~m}$; (C) radial de Cananéia até isóbata de 100 m. Experimento de inverno, ano de La Niña. . . 73

3.39 Nível médio do mar, sem maré, em metros. (A) radial de Ubatuba até isóbata de 100 m; (B) radial de Santos até isóbata de 100 m; isóbata de 100 m; (C) radial de Cananéia até isóbata de 100 m. Experimento de inverno, ano de La Niña. . . 74

3.40 Nível médio do mar em metros. (A) radial de Ubatuba até isóbata de 100 m; (B) radial de Santos até isóbata de 100 m; (C) radial de Cananéia até isóbata de 100 m. Experimento de primavera, no ano neutro. . . . . . . . . . . . . 75

3.41 Nivel médio do mar em metros. (A) radial de Ubatuba até isóbata de 100 m; (B) radial de Santos até isóbata de 100 m; (C) radial de Cananéia até isóbata de 100 m. Experimento de primavera, no ano de La Niña. . . . . . . . . . . . . . 76

3.42 Nivel médio do mar, referente à maré, em metros. (A) radial de Ubatuba até isóbata de $100 \mathrm{~m} ;$ (B) radial de Santos até isóbata de $100 \mathrm{~m} ;$ (C) radial de Cananéia até isóbata de 100 m. Experimento de primavera, no ano de La Niña. . 77

3.43 Nivel médio do mar, sem maré, em metros. (A) radial de Ubatuba até isóbata de 100 m; (B) radial de Santos até isóbata de 100 m; isóbata de 100 m; (C) radial de Cananéia até isóbata de 100 m. Experimento de primavera, no ano de La Niña. 78

3.44 Nível médio do mar em metros. (A) radial de Ubatuba até isóbata de 100 m; (B) radial de Santos até isóbata de 100 m; (C) radial de Cananéia até isóbata de 100 m. Experimento de verão, no ano neutro. . . . . . . . . . . . . . . . . . 79

3.45 Nível médio do mar em metros. (A) radial de Ubatuba até isóbata de 100 m; (B) radial de Santos até isóbata de 100 m; (C) radial de Cananéia até isóbata de 100 m. Experimento de verão no ano de La Niña. . . . . . . . . . . . . . . . 80

3.46 Nível médio do mar, referente à maré, em metros. (A) radial de Ubatuba até isóbata de $100 \mathrm{~m}$; (B) radial de Santos até isóbata de $100 \mathrm{~m}$; (C) radial de Cananéia até isóbata de $100 \mathrm{~m}$. Experimento de verão no ano de La Niña. . . . 
3.47 Nível médio do mar, sem maré, em metros. (A) radial de Ubatuba até isóbata de 100 m; (B) radial de Santos até isóbata de 100 m; isóbata de 100 m; (C) radial de Cananéia até isóbata de 100 m. Experimento de verão no ano de La Niña. . . 82 


\section{Lista de Tabelas}

2.1 Componentes de maré do TPXO 7.2 utilizadas no experimento numérico . 21

3.1 Velocidades de corrente em $\mathrm{m} \mathrm{s}^{-1}$, obtidas para os experimentos forçados pela passagem de frentes frias $(F F)$. Máx, é a velocidade máxima no campo, Min é a velocidade mínima no campo, Média é a velocidade média do campo em um determinado instante, Std é o desvio padrão da média, sup é a superfície, FF1 é o primeiro caso de FF (outono/2010), FF2 é o segundo caso de FF (junho/2010) e FF3 é o terceiro caso de FF (agosto/2012) . . . . . . . . . . . . . . . 56

3.2 Média do transporte de volume paralelo à costa em Sv. Transporte total, barotrópico (BT) e baroclínico (BC). Radial Cananéia é indicada por sul, Radial Santos é indicada por centro e Radial Ubatuba é indicada por norte. LN representa o ano de La Niña, e AN representa o Ano Neutro. . . 


\section{Capítulo 1}

\section{Introdução}

\section{Plataforma Continental Sudeste}

A Plataforma Continental da Bacia de Santos, também conhecida como Plataforma Continental Sudeste (PCSE), estende-se desde Cabo Frio $\left(23^{\circ} \mathrm{S}\right)$ até o Cabo de Santa Marta (2840’S) (Figura 1.1). A largura da PCSE varia entre máximos de $230 \mathrm{~km}$, na porção central, e mínimos de $50 \mathrm{~km}$ nas extremidades norte e sul. As isóbatas são quase paralelas à linha de costa, com a profundidade da quebra da plataforma variando entre $120 \mathrm{~m}$ e 180 m de profundidade (Castro et al. 2006), e a topografia da PCSE é suave (Dottori e Castro 2009).

A Plataforma Continental de São Paulo (PCSP) situa-se na região central da PCSE, apresentando extensão aproximada de $400 \mathrm{~km}$ ao longo da costa. Esta é a porção mais larga da PCSE, com aproximadamente $230 \mathrm{~km}$. A PCSE, como um todo, possui uma área de cerca de $150.000 \mathrm{~km}^{2}$ (Zembruscki e Chaves 1979). Loder et al. (1998) classificam este tipo de plataforma como "Plataforma Larga com Corrente de Contorno Oeste (CCO) na Quebra da Plataforma Continental", sendo esta CCO, na PCSE, a Corrente do Brasil. Plataformas desse tipo apresentam processos hidrodinâmicos complexos, em resposta à diversidade de forçantes que nelas atuam: ventos, marés, descargas fluviais e CCO. Tais forçantes imprimem na PC respostas com escalas espaciais variando de pequena $(0,1 \mathrm{~km})$ a grande $(1000 \mathrm{~km})$ e temporais entre segundos e interanuais ( $>1$ ano).

Na PCSE, a componente normal à costa da corrente é dominada pela maré; a componente paralela é dominada pelo vento e pelos gradientes de densidade, sendo a forçante baroclínica secundária quando comparada à forçante vento (Mazzini 2009). 
Miranda (1982) e Castro e Miranda (1998) identificam a estrutura termohalina da PCSE com três massas de água: Água Costeira (AC), que é resultado da mistura de águas de origem continetal com águas da plataforma continental, apresentando a menor salinidade das águas na PCSE; a Água Tropical (AT), com altas temperaturas e salinidades ( $\mathrm{T}>$ $20^{\circ} \mathrm{C} ; \mathrm{S} \geq 36.4$ ); e a Água Central do Atlântico Sul (ACAS), relativamente fria ( $\mathrm{T}<$ $\left.20^{\circ} \mathrm{C} ; \mathrm{S}<36.4\right)$.

Os gradientes quase-horizontais de densidade que forçam as correntes na PCSE formam frentes, regiões em que o gradiente quase-horizontal de uma ou mais propriedades físicas é intensificado (Castro 1996). Na Plataforma Continental Norte de São Paulo (PCNSP), este autor identificou duas frentes: a Frente Térmica Profunda (FTP) e a Frente Halina Superficial (FHS).

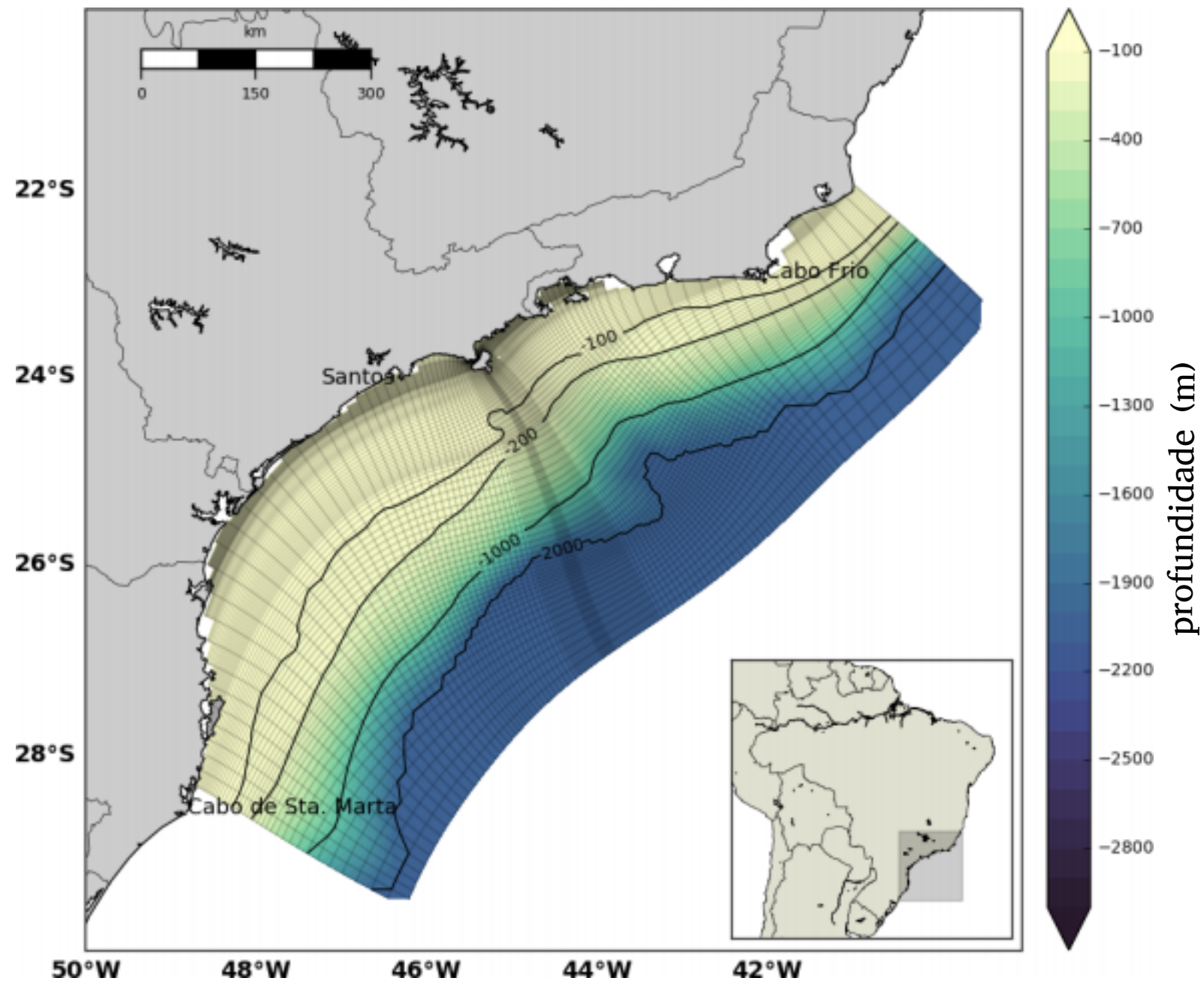

Figura 1.1: Localização da Plataforma Continental Sudeste, com a topografia em metros. Fonte:

Laboratório de Hidrodinâmica Costeira.

A FTP está associada às intrusões da ACAS em direção à costa, a qual é transportada 
pela CB na camada de termoclina. A FTP é definida pela interseção entre a isoterma de $18^{\circ} \mathrm{C}$ e o fundo. É formada na região em que separa esta água oceânica ACAS da AC. A FTP se aproxima da costa durante o verão, corroborando com a ideia de maior intrusão da ACAS em direção à costa neste período, já que o vento típico desta época facilita o transporte de Ekman superficial para fora da costa e consequente transporte de retorno em direção à costa. Já a FHS é responsável por separar, na superfície, a AT, ao largo, e, internamente, águas resultantes da mistura entre AT, ACAS e AC.

Ainda segundo Castro (1996) e Castro (2014), a PCSP pode ser dividida da seguinte forma: Platafoma Continenteal Interna (PCI), Plataforma Continental Média (PCM) e Plataforma Continental Externa (PCE), conforme pode ser visto na Figura 1.2.

A PCI está localizada entre a costa e a FTP, e sua largura varia sazonalmente, de acordo com a variação da posição FTP. Por isso, apresenta maior largura no inverno (40-80 km), e menor no verão $(10-30 \mathrm{~km})$, indo até as isóbatas de 50-70 m e 20-40 m, respectivamente para cada uma das duas estações.

Esta porção da PC tende a ser homogênea, na sua maioria, apresentando estratificação de densidade nas imediações das regiões de descarga dos sistemas estuarinos. No verão, é possível encontrar águas mais quentes e salinas, e menos densas $\left(21^{\circ} \mathrm{C}<\mathrm{T}<28^{\circ} \mathrm{C}\right.$ e $35.4<\mathrm{S}<35.4)$ na PCI. Já no inverno, é possível encontrar águas com $\mathrm{T}<23^{\circ} \mathrm{C}$ e 33.4 $<\mathrm{S}<38.8$. Assim, considera-se que $22^{\circ} \mathrm{C}$ é o valor típico para diferenciar as águas das estações mais quentes das águas das estações mais frias. A PCM está situada ao largo da PCI e tem como limite externo a Frente de Quebra de Plataforma, aqui identificada por FHS. É bem definida durante o verão, quando situa-se desde $10-30 \mathrm{~km}$ até $60-80 \mathrm{~km}$ da costa. Em relação às isóbatas, o limite interno encontra-se na isóbata de 20-40m e o limite externo na isóbata de $70-90 \mathrm{~m}$. Nesta estação, a temperatura varia entre $22^{\circ} \mathrm{C}$ e $24^{\circ} \mathrm{C}$ na superfície, e entre $14^{\circ} \mathrm{C}$ e $15^{\circ} \mathrm{C}$ no fundo. Já a termoclina apresenta temperaturas entre $18^{\circ} \mathrm{C}$ e $25^{\circ} \mathrm{C}$. A salinidade apresenta valores entre 35.0 e 35.4 para a superfície, e 35.6 e 35.8 para o fundo. No inverno, a PCM é menos larga e mais homogênea, apresentando erosão da termoclina.

A PCE, por sua vez, vai desde a FHS até a quebra da plataforma, e seu limite interno encontra-se entre 60-80km distante da costa, entre as isóbatas de 70 e 90 m. A variação sazonal da PCSE é pequena, apresentando elevada estratificação vertical ao longo do ano. No fundo a variação sazonal é praticamente inexistente, apresentando valores típicos de 
$14^{\circ} \mathrm{C}$ de temperatura e 35.4 de salinidade. Já na superfície, verão e inverno apresentam valores de temperatura de $24^{\circ} \mathrm{C}$ e $22^{\circ} \mathrm{C}$ e de salinidade de 36.2 e 35.4 , respectivamente.

No entanto, é valido repetir que em toda a PCSE as águas são resultado da mistura das três massas d'água previamente mencionadas: ACAS, AT, e AC (Cerda e Castro 2013).

Os processos dinâmicos com escala maregráfica são dominados pela co-oscilação com as marés do oceano profundo (Pereira et al. 2007). A amplitude das oscilações maregráficas das correntes na PCSP varia espacialmente, sendo máxima nas proximidades da costa (ordem entre $0.01 \mathrm{~m} \mathrm{~s}^{-1}$ e $0.1 \mathrm{~m} \mathrm{~s}^{-1}$ ), apresentando elipses com grande polarização na direção perpendicular à costa (Harari e Camargo 1994; Harari e Camargo 1998; Pereira et al. 2007; Miranda et al. 2012). Portanto, a escala espacial da maré ao longo da costa é da ordem de $1000 \mathrm{~km}$, enquato a escala temporal é predominantemente semi-diurna, com modulação quinzenal.

Na PCI e PCM, os processos dinâmicos com escala temporal submaregráfica ou subinercial (alguns dias a algumas semanas) são forçados essencialmente pela tensão de cisalhamento do vento sinótico. A resposta do nível do mar pode ou não estar em fase com a tensão de cisalhamento do vento local. Ou seja, pode-se dizer que sempre há contribuição da tensão de cisalhamento do vento local e do vento remoto (que ocorre em posição situada ao sul da estação de medição da elevação da superfície do mar).

A resposta ao vento local é típica de regimes altamente friccionais, isto é, ocorre essencialmente na PCI, onde a camada limite de fundo ocupa parte substancial da coluna de água, e sob ventos intensos.

Quando o vento possui estrutura (variabilidade espacial) ao longo da costa, a resposta do nível do mar ocorre na forma de Onda Topográfica Aprisionada (Csanady 1978). O vento remoto, por outro lado, influencia também regiões da PCM e não requer grandes intensidades da componente da tensão de cisalhamento paralela à costa para que Ondas de Plataforma Continental (OPC) (Gill e Schumann 1974) sejam geradas e se propaguem ciclonicamente ao longo da costa.

Na PCSE, e particularmente na PCSP, ambas as formas de resposta tem sido observadas. As OPC foram primeiramente detectadas na região por Castro (1985) e Castro e Lee (1995) em variações subinerciais da altura da superfície do mar. 


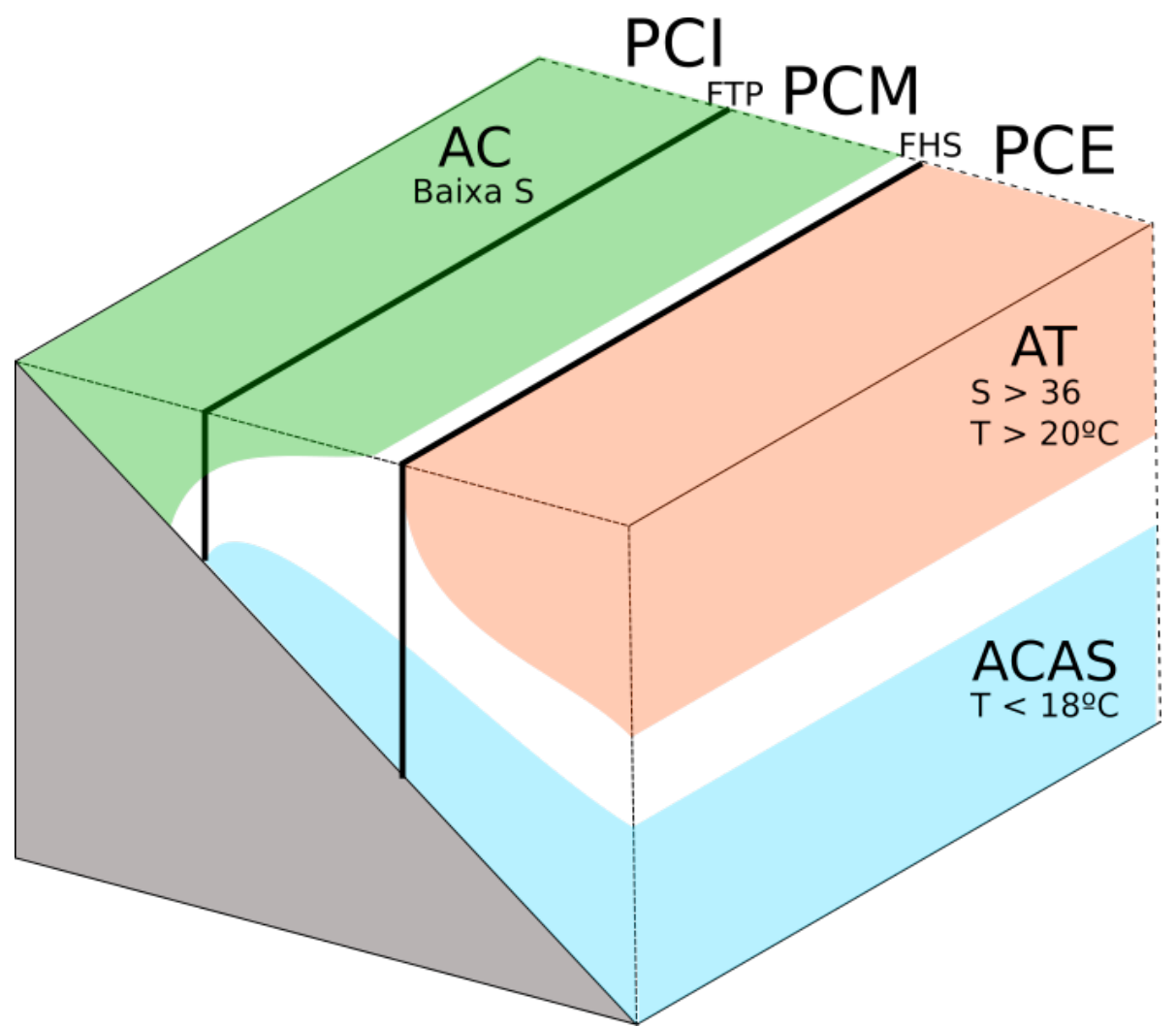

Figura 1.2: Representação esquemática das regiões da Plataforma Continental de São Paulo: Plataforma Continental Interna (PCI), Plataforma Continental Média (PCM) e Plataforma Continental Externa $(P C E)$. Estão representadas também as frentes que limitam estas regiões: a Frente Térmica profunda e a Frente Halina Superfícial. Além disso, encontram-se também representadas as três massas de água da região, com suas principais características, sendo $S$ salinidade e $T$ temperatura: Água Costeira (AC), Água Tropical (AT) e Água Central do Atlantico Sul (ACAS) (Silva 2019).

Através de experimentos de modelagem matemática numérica, Stech e Lorenzzetti (1992) verificaram que a resposta pode acompanhar o deslocamento da forçante, caracterizando a importância da forçante local da tensão de cisalhamento do vento num regime altamente friccional similar à OTA.

Dottori e Castro (2009), analisando dados correntográficos e aplicando modelos semianalíticos, mostraram que a resposta subinercial da PCSP ao vento sinótico pode estar aproximadamente em fase com o vento, dependendo das escalas de variabilidade temporal da tensão de cisalhamento. Entretanto, a importância relativa das variabilidades sinóticas da tensão de cisalhamento do vento local e remoto sobre as oscilações da superfície do mar na PCSE, ainda está para ser determinada.

Campos et al. (2010) analisaram 40 anos de dados de variação subinercial da superfície 
do mar medidos em Santos, em conjunto com dados de vento e de pressão atmosférica, concluindo que eventos extremos de elevação da superfície do mar não são caracterizados por respostas às tensões de cisalhamento do vento local apenas, dependendo do vento remoto na região situada ao sul de Santos.

Filippo et al. (2012) comprovaram a presença de ondas subinerciais barotrópicas na PCSE, em continuação a processos coerentes que ocorreram na costa da Argentina. Estes autores cerificaram que a contribuição do vento sinótico local para a variabilidade subinercial das correntes na PCSE também é importante. Valentim et al. (2013) verificaram que na região de Ubatuba, a elevação do nível do mar causada pelo vento apresentou alta correlação com o vento local paralelo à costa.

As correntes subinerciais forçadas pelo vento da PCSP têm direção preferencial paralela às isobatas, para manter o balanço geostrófico na direção normal à topografia, e intensidades com ordem entre $0.1 \mathrm{~m} \mathrm{~s}^{-1}$ e $1.0 \mathrm{~m} \mathrm{~s}^{-1}$ (Castro 1990; Castro 1996; Mazzini 2009; Dottori e Castro 2009). Esses processos físicos gerados pela tensão de cisalhamento do vento na PCSE tem escala espacial grande e escala temporal subinercial.

A força do gradiente de pressão baroclínico, associada às descargas fluviais, atua essencialmente na PCI, forçando correntes quase paralelas à costa, deixando-na à esquerda na PCSP, devido à condicionante geostrófica. Evidências dessas correntes baroclínicas tem sido destacadas em vários trabalhos, tanto observacionais (Castro 1990; Mazzini 2009; Castro 1996; Dottori e Castro 2009), quanto de modelagem numérica (Morais 2016; Coelho 2008; Rezende 2003).

As correntes baroclínicas estão diretamente associadas à presença da $\mathrm{AC}$ na $\mathrm{PCI}$, pois a baixa densidade dessa massa de água possibilita o aparecimento de gradientes horizontais de densidade quase perpendiculares à costa. Durante a maior parte do ano, a $\mathrm{AC}$ presente na PCSP tem origem local, i. e., é originária das regiões estuarinas da região. No inverno, entretanto, há possibilidade de que a AC presente na PCSP tenha origem remota, resultante da adveção, em direção ao norte, de águas provenientes da Pluma do Rio da Prata e da descarga dos sistemas estuarinos da Lagoa dos Patos e da Lagoa Mirim (Möller et al. 2008; Carvalho et al. 2010; Campos et al. 2013).

A variabilidade interanual dessas intrusões de AC na PCSP apresenta alta correlação com o Índice da Oscilação Sul, conforme demonstrado por (Campos et al. 1999), podendo estar associado ao fenômeno ENSO (El Niño Southern Oscilation), principalmente à fase 
negativa, La Niña (Piola et al. 2005).

Os processos hidrotermodinâmicos baroclínicos da PCSP têm escalas espaciais entre pequena e larga, e temporal sazonal. Entretanto, a influência hidrotermodinâmica de possíveis intrusões na PCSP das águas remotas com baixa salinidade, durante o inverno, e consequentemente efeitos na variabilidade sazonal das correntes e das oscilações da superfície do mar, precisam ser estudadas mais amplamente.

\section{Sistemas atmosféricos na Plataforma Continental Sudeste}

Como o vento é uma forçante de extrema importância para a PCSE, é importante ter conhecimento de alguns sistemas atmosféricos desta região. O Anticiclone Subtropical do Atlântico Sul (ASAS) é um sistema de grande escala, que atua diretamente sobre a PCSE. Por se tratar de um sistema anticiclônico no hemisfério sul, pode-se dizer que possui centro de alta pressão, e gira em sentido anti-horário.

Os ventos sazonais médios, parte oeste do ASAS, sopram de direção NE-E sobre a PCSE, gerando correntes que deixam a costa à direita (Fontes e Castro 2017). Os sistemas atmosféricos, assim como os sistemas oceânicos, variam sazonalmente.

O ASAS, e suas alterações, são fundamentais para entender as variações no clima regional do litoral brasileiro. Este sistema apresenta-se de forma mais intensa durante as estações de inverno e de verão. No inverno, o centro do giro está mais perto do equador e da borda oeste do Oeano Atlântico Sul. Já no verão, o centro desloca-se em sentido ao pólo, no centro do mesmo oceano. Durante o verão austral, a maior variação espacial, na escala interanual, ocorre na direção meridional e é dominada pelo ENSO. Visto que este sistema encontra-se mais próximo à PCSE durante o inverno, pode-se dizer que os ventos de macro escala têm origem NE/E, e as maiores pressões ocorrem durante o inverno (Sun et al. 2017).

Sobre o campo médio atmosférico, as frentes frias (FF) atuam como perturbações de escala sinótica, que através da interação entre oceano e atmosfera são importante fonte de energia para os movimentos no oceano costeiro, na escala temporal de dias a semanas. No inverno a média de ocorrência é de 3 a 5 por mês, com espaçamento de 6 a 10 dias entre cada uma (Castro 1985).

Diversos estudos mostram a resposta da PCSE à tensão de cisalhamento do vento as- 
sociada à passagem de FF ao longo da costa. Stech e Lorenzzetti (1992) estudaram a resposta da PCSE à passagem de sistemas frontais, forçando um modelo numérico barotrópico, com campo de vento que representa campo real associado à passagem de frente fria no Brasil. Os autores apresentam um modelo conceitual da passagem de uma FF na PCSE (Figura 1.3). As correntes oceânicas geradas por estes sistemas são alinhadas com as isóbatas (Fontes e Castro 2017), deixando a costa à esquerda (Dottori e Castro 2009).

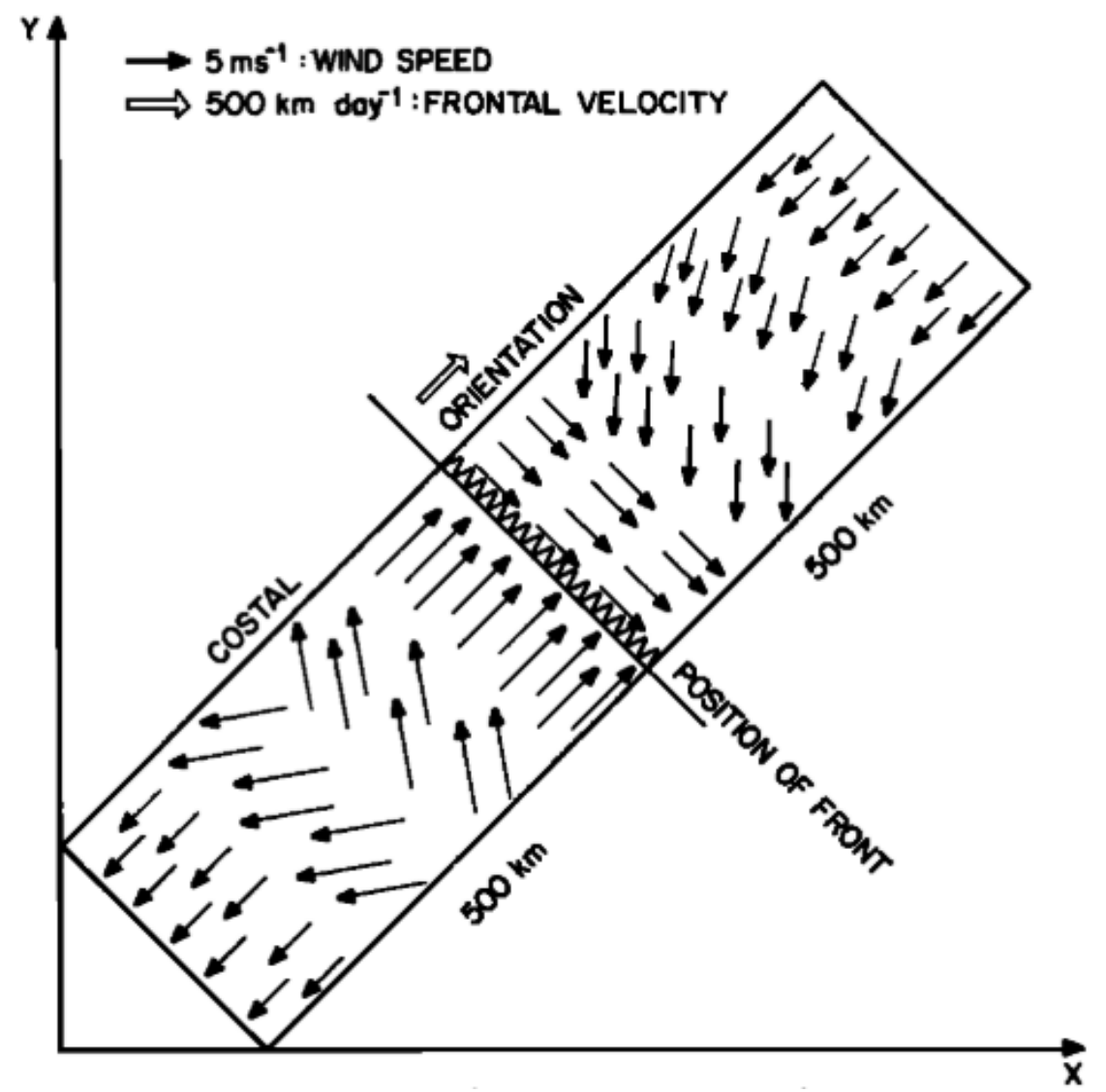

Figura 1.3: Representação gráfica de um modelo conceitual de frente fria durante o inverno, no sudeste do Brasil. Y aponta para o norte geográfico e X aponta para o leste geográfico. (Stech e Lorenzzetti 1992)

As FF possuem origem polar, e deslocam-se em direção ao equador sendo que aquelas que percorrem a PCSE propagam-se de SW para NE (Rodrigues et al. 2004). Na Figura 1.4, é possível ver a posição de uma FF, no Brasil, em 1996. Esta frente apresenta as mesmas características que as encontradas no modelo teórico proposto por Stech e Lorenzzetti (1992).

As FF estão associadas a distúrbios de grande escala, deslocando-se como ciclones e anti-ciclones. No seu caminho são responsáveis por alterações em variáveis atmosféricas 
como a pressão atmosférica e o vento (Wallace e Hobbs 2006), e são típicas de médias latitudes (Kousky 1979; Satyamurty et al. 1998).

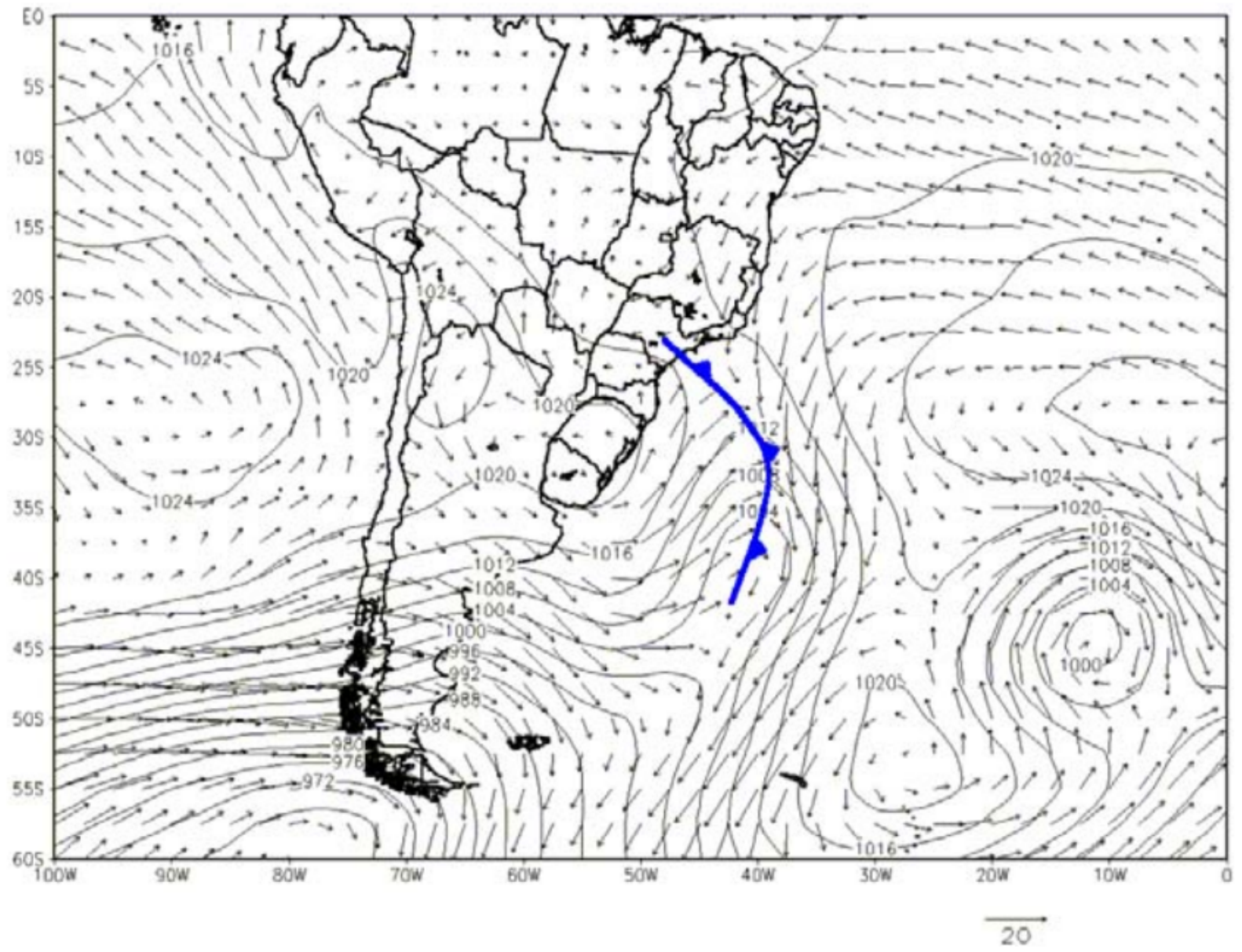

Figura 1.4: Exemplo de uma frente fria na costa do Brasil, em 10 de agosto de 1996 (Rodrigues et al. 2004).

\section{A circulação na Plataforma Continental Sudeste}

Como já foi mencionado anteriormente, a circulação da PCSE ocorre em resposta à combinação de diversas forçantes: as marés, os ventos, as variações nos campos de densidade (forçante baroclínica) e a Corrente do Brasil (Figura 1.5). Pode-se dizer que movimentos forçados por ventos médios, FF, variações laterais de densidade e o escoamento da CB, são movimentos subinerciais.

Os ventos, através da tensão de cisalhamento, transferem energia para o oceano, forçando movimentos energéticos e paralelos à costa. As variabilidades sinótica e sazonal dos ventos são as mais importantes para forçar as correntes na PCSE (Castro 1996). O 
ASAS e as FF, anteriormente explicados, são centros de alta e baixa pressão, respectivamente, sendo que o ASAS é responsável pelos ventos de NE/L, os quais são intensificados no verão, enquanto os ventos da FF costumam vir do sul, atingindo a PCSE (Stech e Lorenzzetti 1992).

A forçante baroclínica, associada à descarga continental, gera gradientes de densidade na direção quase perpendicular à costa. Devido à geostrofia, a corrente baroclínica assim gerada deixa a costa à esquerda no hemisfério sul (Brink 2005).

As marés geram correntes com direções diferentes, dependendo da largura da plataforma. Em plataformas estreitas, são geradas correntes paralelas à costa; já em plataformas largas, como a PCSP, são geradas correntes perpendiculares à costa (Pereira et al. 2007).

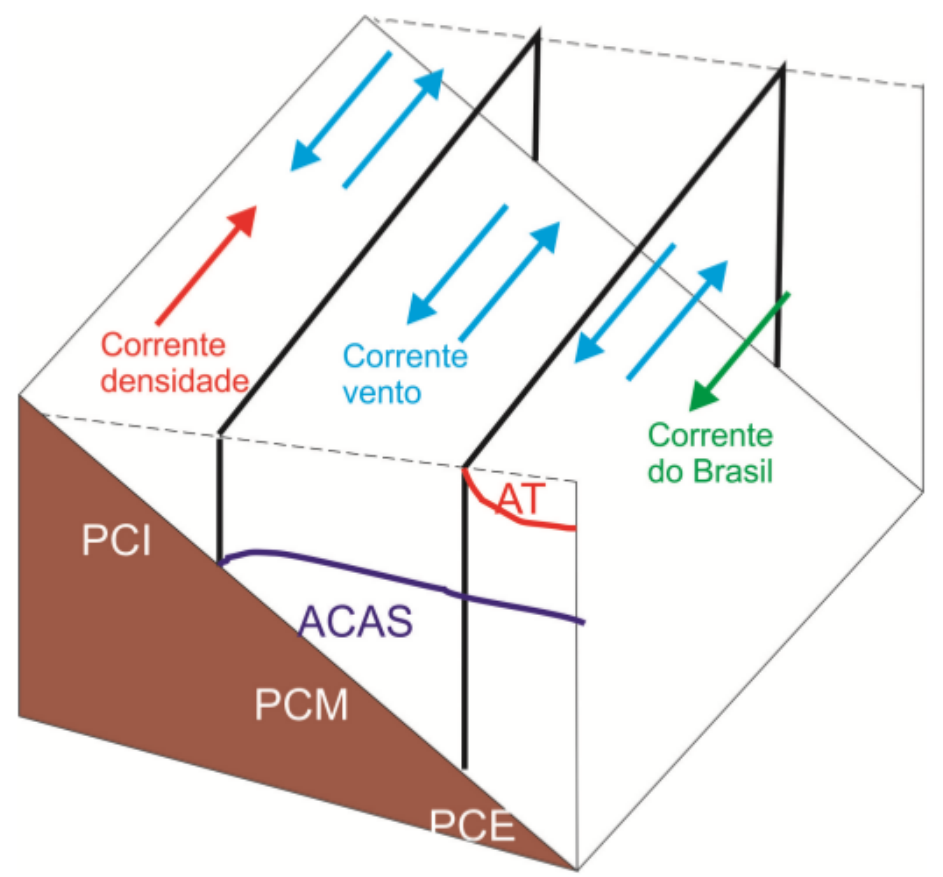

Figura 1.5: Divisão da PCSE e as forçantes atuantes em cada uma das sub divisões (Gregorio 2014).

A CB gera movimentos na porção mais externa da PCSP, devido ao seu fluxo médio e também aos seus meandros e possíveis desprendimentos de vórtices (Silveira et al. 2000). Segundo Castro (1996), a CB força diretamente movimentos sobre a PCI da PCSE.

Segundo Castro (2014), as Ondas de Plataforma Continental (OPC) são responsáveis por levar as influências do vento remoto para as porções central e norte da PCSE. As OPC são ondas longas, de vorticidade potencial (dependem de uma variação da profundidade), 
confinadas pela topografia e de baixa frequência (subinercial). Propagam-se de forma ciclônica e são unidirecionais (Huthnance 1975), ou seja, propagam-se para o norte na costa do Brasil, deixando a costa à esquerda.

Na PCI da PCSE, as principais forçantes são a tensão de cisalhamento do vento e a descarga estuarina. Considerando um cenário sem entrada de FF, os ventos predominantes são de NE/E, conforme dito anteriormente, e este fator, associado à orientação da costa, leva à divergência unilateral do transporte de deriva do vento na costa, rebaixamento do nível da superfície livre do mar (SLM), gradientes de pressão predominantemente barotrópicos e perpendiculares à costa, e correntes geostróficas deixando a costa à direita, na forma de jatos costeiros (Csanady 1978).

A tensão de cisalhamento do vento de NE/E e o gradiente de densidade forçam as correntes com sentidos opostos. Normalmente a resposta ao vento é mais intensa, mas quando há elevado aporte de água continental na PCI, a forçante baroclínica pode predominar. Em consequência, direção sazonal média das correntes na PCI da PCSE pode variar (Castro 2014).

Inversões do sentido das correntes na PCI também podem estar associadas à entrada de FF, pois os ventos deste sistema, com sentido oposto aos ventos do ASAS, são capazes de forçar jatos costeiros que deixam a costa à esquerda na PCI, pois a tensão de cisalhamento do vento é somada ao gradiente de pressão devido às descargas fluviais (Gregorio 2014).

A PCM, assim como a PCI, tem as correntes subinerciais forçadas principalmente pela tensão de cisalhamento do vento e, secundariamente, pela forçante baroclínica. No entanto, diferencia-se da anterior devido à eventual influência da $\mathrm{CB}$, sendo que esta é observada nas áreas mais estreitas da PCSE (Castro 2014). A forçante baroclínica, por sua vez, ocorre apenas na porção sul da PCSE, quando as águas frias provenientes do sul chegam na região. No litoral norte de São Paulo, em Ubatuba, foram observadas correntes médias com sentido S/W, deixando a costa à direita, em todos os níveis (Castro 1996). Em Santos foram obtidos resultados semelhantes por diversos autores, entre eles, Mazzini (2009). Devido à influência do ASAS, as correntes tendem a fluir para o sul, entre Santos e o Rio de Janeiro. Coelho (2008) observou, através de modelagem numérica, correntes opostas na PCM e na PCI. A corrente paralela à costa também pode variar devido à ação do vento remoto (Pimenta et al. 2005).

A PCE é dominada pela ação da CB, havendo, também, influência da tensão de cisa- 
lhamento do vento (Castro 2014). Em Santos, em toda a coluna de água foi verificada a corrente fluindo para $\mathrm{S} / \mathrm{SW}$, deixando a costa à direita, sendo que poucas inversões foram identificadas, as quais estão associadas a meandros ou vórtices da CB (Dottori e Castro 2009). Estes autores não identificaram significante correlação entre os ventos sinóticos e a corrente subinercial na PCE.

Águas de baixa temperatura e de baixa salinidade podem ser encontradas na PCSE, entre a costa a Corrente do Brasil, no inverno. Estas águas são advectadas desde o entorno do estuário do Rio da Prata $\left(35^{\circ} \mathrm{S}\right)$, até $23^{\circ} \mathrm{S}$ (nordeste de do estado de São Paulo) (Campos et al. 1996). No inverno, as águas vindas do sul chegam a latitudes muito menores do que durante o verão. Na região da PCSE não há vazão de grandes rios, o que corrobora com a ideia de que estas águas sejam provenientes do sul. Piola (1999) sugere que massas de água de baixa temperatura e salinidade podem ser resultado da advecção da pluma do estuário do Rio da Prata e do complexo Lagoa dos Patos/Mirim, sendo as fontes primária e secundária, respectivamente. O Estuário do Rio da Prata apresenta descarga média de $23000 \mathrm{~m}^{3} \mathrm{~s}^{-1}$ (Pereira 1989). Já a Lagoa dos Patos/Mirim possui descarga média de 2 $400 \mathrm{~m}^{3} \mathrm{~s}^{-1}$ (Vaz et al. 2006), podendo chegar a $12000 \mathrm{~m}^{3} \mathrm{~s}^{-1} \mathrm{em}$ anos de El Niño (Moller et al. 2001).

Existem algumas forçantes que permitem a advecção dessas águas proveniente do sul até a PCSE. Uma delas é a geostrofia, associada à baroclinicidade, como já foi comentado. Através de estudos numéricos, Pimenta (2001) sugere que a descarga dos rios determina a quantidade de água doce disponível na plataforma, podendo modular a extensão da pluma de baixa salinidade. A descarga de água doce se espalha como uma pluma flutuante ao longo da costa da Argentina, Uruguai e Brasil (Möller et al. 2008). Ao se afastar da boca do estuário, o vento paralelo à costa se mostra como mecanismo mais relevante para forçar a pluma para o norte (Piola et al. 2005). O vento pode intensificar ou frear estes sistemas: ventos de sudoeste (SW) tendem a aumentar o escoamento em direção ao norte, enquanto ventos de nordeste (NE) forçam o escoamento mais para o sul (Soares e Möller 2001).

Dados históricos sugerem que a extensão da água de baixa salinidade sofre grande variação sazonalmente (Piola et al. 2000). Durante o inverno, época de predominância dos ventos de SW, a pluma do Rio da Prata pode ultrapassar o Cabo de Santa Marta $\left(28^{\circ} \mathrm{S}\right)$, ocupando uma faixa rasa ao longo da costa. Mesmo em épocas de baixa descarga fluvial, 
se houver vento favorável, de S/SW, há advecção da pluma para baixas latitudes. Já no verão, época de predominância de ventos de NE, a pluma é retraída até aproximadamente $32^{\circ} \mathrm{S}$. Com isso, Piola et al. (2005) tratam a sazonalidade do campo de vento como o fator mais importante para a advecção da pluma de baixa salinidade. O transporte de Ekman, associado aos ventos de $\mathrm{S}$ característicos do inverno, concentra água pouco salina na costa, produz elevado gradiente de salinidade transversal à costa, e inibe a circulação lateral (Möller et al. 2008).

Eventos climáticos interanuais, como El Niño e La Niña, alteram o comportamento da pluma devido a alterações no padrão dos ventos. No entanto, Piola et al. (2005) acreditam que a alteração ocasionada pelo vento é compensada pelas anomalias de precipitação, impedindo que ocorram deslocamentos anômalos da pluma para o norte.

\section{Hipótese e objetivos}

A hipótese científica deste trabalho é que as variações sazonais da Água Costeira modificam os processos hidrodinâmicos na Plataforma Continental Interna do Estado de São Paulo, particularmente as correntes e as oscilações da superfície do mar. Para comprovar essa hipótese, o objetivo proposto é estudar a resposta das águas da região às forçantes marés, ventos e baroclínicas associadas à drenagem continental, durante as quatro estações do ano, considerando condições atmosféricas normais e em situações de ENSO. O trabalho será orientado, ainda, para atingir alguns objetivos específicos:

1. Determinar as correntes médias sazonais na PCI e na PCM;

2. Determinar o transporte paralelo à costa médio sazonal e sua variabilidade espacial em toda PCSP;

3. Determinar o balanço de forças dominante médio sazonal, tanto na PCI quanto na PCM. 


\section{Capítulo 2}

\section{Métodos e dados}

\section{Modelo numérico}

O principal método empregado neste trabalho foi a modelagem numérica. A ferramenta utilizada para tal foi a suíte de modelos matemático-numéricos conhecida por ECOM (Estuarine and Coastal Ocean Model). Esse sistema de modelos (Blumberg et al. 2008) é uma evolução do conhecido Princeton Ocean Model (POM), introduzido nos anos 80 (Blumberg e Mellor 1987), e de sua versão para águas rasas, denominada ECOMSED (Blumberg et al. 1999). O ECOM utiliza as equações de águas rasas discretizadas horizontalmente numa grade $\mathrm{C}$ de Arakawa e, verticalmente, em coordenadas sigma. Esse modelo demonstrou capacidade para prever acuradamente marés astronômicas e meteorológicas, velocidade da água e transporte de sedimento em muitas aplicações (Liberto et al. 2011; Georgas et al. 2009), e tem sido utilizado para previsão de correntes e outros parâmetros oceanográficos no Porto de Nova Iorque, no sistema NYHOPS (New York Harbor Observing and Prediction System, http://hudson.dl.stevens-tech. edu/maritimeforecast/).

O modelo trabalha com as seguintes variáveis prognósticas: as três componentes de velocidade $(u, v, w)$, temperatura, salinidade, energia cinética turbulenta e turbulência de macroescala. As equações do momento não são lineares e incorporam o parâmetro de Coriolis. Equações prognósticas que governam as quantidades termodinâmicas, temperatura e salinidade, são responsáveis pelas variações das massas de água provocadas por processos de ressurgência e subsidência costeiras, altamente dependentes do tempo, bem como por processos de advecção horizontal. A elevação da superfície do mar também 
é calculada de forma prognóstica. Há representação realística da geometria da linha de costa e da topografia de fundo devido ao sistema de coordenadas curvilíneas.

O módulo hidrodinâmico do ECOM está implementado, calibrado e validado para a PCSE, no Laboratório de Hidrodinâmica Costeira (LHiCo), do Instituto Oceanográfico da Universidade de São Paulo (IO-USP). A região coberta pela grade de diferenças finitas estende-se além da PCSP, cobrindo toda a PCSE (Figura 1.1).

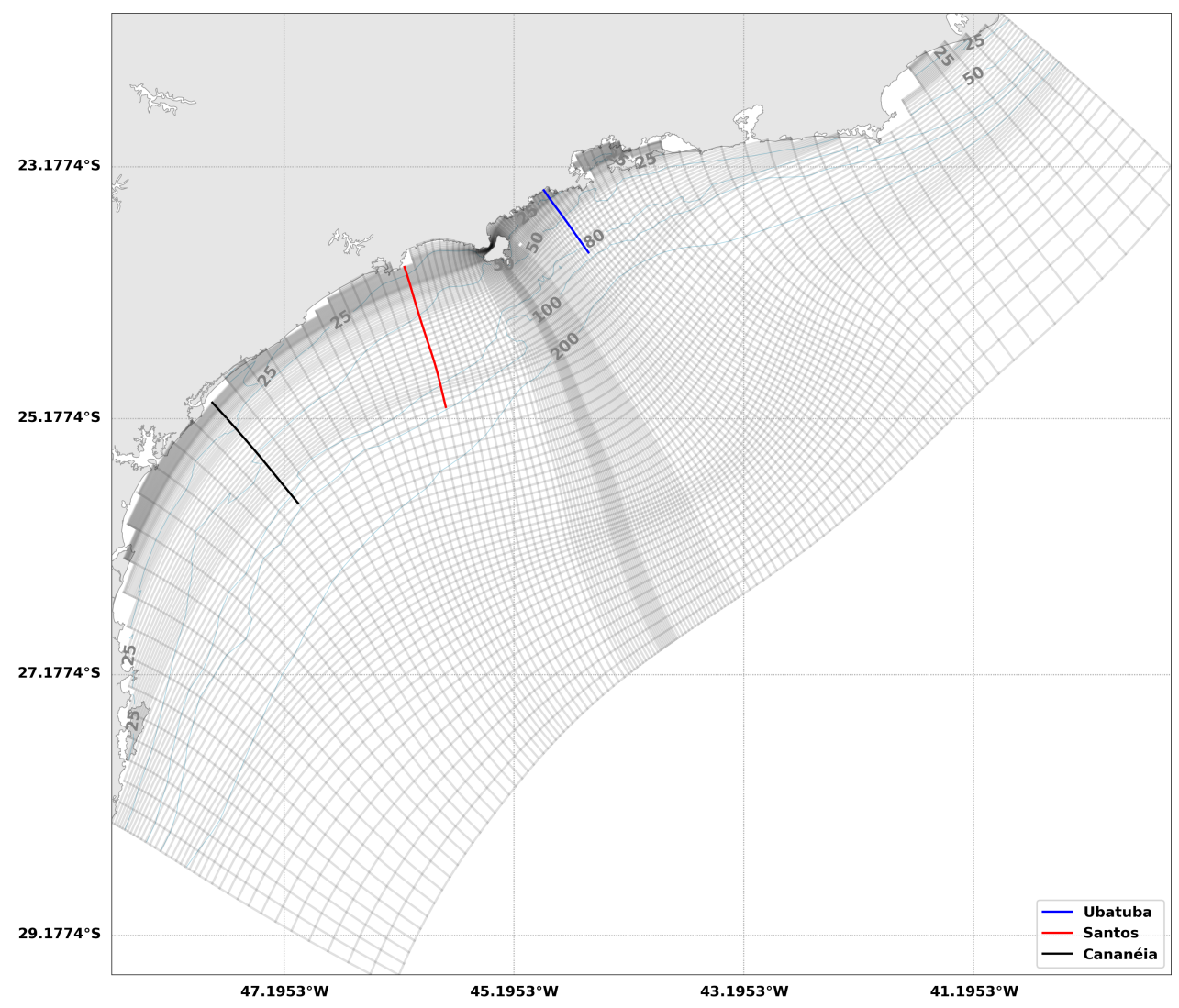

Figura 2.1: Grade de diferenças finitas utilizada no Laboratório de Hidrodinâmica Costeira no modelo operacional da Plataforma Continental Sudeste. Topografia em metros. As radiais coloridas representam as sessões perpendiculares à costa em frente a Ubatuba (azul), Santos (vermelho) e Cananéia (preto).

Quanto ao sistema de coordenadas verticais, o modelo utiliza o sistema de coordenadas sigma $(\sigma)$, o qual apresenta melhor configuração para irregularidades batimétricas:

$$
\sigma=\frac{z-\eta}{H+\eta}
$$

sendo $\mathrm{z}$ a coordenada cartesiana vertical, $\eta$ a elevação do nível do mar e $\mathrm{H}$ a profundidade total da coluna d'água (Figura 2.2). 
Em todos os experimentos, a grade numérica utilizada é curvilinear ortogonal, com 110 pontos de grade na direção $x$ (orientação NW-SE, quase perpendicular à quebra da plataforma) e 137 pontos de grade na direção y (orientação SW-NE). A grade é irregular, apresentando maior resolução sobre a plataforma continental, com espaçamento variando de $0.2 \mathrm{~km}$ a $5 \mathrm{~km}$.

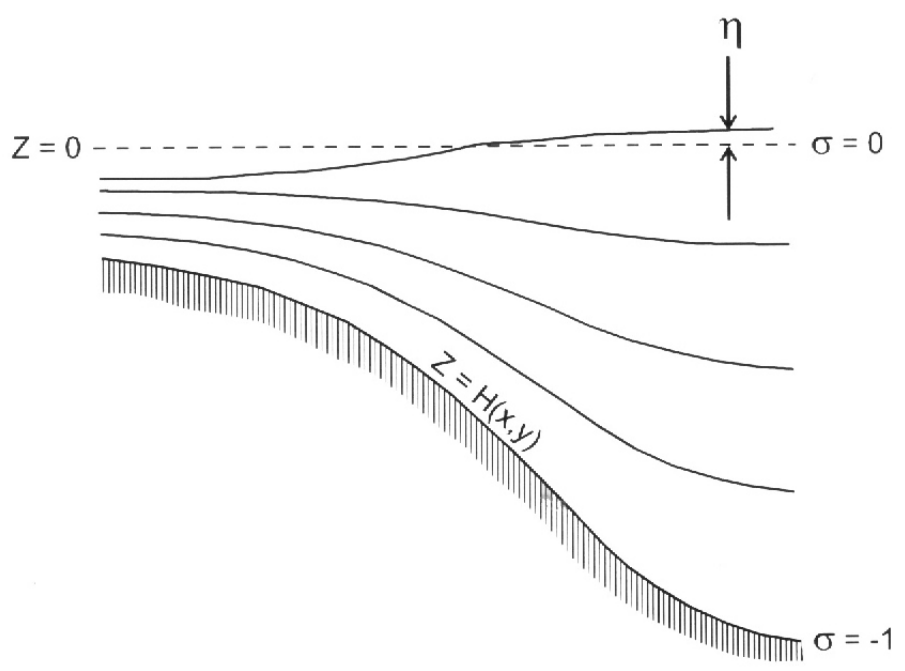

Figura 2.2: Sistema de coordenadas vertical sigma $(\sigma)$. Z é a profundidade local em metros, $H$ é topografia e $\eta$ é a variação do nível médio do mar.

Em direção ao talude, a resolução diminui, com espaçamento variando entre $5 \mathrm{~km}$ a $10 \mathrm{~km}$. Em profundidades maiores que 2100 m, a resolução perpendicular à quebra da plataforma chega a $35 \mathrm{~km}$. Já na direção $y$, a maior resolução econtra-se no centro da grade, com espaçamento variando de $0.5 \mathrm{~km}$ nesta região, até $35 \mathrm{~km}$ próximo às bordas NE e SW. Esta grade é adaptada de Pereira et al. (2007). A resolução vertical utilizada foi de 21 níveis sigma. O passo de tempo interno (DTI) utilizado foi 10, e o passo de tempo externo (DTE) foi 1.

As equações base do modelo de circulação descrevem os campos de velocidade, elevação da superfície, temperatura e salinidade. Para a solução das equações, duas simplificações são feitas: assume-se um fluido hidrostático, e considera-se a aproximação de Boussinesq.

Considera-se um sistema ortogonal, de coordenadas cartesianas, com $x$ crescendo para leste, $y$ crescendo para norte e $z$ crescendo verticalmente para cima. A superfície livre está localizada em $z=\eta(x, y, z)$, e o fundo em $z=-H(x, y)$. Sendo $\vec{V}$ o vetor velocidade horizontal com componentes $u$ e $v$, e $\nabla$ o operador gradiente horizontal, então temos que 
a equação da continuidade é:

$$
\nabla \cdot \vec{V}+\frac{\partial w}{\partial z}=0
$$

onde $w$ é a velocidade vertical. As equações do momento são dadas por

$$
\begin{gathered}
\frac{\partial u}{\partial t}+\vec{V} \cdot \nabla u+w \frac{\partial u}{\partial z}-f v=\frac{-1}{\rho_{0}} \frac{\partial P}{\partial x}+\frac{\partial\left(K_{M} \frac{\partial u}{\partial z}\right)}{\partial z}+F_{x} \\
\frac{\partial v}{\partial t}+\vec{V} \cdot \nabla v+w \frac{\partial v}{\partial z}+f u=\frac{-1}{\rho_{0}} \frac{\partial P}{\partial y}+\frac{\partial\left(K_{M} \frac{\partial v}{\partial z}\right)}{\partial z}+F_{y} \\
\rho g=-\frac{\partial P}{\partial z}
\end{gathered}
$$

sendo $\rho_{0}$ a densidade hidrostática, $\rho$ a densidade total, $g$ a aceleração da gravidade, $P$ a pressão, $K_{M}$ coeficiente de mistura turbulenta vertical. Ao considerar o plano $\beta$, a variação latitudinal do parâmetro de Coriolis, $f$, é introduzida. $F_{x}$ e $F_{y}$ representam as parametrizações de processos de pequena escala que não são resolvidos diretamente pelo modelo.

A pressão na profundidade $z$ pode ser obtida integrando a Equação 2.5, de $z$ até a superfície $\eta$

$$
P(x, y, z, t)=P_{a t m}+g \rho_{0} \eta+g \int_{z}^{\eta} \rho\left(x, y, z^{\prime}, t\right) d z^{\prime}
$$

As equações de conservação de temperatura e salinidade utilizadas são, respectivamente:

$$
\begin{gathered}
\frac{\partial \theta}{\partial t}+\vec{V} \cdot \nabla \theta+w \frac{\partial \theta}{\partial z}=\frac{\partial\left(K_{H} \frac{\partial \theta}{\partial z}\right)}{\partial z}+F_{\theta} \\
\frac{\partial S}{\partial t}+\vec{V} \cdot \nabla S+w \frac{\partial S S}{\partial z}=\frac{\partial\left(K_{H} \frac{\partial S}{\partial z}\right)}{\partial z}+F_{S}
\end{gathered}
$$

sendo $\theta$ a temperatura potencial (ou in situ para águas rasas), e $S$ a salinidade. A difusividade vertical de calor e sal é denotada como $K_{H}$. A partir da salinidade e da temperatura, a densidade é computada de acordo com a equação de estado dada por Fofonoff (1962):

$$
\rho=\rho(\theta, S)
$$


A densidade potencial $\rho$, ou seja, a densidada relativa à salinidade e à temperatura, medida na pressão atmosférica, permite ter informação precisa da densidade para calcular o gradiente horizontal baroclínico, o qual entra no termo do gradiente de pressão, e a estabilidade vertical da coluna de água, que entra no módulo de fechamente turbulento, mesmo em profundidades em que a pressão se torna importante. O ECOM utliza o modelo de fechamento turbulento de Mellor et al. (1982) para calcular $K_{M}$ e $K_{H}$, os quais são usados para parametrizar a mistura, usando as variáveis de macroescala dadas pelas equações do movimento. Os termos de mistura horizontal são:

$$
\begin{gathered}
F_{x}=\frac{\partial\left(2 A_{M} \frac{\partial u}{\partial x}\right)}{\partial x}+\frac{\partial A_{M}\left(\frac{\partial u}{\partial y}+\frac{\partial v}{\partial x}\right)}{\partial y} \\
F_{y}=\frac{\partial\left(2 A_{M} \frac{\partial v}{\partial y}\right)}{\partial y}+\frac{\partial A_{M}\left(\frac{\partial u}{\partial y}+\frac{\partial v}{\partial x}\right)}{\partial x} \\
F_{\theta, S}=\frac{\partial\left(A_{H} \frac{\partial(\theta, S)}{\partial x}\right)}{\partial x}+\frac{\partial\left(A_{H} \frac{\partial(\theta, S)}{\partial y}\right)}{\partial y}
\end{gathered}
$$

sendo $A_{M}$ e $A_{H}$ coeficientes de difusividade horizontal parametrizadas por Smagorinsky (1963):

$$
A_{M}=A_{H}=\alpha \Delta x \Delta y\left[\left(\frac{\partial u}{\partial x}\right)^{2}+\left(\frac{\partial v}{\partial y}\right)^{2}+\frac{1}{2}\left(\frac{\partial u}{\partial y}\right)+\left(\frac{\partial v}{\partial x}\right)^{2}\right]^{\frac{1}{2}}
$$

sendo $\Delta x$ e $\Delta y$ as dimensões zonal e meridional da grade, em metros, respectivamente e $\alpha$ o coeficiente de Smagorinsky.

As condições de contorno (cc) para componentes de velocidade, temperatura e salinidade na superfície $\eta=z(x, y, t)$ são dadas por

$$
\begin{gathered}
\rho_{0} K_{M}\left(\frac{\partial u}{\partial z}, \frac{\partial v}{\partial z}\right)=\left(\tau_{0 x}, \tau_{0 y}\right) \\
w=u \frac{\partial \eta}{\partial x}+v \frac{\partial \eta}{\partial y}+\frac{\partial \eta}{\partial t} \\
\rho_{0} K_{H}\left(\frac{\partial \theta}{\partial z}, \frac{\partial S}{\partial z}\right)=(H, S)
\end{gathered}
$$


sendo $\tau_{0} x \tau_{0} y$ as componentes do vetor tensão de cisalhamento do vento na superfície, $H$ o fluxo de calor, o qual foi desconsiderado neste trabalho, sendo configurado igual a zero; $S=\frac{S(0)[E-P]}{\rho_{0}}$, sendo $(E-P)$ a taxa do fluxo de evaporação-precipitação de água doce na superfície, e $S(0)$ a salinidade na superfície. No fundo e nas laterais, o gradiente normal de $\theta$ e $S$ são zero, para que não haja fluxo advectivo e difusivo de sal e calor através dos contornos. No fundo (b),

$$
\begin{gathered}
\rho_{0} K_{M}\left(\frac{\partial u}{\partial z}, \frac{\partial v}{\partial z}\right)=\left(\tau_{b x}, \tau_{b y}\right) \\
q^{2}=B_{1}^{2 / 3} u_{\tau b}^{2} \\
q^{2} l=0 \\
w_{b}=-u_{b} \frac{\partial H}{\partial x}-v_{b} \frac{\partial H}{\partial y},
\end{gathered}
$$

sendo $u_{\tau b}$ a velocidade de atrito, associada à fricção devido à tensão de cisalhamento do fundo $\left(\tau_{b x}, \tau_{b y}\right)$, o qual é determinado pela correspondência das velocidades com a regra logarítimica da parede:

$$
\vec{\tau}_{b}=\rho_{0} C_{D}\left|\vec{V}_{b}\right| \vec{V}_{b}
$$

com coeficiente de arrasto $C_{d}$ dado por

$$
C_{d}=\left[\frac{1}{k} \ln \left(H+z_{b}\right) / z_{0}\right]^{2}
$$

onde $z_{b}$ e $v_{b}$ são pontos de grade correspondentes ao ponto de grade mais próximo ao fundo, e $K$ é a constante de von Karman. O resultado das equações 2.21 e 2.22, e junto ao fechamento turbulento derivado $K_{M}$ temos que

$$
\vec{V}=\left(\frac{\vec{\tau}_{b}}{\rho k u_{\tau n}}\right) \ln \left(\frac{H+z}{z_{0}}\right)
$$

no fundo, caso haja resolução suficiente. No caso deste trabalho, foi utilizado $C_{d}=2,5$. $10^{-3}$.

De forma a representar a circulação oceânica, condições de contorno nas fronteiras abertas, que permitam a passagem da energia de ondas, devem ser configuradas. Para isso, 
considera-se a condição de contorno radiativa RANDB, a qual permite que ondas longas, como a maré, e também as ondas de alta frequência geradas no interior da grade, irradiem através da borda. Esta condição foi desenvolvida por Reid e Bodine (1968):

$$
\eta=\eta_{0}+\lambda_{t} u_{n}\left(\frac{g}{D}\right)^{1 / 2}
$$

sendo $\eta$ a elevação do mar na borda, $\eta_{0}$ a variação no nível em um ponto de grade, relativa à variação conhecida da maré e de possíveis elevações de baixa frequência, $u_{n}$ é a velocidade prevista pelo modelo, perpendicular à borda, $g$ é a aceleração da gravidade e $D$ a profundidade no ponto de grade. $O$ coeficiente $\lambda_{t}$ é calculado a cada passo de tempo. A magnitude da tensão de cisalhamento do vento é definida pela lei do arrasto quadrático:

$$
\tau_{s i}=\frac{\rho_{a}}{\rho_{w}} C_{10} w_{i} w \quad i=(x, y)
$$

onde $\tau_{s i}$ são as componentes horizontais da tensão de cisalhamento do vento, $\rho_{a}$ é a densidade do ar, $\rho_{w}$ a densidade da água, $C_{10}$ é o coeficiente de arrasto e $w$ é a velocidade do vento medido a $10 \mathrm{~m}$ a cima do nível do mar. O coeficiente de arrasto é utilizado conforme sugerido por Large e Pond (1981)

$$
10^{3} C_{10}= \begin{cases}1.2, & \text { se } 4 \leq W<11 \mathrm{~m} \mathrm{~s}^{-1} \\ 0.49+0.065 W, & \text { se } 11 \leq W<25 m s^{-1}\end{cases}
$$

As equações podem ser rotacionadas em torno de um eixo vertical, mantendo a mesma forma, com as direções $x$ e $y$ representando, respectivamente, as direções quase perpendiculares e quase paralelas às isóbatas.

\section{Experimentos numéricos}

Para atingir os objetivos deste trabalho, foram escolhidos dois anos para realizar os experimentos. Um ano com fenômeno de La Niña (LN), e um ano sem anomalias atmosféricas, Ano Neutro (AN), 2010/2011 e 2012/2013, respectivamente (National Oceanic and Atmospheric Administration, https://origin.cpc.ncep.noaa.gov/products/ analysis_monitoring/ensostuff/ONI_v5.php). Desta forma, são necessários 8 experimentos, sendo um para cada estação de cada ano. 
Para a região do talude continetal foi utilizada a climatologia de Rezende (2003), a qual foi construída a partir do Banco Nacional de Dados Oceanográficos (BNDO). Para a PCI, PCM e PCE foi utilizada a climatologia elaborada por Gabriel Paschoal, enquanto aluno de mestrado do IO-USP, disponível no LHiCo. Estas duas climatologias, de temperatura e salinidade, foram interpoladas, para então serem usadas como condição inicial e de contorno do modelo. Desta forma, há dados de temperatura e salinidade para a quatro estações do ano.

Como forçantes, foram utilizados dados de vento do Research Data Archive - Computation and Information Systems Lab do National Center for Atmospheric Research (NCAR), e maré do TPXO 7.2, cuja metodologia consta nos trabalhos de Egbert et al. (1994), Egbert e Erofeeva (2002). As informações de maré são fornecidas como amplitudes complexas da elevação da superfície do mar em relação à Terra, em constituintes harmônicas. A resolução espacial é de 1/4 de grau. Foram utilizadas as 6 principais constinuintes da maré, 3 semidiurnas e 3 diurnas: $M 2, S 2, N 2$ e K1,P1,O1 respectivamente (Tabela 2.1). Na região, a constinuinte M2 é a dominante nas oscilações maregráficas do nível do mar (Castro 1996).

Tabela 2.1: Componentes de maré do TPXO 7.2 utilizadas no experimento numérico

\begin{tabular}{llll}
\hline Periodicidade & Componente & Período & Descrição \\
\hline \multirow{3}{*}{ Semidiurna } & M2 & $12.42 \mathrm{~h}$ & Lunar principal \\
& K2 & $12 \mathrm{~h}$ & Solar principal \\
\hline \multirow{3}{*}{ Diurna } & K1 & $12.66 \mathrm{~h}$ & Lunar elíptica \\
& P1 & $23.94 \mathrm{~h}$ & Declinação diurna lunar \\
& O1 & $24.06 \mathrm{~h}$ & Declinação diurna solar \\
& & $25.82 \mathrm{~h}$ & Declinação diurna lunar \\
\hline
\end{tabular}

Para inicializar o modelo, foi rodado um aquecimento de 10 dias, para estabilizá-lo. Esta rodada é feita para cada experimento, em modo prognóstico, o qual permite a evolução da temperatura e da salinidade ao longo do tempo. Além disso, a climatologia é utilizada como condição inicial e a maré como forçante. Nesta situação de aquecimento, o vento não é utilizado. A condição de contorno utilizada é radiativa do tipo RANDB, a qual é descrita por Reid e Bodine (1968). Estas rodadas geram um arquivo de saída, que é então utilizado como condição inicial para a rodada do período sazonal de interesse. Nesta 
segunda rodada é definido o modo diagnóstico, o qual não permite evolução temporal de temperatura e salinidade. Além da maré, o vento também atua como forçante. Para tanto, foi utilizado os bancos de dados do NCAR, The National Centers for Environmental Prediction (NCEP) Climate Forecast System (CFSv2) e o Climate Forecast System Reanalysis (CFSR). A resolução temporal é de 6 horas (Saha et al. 2014).

\section{Dados}

Para validar o modelo, foi utilizado o banco de dados do projeto Transporte e Difusão no Canal de São Sebastião - TRADICAS. Este projeto realiza o monitoramento das propriedades físicas da água do mar e das correntes marinhas no Canal de São Sebastião (CSS) desde 1990. Além de permitir melhor compreensão dos processos físicos que ocorrem na região, estes dados ainda permitem a validação de modelos numéricos.

Os dados utilizados para validação são as componentes $u$ e $v$ de velocidade, coletados no fundeio oceanográfico $\mathrm{C} 2$, na posição em $23.83^{\circ} \mathrm{S}$ e $45.40^{\circ} \mathrm{W}$, dentro do CSS, por dois correntógrafos (Figura 2.3). Neste ponto, a profundidade do canal é de aproximadamente $30 \mathrm{~m}$. A velocidade foi rotacionada $-51^{\circ}$ para que ficasse orientada de acordo com a linha de costa. A mesma rotação foi aplicada aos valores gerados pelo modelo. Para a comparação dos dados com o modelo, foi escolhido o ponto de grade representado na Figura 2.3, onde também está representado o C2. 


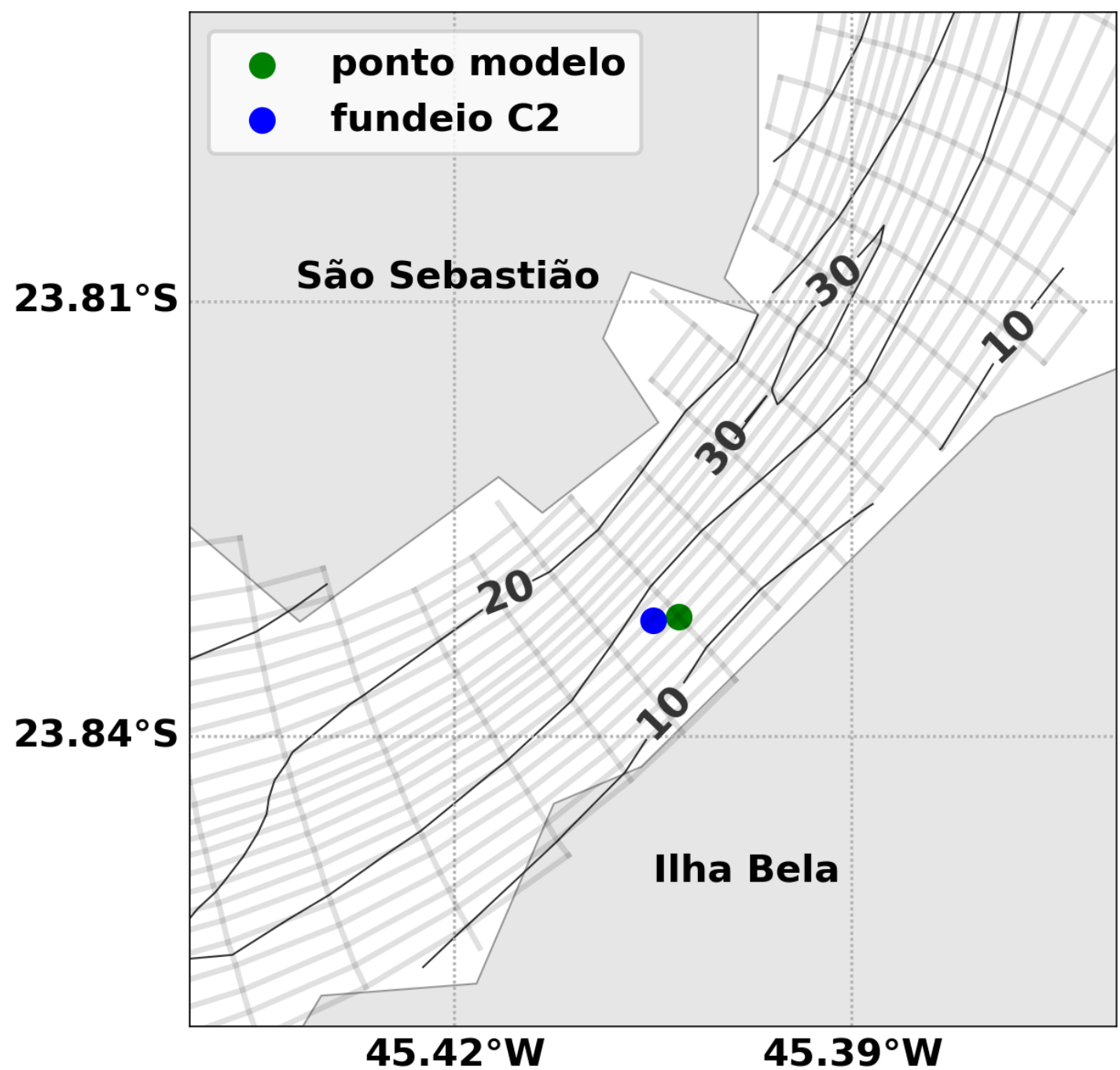

Figura 2.3: Localização do fundeio de correntógrafos $C 2$ e do ponto de grade do modelo ECOM, selecionado para validação dos experimentos numéricos.

A comparação dos resultados do modelo com os dados medidos no CSS foi feita a partir do método skill de Willmott (1981), utilizando a equação apresentada por Warner et al. (2005):

$$
\text { Skill }=1-\frac{\sum\left|X_{\text {modelo }}-X_{\text {dado }}\right|^{2}}{\sum\left(\left|X_{\text {modelo }}-\overline{X_{\text {dado }}}\right|+\left|X_{\text {dado }}-\overline{X_{\text {dado }}}\right|\right)^{2}},
$$

sendo $X$ a variável a ser comparada e $\bar{X}$ a média no tempo dessa variável. O skill pode ser calculado para qualquer variável prognóstica, e por isso será calculado para velocidade. Os valores variam de 0 a 1 , quanto mais próximo de 1 for o valor, mais representativos estão os resultados do modelo quando comparados com as observações.

Para o cálculo do skill, os campos horizontais de velocidade foram utilizados para esti- 
mar a média vertical nos primeiros 5 níveis sigma para a camada superficial, e a média dos 5 últimos níveis sigma para a camada de fundo. No entanto, para todos os resultados, o último nível sigma é desconsiderado. Essas médias foram então comparadas com os dados medidos no ponto $\mathrm{C} 2$ pelos correntógrafos superficial e de fundo.

Três sessões quase transversais à costa foram selecionadas: Ubatuba, Santos e Cananéia (Figura 2.1), nas quais foram analisádos os resultados para o transorte de volume paralelo à costa e a evolução temporal do nível do mar, através de diagramas do tipo Hövmoller,o que permite ver a evolução em toda a sessão.

Para calcular o transporte, primeiro foi aplicado um filtro passa baixa do tipo Lanczos Quadrático, com período de 40 horas (Duchon 1979), para tirar o sinal da maré. Em seguida, a velocidade foi dividida em velocidade barotrópica e velocidade baroclínica. Para a velocidade barotrópica, foi feita a média na profundidade, e para encontrar a velocidade baroclínica, foi feita a diferença entre a velocidade total e a velocidade barotrópica. Assim, para cada transporte (total, barotrópico e baroclínico), o transporte foi calculado através da equação

$$
v_{t}=\int_{0}^{L} \int_{-H}^{\eta} v(x, z, t) d z d x,
$$

sendo $v_{t}$ o transporte em Sv, $L$ a largura da sessão, $H$ a profundidade, $\eta$ o nível do mar e $v$ a velocidade meridional rotacionada de acordo com a linha de costa. 


\section{Capítulo 3}

\section{Resultados e discussão}

\section{Validação do modelo}

A validação dos resultados do modelo foi feita para os experimentos de outono, inverno e primavera de 2010. Embora haja manutenção frenquente do fundeio (aproximadamente 4 vezes por ano), não foi possível utlizar os dados de verão 2010/2011, por motivo de falha técnica no equipamento de medição.

Para o outono, a comparação foi feita através de uma série temporal de 20 de março de 2010 a 20 de junho de 2010. No entanto, há uma lacuna de 16 horas sem medição, período que foi deixado sem dados na série temporal. Para este período foram utilizados apenas os dados do sensor de superfície do fundeio, pois o outro sensor apresentou problemas. O sensor de superfície estava virado para baixo, fazendo a medição a aproximadamente 14 $\mathrm{m}$ de profundidade.

É possível ver as séries temporais do modelo e dos dados, para ambas componentes da velocidade perpendicular e paralela à costa (Figura 3.1). Este foi o período mais representativo do modelo, apresentando valor de skill de 0.78 . 

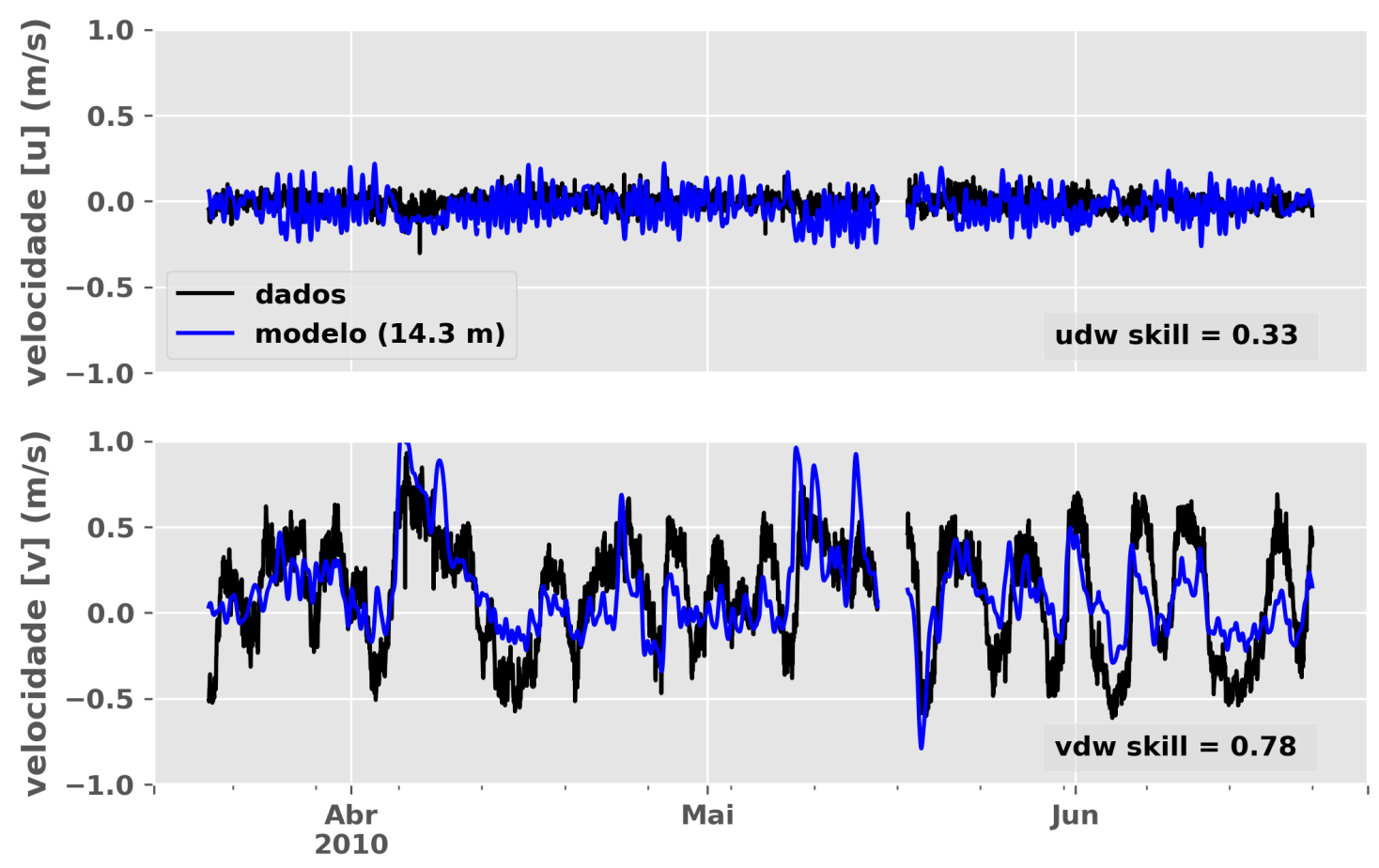

Figura 3.1: Série temporal das componentes da velocidade perpendicular e paralela à costa. Profundidade utilizada no modelo para o skill: $13.40 \mathrm{~m}$. Valor médio do skill é de 0.78 para a componente paralela à costa da velocidade, e 0.33 para a componente perpendicular à costa. Em preto estão os dados, e em azul, o resultado do modelo.

Para o inverno, a comparação foi feita através de uma série temporal de 21 de junho de 2010 a 22 de setembro de 2010. Na Figura 3.2 é possível ver as séries temporais tanto do modelo quanto dos dados, para ambas componentes de velocidade perpendicular e paralela. Conforme esperado, é possível perceber melhores valores para a velocidade paralela à linha de costa, enquanto a velocidade perpendicular apresenta valores menores. Neste período, o sensor de fundo, que estava posicionado para cima, representou melhor valor de skill, 0.68. Ao longo da coluna de água, os valores encontrados foram bem homogêneos, o que corrobora com o fato de a água ser menos estratificada nesta época (Castro 2014). 

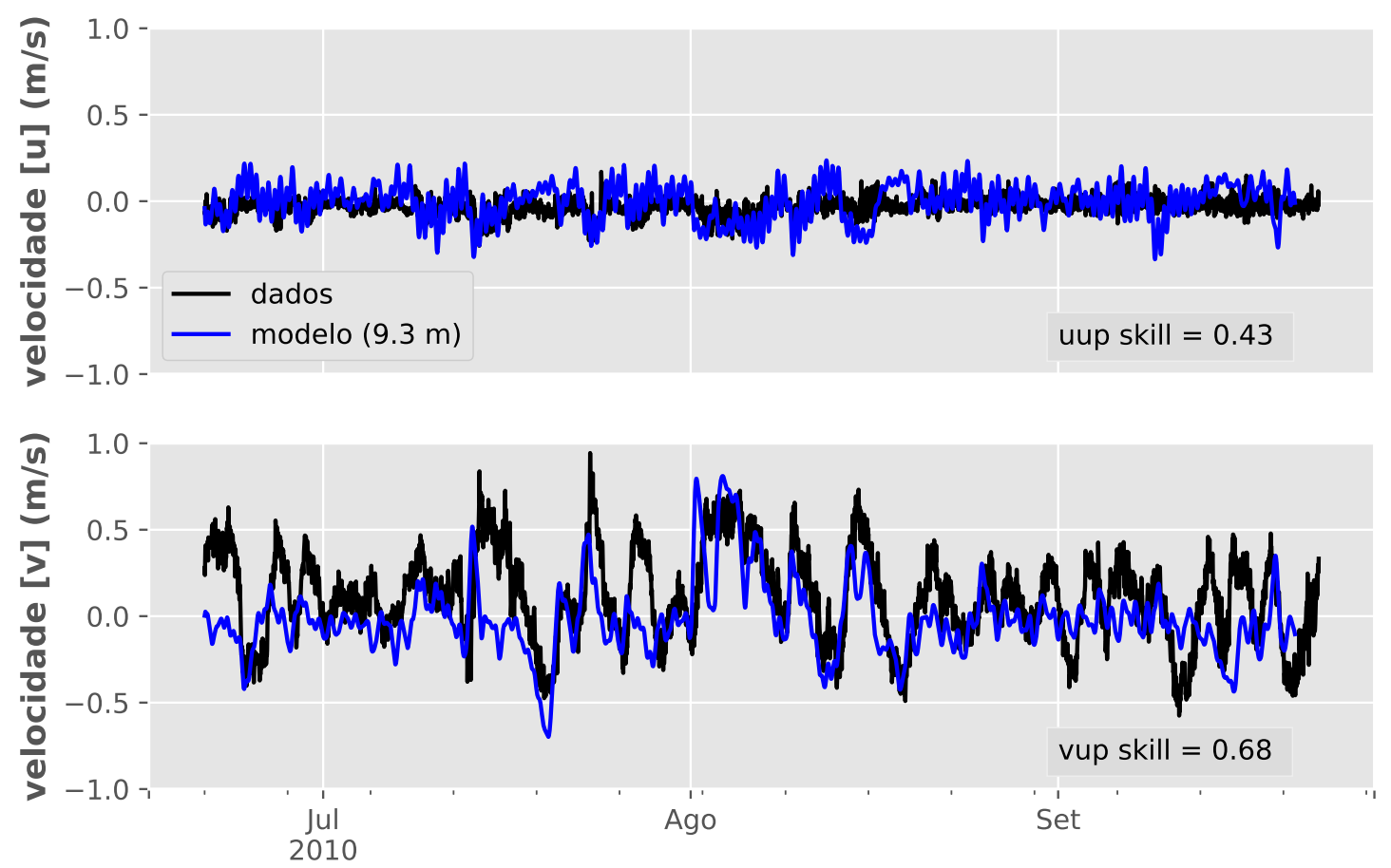

Figura 3.2: Série temporal das componentes da velocidade perpendicular e paralela à costa. Profundidade utilizada no modelo para o skill: $9.3 \mathrm{~m}$. Valor médio do skill é de 0.68 para a componente paralela à costa da velocidade, e 0.43 para a componente perpendicular à costa. Em preto estão os dados e, em azul, o resultado do modelo.

Para o período da primavera, foram análisadas as séries temporais do modelo e dos dados, para ambas velocidades perpendicular e paralela (Figura 3.3). A primavera foi definida como o período entre 23/09/2010 e 20/12/2010. No entanto, apesar de o modelo ter simulado por este período, a comparação com os dados ocorreu apenas entre 23/09/2010 e 17/11/207, pois os dados de dezembro/2010 e janeiro-fevereiro/2011 não estão confiáveis. Para este período, o valor de skill encontrado foi de 0.73 para a velocidade paralela, e 0.33 para a velocidae perpendicular. 

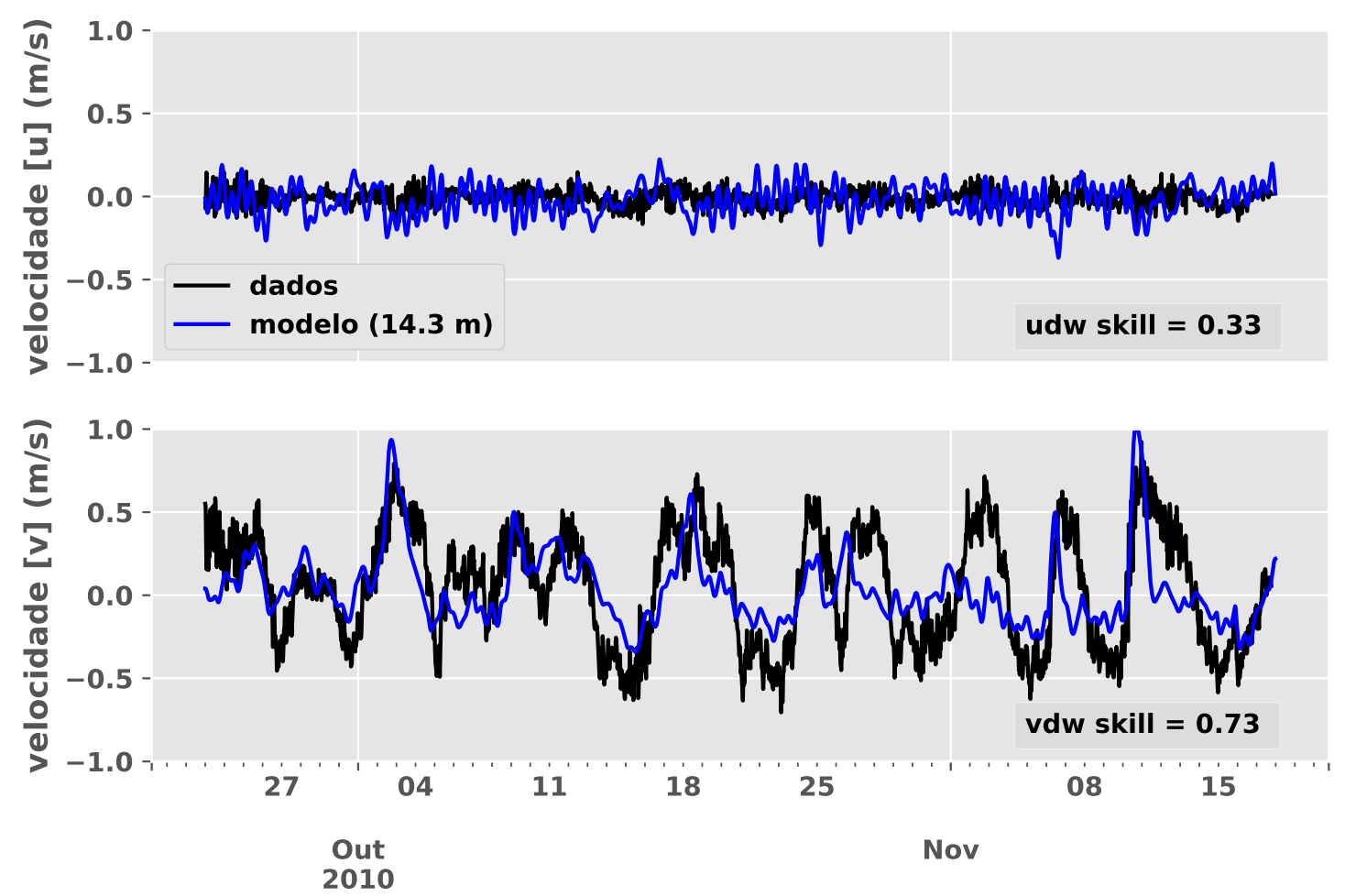

Figura 3.3: Série temporal das componentes da velocidade perpendicular e paralela à costa. Profundidade utilizada no modelo para o skill: $14.3 \mathrm{~m}$. Valor médio do skill é de 0.73 para a componente paralela à costa da velocidade, e 0.33 para a componente perpendicular à costa. Em preto estão os dados, e em azul, o resultado do modelo.

Como não foi possível utilizar os dados de dezembro/2010 e janeiro-fevereiro/2011, o verão não foi validado. No entanto, visto que para as outras três estações do ano os valores de skill apresentados no presente trabalho estão dentro do esperado, assemelhando-se ao valor obtido por Zhang et al. (2012), por exemplo. Sendo assim, o experimento de verão será considerado validado. Estes autores apresentaram um modelo pré-operacional para a circulação na PC e no talude do Texas/Luisiana - Estados Unidos. Para validar os experimentos realizados, os autores calcularam o skill entre os resultados do modelo e dados observacionais. Para as velocidades paralelas e perpendiculares à costa, os valores máximos obtidos foram 0.78 e 0.59 , respectivamente. No entanto, a maioria dos valores encontrados para velocidade perpendicular ficaram abaixo de 0.3. Segundo os autores, é esperado que os valores da componente paralela da velocidade sejam maiores do que da compontente perpendicular, visto que estes são influenciados principalmente pelo vento, enquanto a componente perpendicular é fortemente influenciada por outros fatores, como 
o gradiente de pressão, variável esta mais difícil de simular. Os dados utilizados pelos autores para esta comparação não sofreram nenhum tipo de alisamento, assim como foi feito neste trabalho, o que diminui os valores do skill.

\section{Campos horizontais de temperatura e salinidade}

As condições termohalinas dos campos horizontais, foram representadas por mapas de temperatura e de salinidade para a superfície e fundo, interpolados após os 10 dias de aquecimento. Durante estes 10 dias, o experimento foi feito em modo prognóstico, sendo forçado com vento e, nas bordas, com a maré.

Para a superfície, foi considerada a média dos primeiros 5 níveis sigma e, para o fundo, a média dos últimos 5 níveis sigma, desconsiderando o último, pois a condição de contorno zera as velocidades nesta camada. Foi levada em consideração a distância de influência de cada nível sigma, conforme proposto por Castro (1996) para o cálculo das médias.

No outono (Figura 3.4), é observado um intenso gradiente vertical de temperatura entre o fundo e a superfície, principalmente para as isóbatas maiores que $25 \mathrm{~m}$. Na superfície, é possível ver que as maiores temperaturas ocorrem ao redor de Cananéia, e que as menores temperaturas estão entre as isóbatas de 50 e 200 m (Figura 3.4A). Já no fundo, as faixas de temperatura seguem as isóbatas: as maiores temperaturas estão entre a costa e a isóbata de $25 \mathrm{~m}$, diminuindo até a isóbata de $80 \mathrm{~m}$, e sendo mínimas entre as isobatas de 80 e 200 m (Figura 3.4B).

Em relação à salinidade, a variação é bem pequena entre superfície (Figura 3.4C) e fundo (Figura 3.4D). A maior diferença está na PCI, principalmente entre São Sebastião e Ubatuba, e ao sul de Cananéia, onde a água é menos salina. Esta característica está associada à presença da AC.

No inverno (Figura 3.5), o gradiente vertical de temperatura entre a superfície e o fundo é menor do que no outono. No entanto, o gradiente horizontal de temperatura é mais intenso. Na superfície, a água mais fria encontra-se no sul da PCSE, aumentando gradualmente para o norte, o que sugere uma advecção de águas frias provenientes do quadrante sul. As maiores temperaturas concentram-se ao norte da Ilha de São Sebastião (Figura 3.5A). No fundo, os valores de temperatura seguem as isóbatas, sendo que os maiores valores estão entre a isóbata de $50 \mathrm{~m}$ e a costa, de Santos até o norte da grade 
(Figura 3.5B).
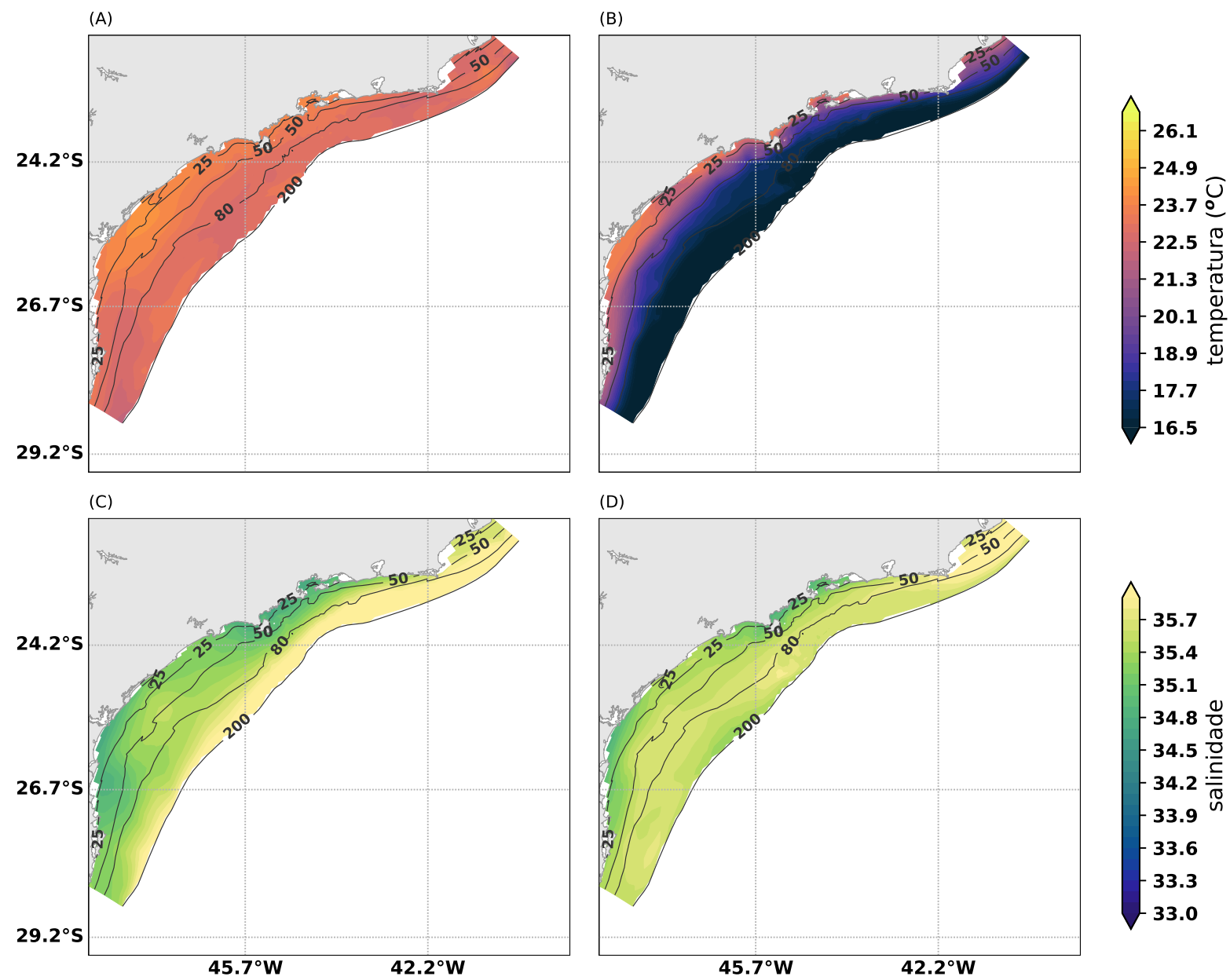

Figura 3.4: Campo horizontal de Temperatura $\left({ }^{\circ} \mathrm{C}\right)$ e Salinidade. Figuras $(A)$ e $(C)$ representam a superfície, e figuras $(B)$ e $(D)$ representam o fundo. Figuras obtidas para o outono, após integração do modelo por 10 dias em modo prognóstico.

A salinidade, na superfície, acompanha o padrão de distribuição da temperatura, com valores menores de salinidade na porção sul da PCSE, aumentando gradualmente para o norte, dando suporte à ideia da entrada de águas menos salinas vindas do sul (Figura 3.5C). Estes padrões indicam a presença da $\mathrm{AC}$ na região. No fundo, o mesmo padrão de distribuição de salinidade é encontrado (Figura 3.5D). A diferença é que esta água menos salina vai até a isóbata de $50 \mathrm{~m}$ no fundo, enquanto na superfície encontra-se até a isóbata de $80 \mathrm{~m}$. 

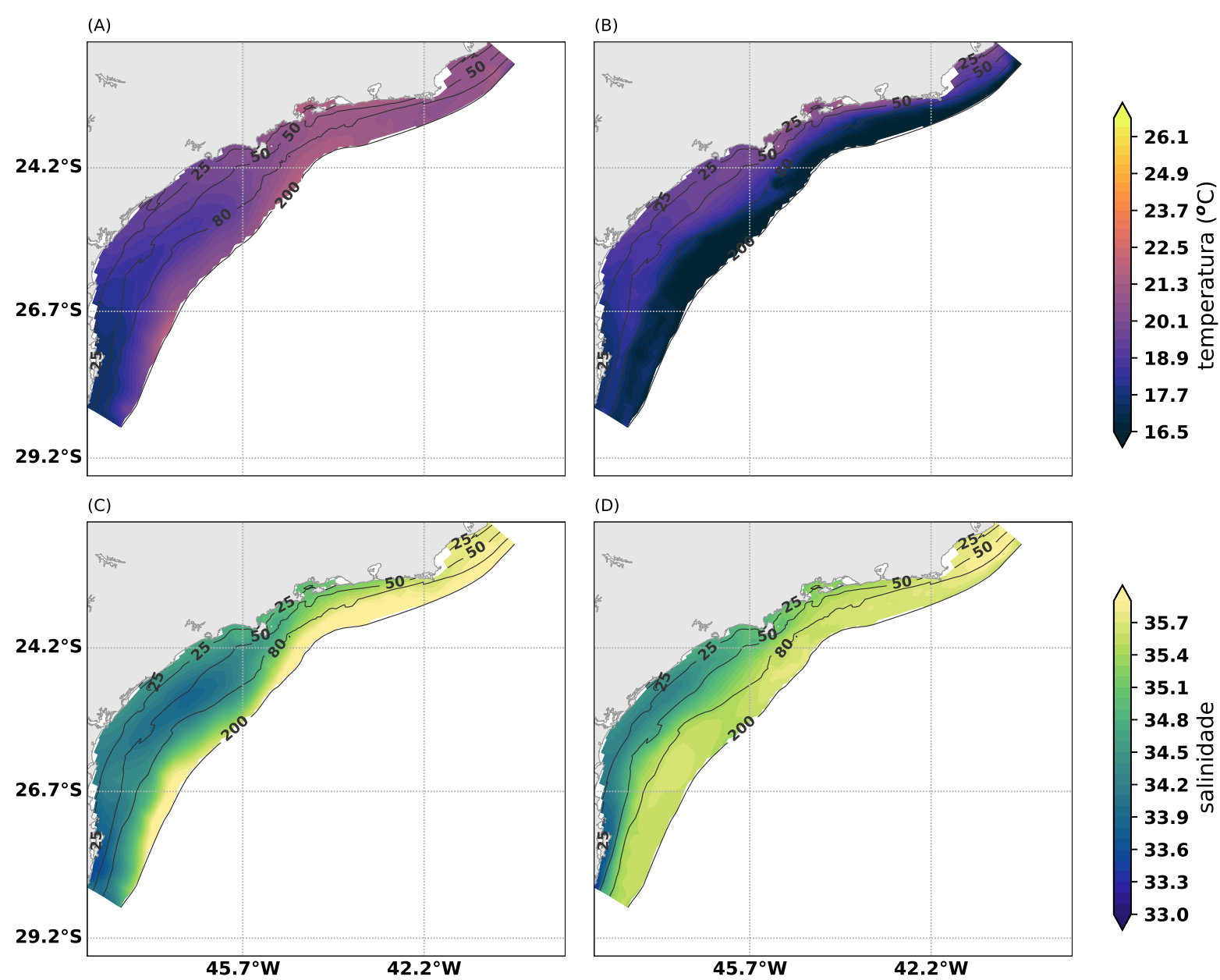

Figura 3.5: Campo horizontal de Temperatura $\left({ }^{\circ} \mathrm{C}\right)$ e Salinidade. Figuras $(A)$ e $(C)$ representam a superfície, e figuras $(B)$ e $(D)$ representam o fundo. Figuras obtidas para o inverno, após integração do modelo por 10 dias em modo prognóstico.

Na primavera (Figura 3.6), há estratificação vertical da coluna de água nas isóbatas superiores a $25 \mathrm{~m}$. Os valores de temperatura apresentados na superfície são intermediários em comparação ao inverno e o outono, e é possível ver certa homogeneidade da temperatura horizontal, sendo que as menores temperaturas encontram-se na porção norte da PCSE (Figura 3.6A). Já no fundo, do norte de Florianópolis até o norte da PCSE, entre as isóbatas de 80 e de $200 \mathrm{~m}$, são encontradas as menores temperaturas, e do norte da Ilha de São Sebastião, até o norte da PCSE, essas temperaturas baixas são encontradas a partir da isóbata de $50 \mathrm{~m}$ (Figura 3.6B).

A salinidade é quase homogêna na profundidade. Os menores valores encontrados estão entre Itajaí e Cananéia, indo até a isóbata de $80 \mathrm{~m}$ na superfície (Figura 3.6C) e até a isóbata de $25 \mathrm{~m}$ no fundo (Figura 3.6B). Na superfície é possivel ver ainda um pequeno 
aumento da salinidade entre as isóbatas de 80 e $100 \mathrm{~m}$.
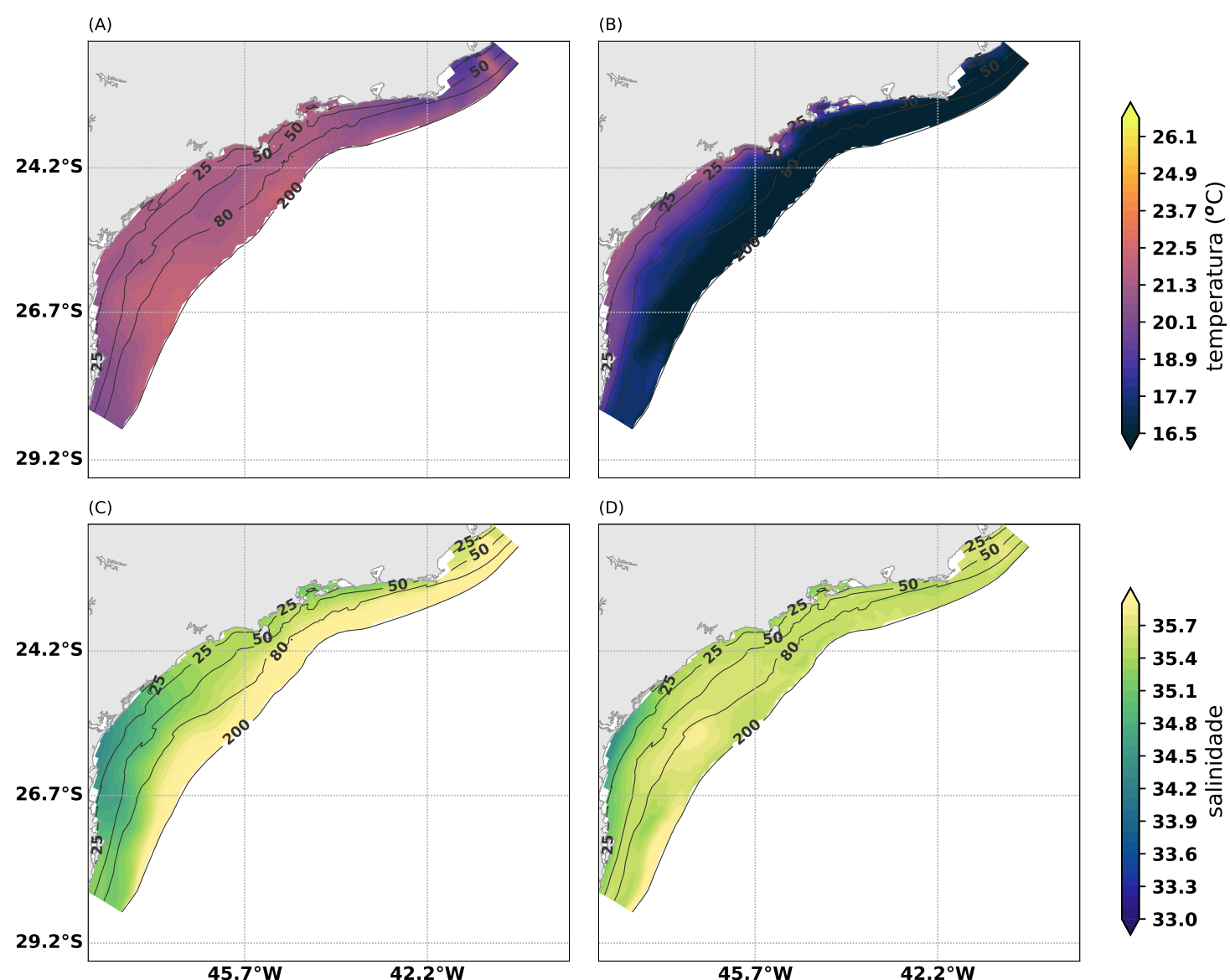

Figura 3.6: Campo horizontal de Temperatura $\left({ }^{\circ} \mathrm{C}\right)$ e Salinidade. Figuras $(A)$ e $(C)$ representam a superficie, e figuras $(B)$ e $(D)$ representam o fundo. Figuras obtidas para o primavera, após integração do modelo por 10 dias em modo prognóstico.

O verão (Figura 3.7) é o período que apresenta a maior estratificação vertical da temperatura. Na superfície é possível ver valores maiores do que $23^{\circ} \mathrm{C}$ em quase toda extensão da área de estudo e, no entorno de Santos, a temperatura chega a valores superiores a $26^{\circ} \mathrm{C}$ (Figura 3.7A). Os menores valores de temperatura para a superfície são encontrados a partir da ilha de São Sebastião entre as isóbatas de 80 e 200 m, e a partir de Ubatuba entre as isóbatas de 50 e 100 até o norte da PCSE. No fundo a temperatura segue as isóbatas, sendo maior entre a costa e $25 \mathrm{~m}$, e os maiores valores encontrados estão entre Santos e São Sebastião. Há diminuição da temperatura entre as isóbatas de 25 e $50 \mathrm{~m}$, sendo as menores temperaturas encontradas entre as isóbatas de 50 e 200 (Figura 3.7B).

A salinidade apresenta menores valores na superfície entre a costa e a isóbata de $50 \mathrm{~m}$, até aproximadamente Ubatuba (Figura 3.7C). Já no fundo apresenta-se bastante homogênea, com valores menores apenas bem próximo à costa, principalmente entre Santos e 
São Sebastião (Figura 3.7D). A coluna d'água é mais homogênea entre as isóbatas de 50 e $80 \mathrm{~m}$.
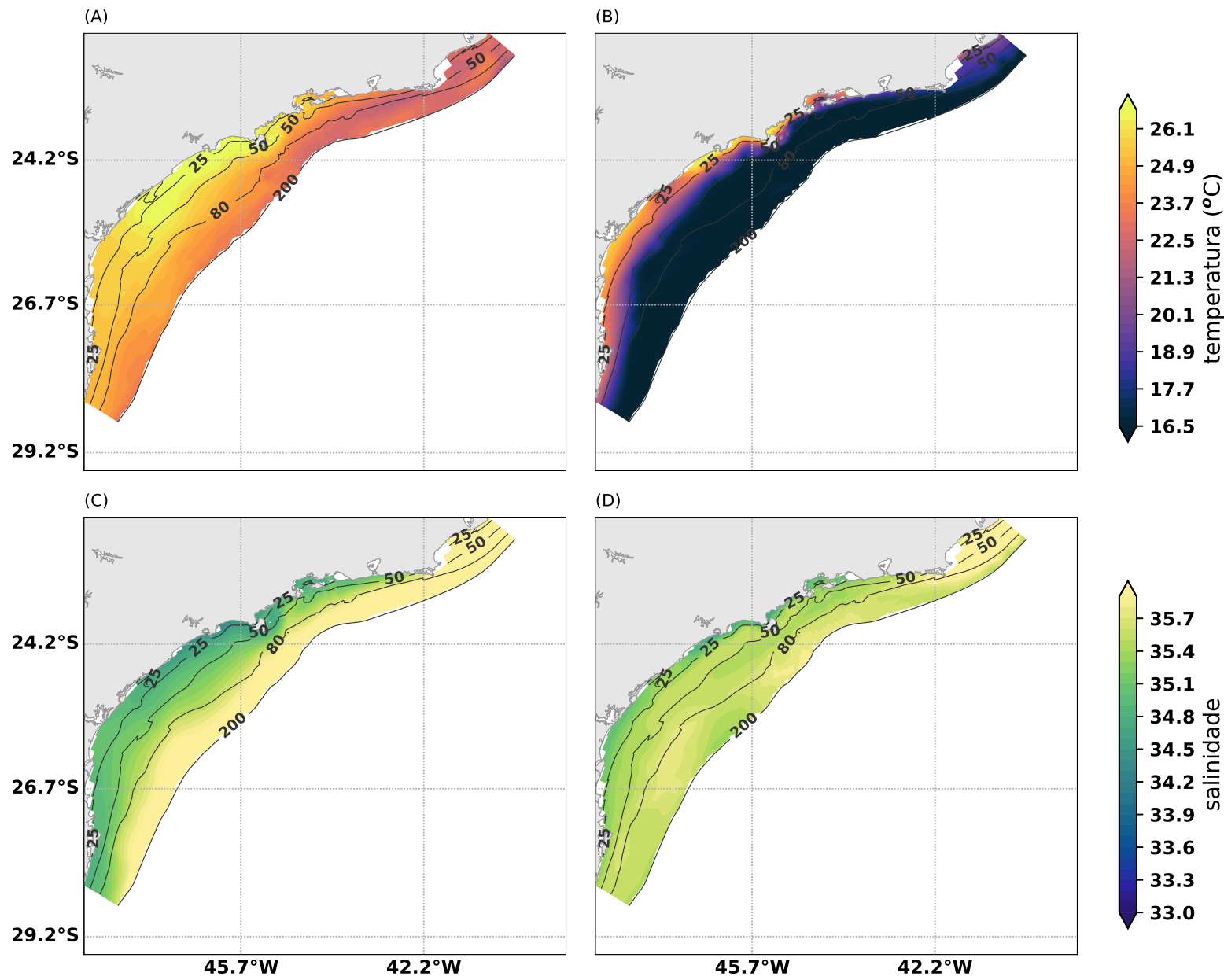

Figura 3.7: Campo horizontal de Temperatura $\left({ }^{\circ} \mathrm{C}\right)$ e Salinidade. Figuras $(A)$ e $(C)$ representam a superfície, e figuras $(B)$ e $(D)$ representam o fundo. Figuras obtidas para o verão, após integração do modelo por 10 dias em modo prognóstico.

Os valores de temperatura e de salinidade para inverno e verão estão de acordo com aqueles apresentados por Castro e Miranda (1998), sendo maiores que $22^{\circ} \mathrm{C}$ no verão e menores no inverno. Além disso, os valores de temperatura de fundo estão alinhados com as isóbatas nas quatro estações. Castro (1996) encontrou este mesmo padrão para o inverno e o verão, ao analisar dados históricos. A temperatura de inverno e verão na superfície também apresentam comportamento semelhante ao encontrado por Castro (1996): temperaturas mais baixas entrando no sul no formato de uma língua no inverno, e no verão temperaturas mais baixas de Ubatuba para o norte. 
A salinidade na superfície, no inverno e no verão, também apresentam comportamento semelhante àquele apresentado por Castro (1996): águas menos salinas na PCI e mais salinas entre as isóbatas de 100 e 200 m, e águas menos salinas na PCI ao sul da ilha de São Sebastião, respectivamente. No fundo, os padrões encontrados também são semelhantes, sendo bastante homogêneo tanto no inverno quanto no verão.

Os campos de temperatura obtidos (Figuras 3.4 a 3.7), são utilizados para inicializar os oito experimentos numéricos em modo diagnóstico. Feitos no modo diagnóstico, a temperatura e a salinidade não evoluem no tempo nesses oito experimentos. No entanto, cada estação do ano apresenta uma climatologia diferente.

\section{Campos horizontais de correntes sazonais}

Para caracterizar a circulação da PCSE, foram analisados os campos horizontais de velocidade de corrente em quatro situações diferentes: média sazonal, pré-frente fria, frente fria e pós-frente fria. Estes quatro casos foram representados para as quatro estações do ano, tanto do AN, quanto do ano de LN, tanto para o fundo quanto para a superfície. Tanto na PCI quanto na PCM, as correntes são dominadas por ventos sazonais (escala anual) e por ventos sinóticos (escala de dias a semanas), e as correntes estão alinhadas às isóbatas, sendo o sentido dependente do vento (Fontes e Castro 2017).

Considerando primeiramente o experimento de outono, para superfície (Figura 3.8), temse que a velocidade máxima encontrada para o campo médio de LN é de $0.68 \mathrm{~m} \mathrm{~s}^{-1}$, a velocidade mínima é praticamente nula, a velocidade média é de $0.09 \mathrm{~m} \mathrm{~s}^{-1}$ e o desvio padrão é de $0.05 m \mathrm{~s}^{-1}$. É possível perceber que ao sul de Cananéia há predomínio das correntes de NW quase perpendiculares à costa. Entre Cananéia e Santos, na PCI, as correntes também são de NW, mas começam a girar para norte. No entano, na PCM, é possível perceber a ocorrência de correntes para SW, que acabam se juntando às anteriores. Este padrão forma um giro ciclônico na região. No canal de São Sebastião a corrente é de NE, assim como na PCI, a leste da ilha de São Sebastião. Já na PCM a corrente é de sul. Na região de Ubatuba, as correntes apresentam sentido predominante para N/NE.

Já no experimento de AN, a velocidade máxima é de $0.41 \mathrm{~m} \mathrm{~s}^{-1}$, a mínima é quase nula, a média é de $0.08 \mathrm{~m} \mathrm{~s}^{-1}$ e o desvio padrão é de $0.04 \mathrm{~m} \mathrm{~s}^{-1}$. A direção da circulação é bastante semelhante à encontrada para no LN, já a intensidade, em geral, é menos intensa 
do que no LN.

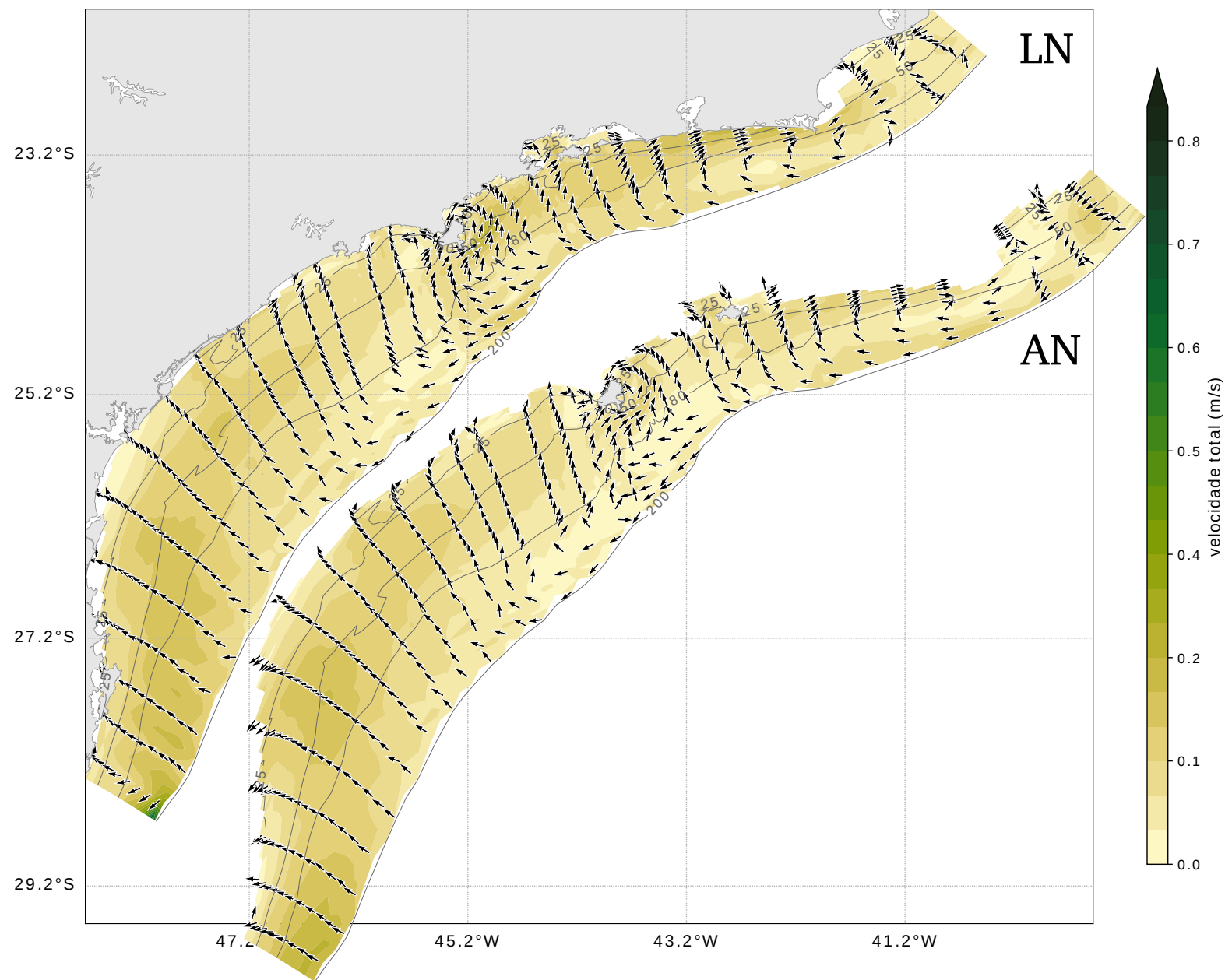

Figura 3.8: Campo horizontal de velocidade média na camada superficial. Experimento de outono. Anos de La Niña (LN) e de ano neutro (AN). Intensidade representada pela cor, em $\mathrm{m} \mathrm{s}^{-1}$, e direção representada pelos vetores normalizados.

No fundo (Figura 3.9), no experimento de LN, a velocidade máxima encontrada é de $0.22 \mathrm{~m} \mathrm{~s}^{-1}$ e a velocidade mínima é praticamente nula. A velocidade média ficou em 0.04 $m s^{-1}$ e o desvio padrão em $0.02 \mathrm{~m} \mathrm{~s}^{-1}$. Diferentemente da superfície, o fundo apresenta predominância de correntes de nordeste no campo todo. Estas diferenças mostram que ocorre cisalhamento da velocidade ao longo da coluna de água.

No experimento de AN, assim como no experimento $\mathrm{LN}$, a velocidade diminui em relação à superfície. A velocidade máxima encontrada é de $0.21 \mathrm{~m} \mathrm{~s}^{-1}$, já a mínima é praticamente nula. A velocidade média é de $0.03 \mathrm{~m} \mathrm{~s}^{-1}$ e o desvio padrão é quase zero. As correntes de fundo seguem o mesmo padrão das correntes de superfície, ou seja, escoam 
predominantemente para NE-E, em toda a PCSP. Também nesta estação do ano, igualmente à superfície, as correntes são em geral menos intensas no AN comparativamente ao LN.

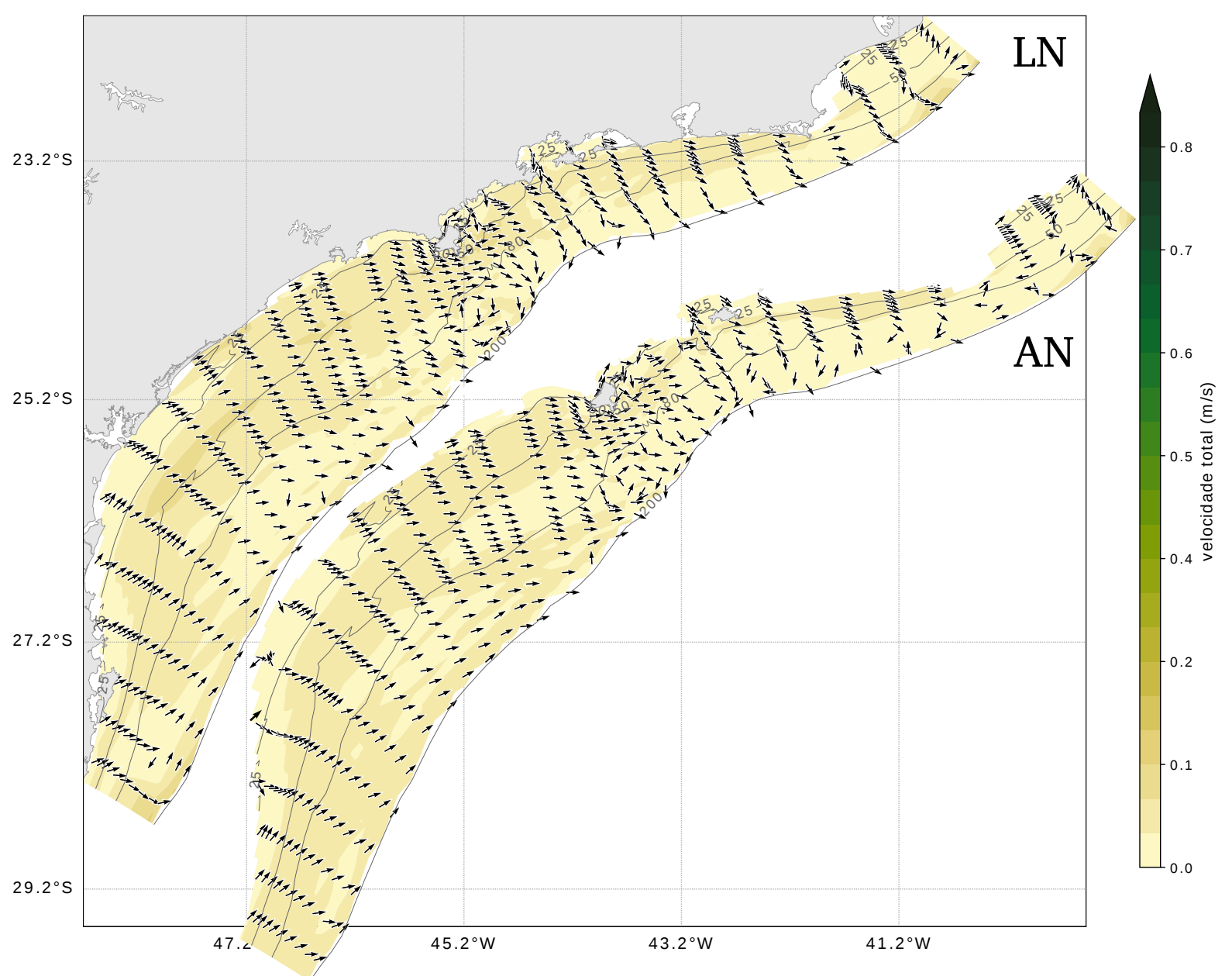

Figura 3.9: Campo horizontal de velocidade média na camada de fundo. Experimento de outono. Anos de La Niña (LN) e de ano neutro (AN). Intensidade representada pela cor, em $\mathrm{m} \mathrm{s}^{-1}$, e direção representada pelos vetores normalizados.

No inverno, começando pela superfície (Figura 3.10), a velocidade máxima encontrada no LN é de $0.41 \mathrm{~m} \mathrm{~s}^{-1}$, a velocidade mínima é praticamente nula. A velocidade média é de $0.08 \mathrm{~m} \mathrm{~s}^{-1}$ e o desvio padrão é de $0.04 \mathrm{~m} \mathrm{~s}^{-1}$. Ao sul de São Sebastião, na PCI, a corrente é predominante de SW. Na altura de Santos, na PCM, há uma convergência de correntes vindas do sul e do norte. Entre Ubatuba e Cabo Frio, é possível ver um padrão de circulação ciclônica. Na estação fria, as correntes médias superficiais no LN são menos intensas que no outono. 
No experimento AN, durante o inverno, a velocidade máxima encontrada na superfície (Figura 3.10) é de $0.94 \mathrm{~m} \mathrm{~s}^{-1}$ e a mínima é quase nula. A média é de $0.06 \mathrm{~m} \mathrm{~s}^{-1}$ e o desvio padrão de $0.04 \mathrm{~m} \mathrm{~s}^{-1}$. Os valores máximos mais altos, em relação ao LN encontram-se no sul e no norte da PCSE. Já em relação à média, AN apresenta valores menores. Quanto à direção das correntes, é possível perceber que entre Cananéia e São Sebastião, a PCI e a PCM também apresentam direções opostas, sendo de SW na PCI e NE na PCM. Entre Ubatuba e Cabo Frio, o mesmo padrão ciclônico do LN também se repete.

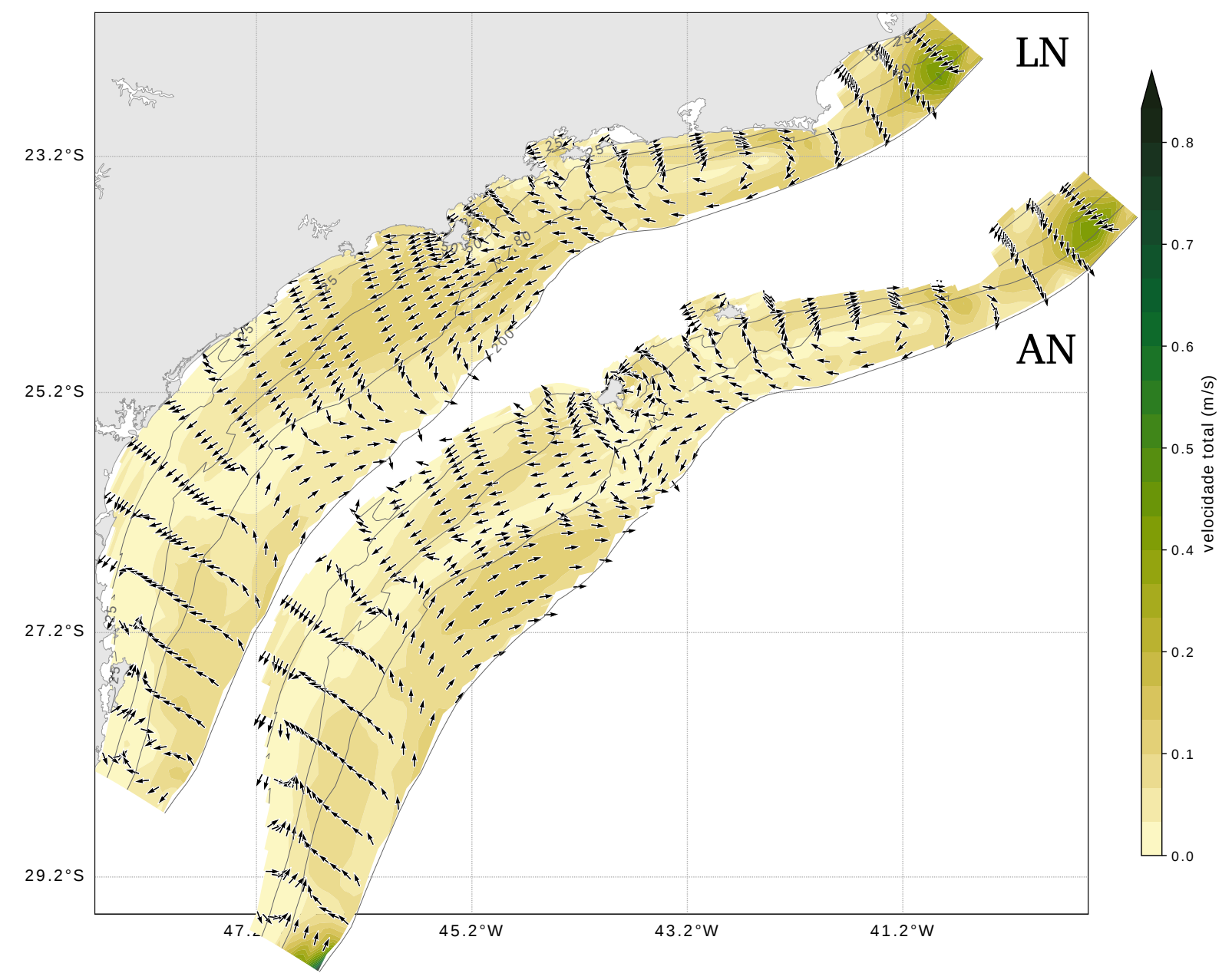

Figura 3.10: Campo horizontal de velocidade média na camada de superfície. Experimento de inverno. Anos de La Niña (LN) e de ano neutro (AN). Intensidade representada pela cor, em m $\mathrm{s}^{-1}$, e direção representada pelos vetores normalizados.

No fundo (Figura 3.11), no ano LN, durante o inverno, a velocidade máxima é de 0.31 $m \mathrm{~s}^{-1}$ e a mínima é quase nula, assim como na superfície. A velocidade média é de 0.03 $m s^{-1}$ e o desvio padrão de $0.02 \mathrm{~m} \mathrm{~s}^{-1}$. Diferentemente da superície, em todo o campo a 
direção predominante da corrente é de NE.

No AN, a velocidade máxima é de $0.317 \mathrm{~m} \mathrm{~s}^{-1}$, a mínima praticamente nula, a média de $0.03 \mathrm{~m} \mathrm{~s}^{-1}$ e o desvio padrão de $0.02 \mathrm{~m} \mathrm{~s}^{-1}$. Assim como no LN, a predominância do sentido das correntes é de NE. A velocidade média no fundo foi a mesma para os dois experimentos, e a máxima aproximadamente igual também.

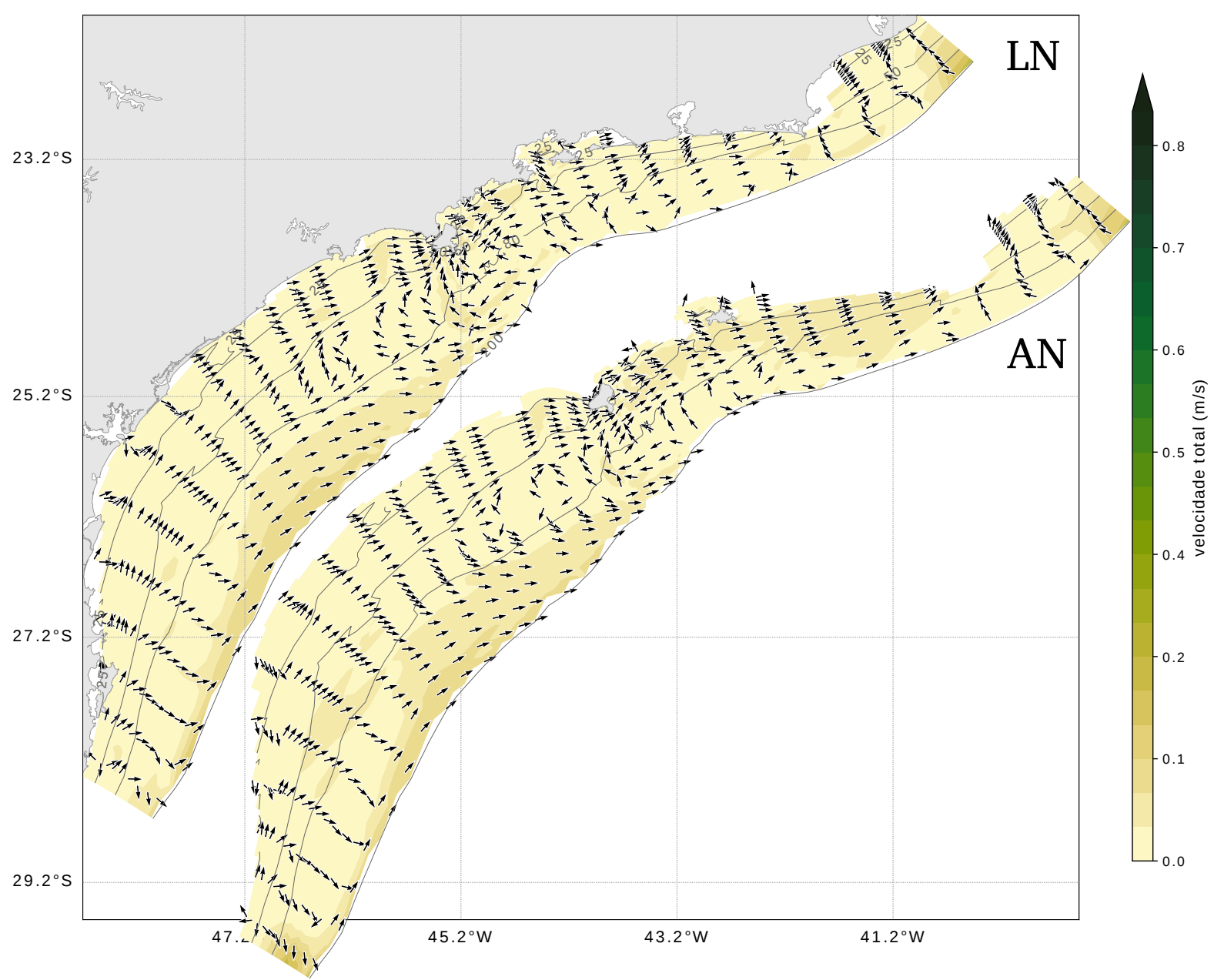

Figura 3.11: Campo horizontal de velocidade média na camada de fundo. Experimento de inverno. Anos de La Niña (LN) e de ano neutro (AN). Intensidade representada pela cor, em m s $\mathrm{s}^{-1}$, e direção representada pelos vetores normalizados.

Na primavera, na superfície (Figura 3.12), a velocidade máxima encontrada no experimento de $\mathrm{LN}$ é de $0.31 \mathrm{~m} \mathrm{~s}^{-1}$. A velocidade mínima é praticamente nula, enquanto a média é $0.09 \mathrm{~m} \mathrm{~s}^{-1}$ e o desvio padrão é de $0.05 \mathrm{~m} \mathrm{~s}^{-1}$. A circulação média não apresenta um padrão predominante. Ao norte de São Sebastião, na PCE a corrente é de NE. Ao se aproximar da Ilha de São Sebastião esta corrente entra na PCI. Já na PCI entre São 
Sebastião e Cabo Frio a corrente apresenta comportamento ciclônico. Ao norte de Cabo Frio, tanto na PCI quanto na PCM a corrente é de nordeste. Ao sul de Cananéia, na PCM, há correntes de NW.

Já no experimento de AN, o campo de velocidade médio na superfície apresentou-se mais homogêneo, principalmente ao norte de São Sebastião, onde a corrente apresenta direção dominante de SW. Ao sul de São Sebastião, na PCI, a velocidade segue a mesma orientação. Apenas mais para o sul da grade, na PCM, é que há um sinal de corrente de N-NW. O valor máximo encontrado foi de $0.50 \mathrm{~m} \mathrm{~s}^{-1}$ e o mínimo é praticamente nulo. Já a média é de $0.12 \mathrm{~m} \mathrm{~s}^{-1}$ e o desvio padrão de $0.07 \mathrm{~m} \mathrm{~s}^{-1}$.

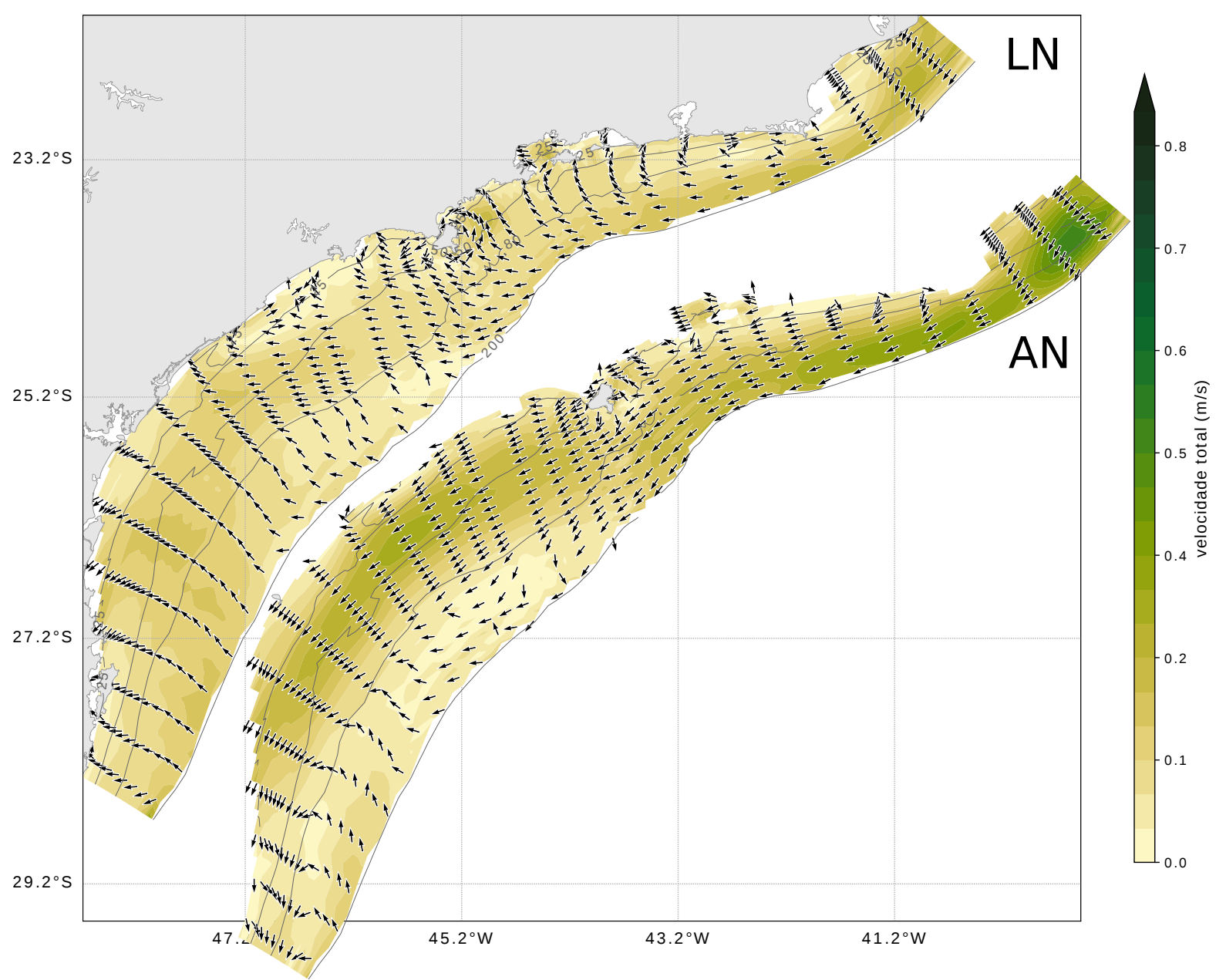

Figura 3.12: Campo horizontal de velocidade média na camada de superfície. Experimento de primavera. Anos de La Niña (LN) e de ano neutro (AN). Intensidade representada pela cor, em $m s^{-1}$, e direção representada pelos vetores normalizados.

No fundo (Figura 3.13), no experimento de LN para a primavera, diferentemente da 
superfície, a corrente apresenta padrão quase uniforme de NW. A velocidade máxima é de $0.218 \mathrm{~m} \mathrm{~s}^{-1}$, e a mínima é quase nula. A velocidade média é $0.04 \mathrm{~m} \mathrm{~s}^{-1}$ e o desvio padrão é de $0.02 \mathrm{~m} \mathrm{~s}^{-1}$.

Durante o experimento de AN, na primavera, a corrente tem direção menos uniforme que no experimento de LN. Ao norte de São Sebastião, na PCI, a direção das corrente é de NE, enquanto na PCM está de SW. Ao sul da grade, tanto na PCI quanto na PCM a corrente é de NE, e mantém esse sentido no canal de São Sebastião. A velocidade máxima encontrada é de $0.23 \mathrm{~m} \mathrm{~s}^{-1}$, a mínima é praticamente nula, a média é $0.03 \mathrm{~m} \mathrm{~s}^{-1}$ e o desvio padrão é $0.028 \mathrm{~m} \mathrm{~s}^{-1}$.

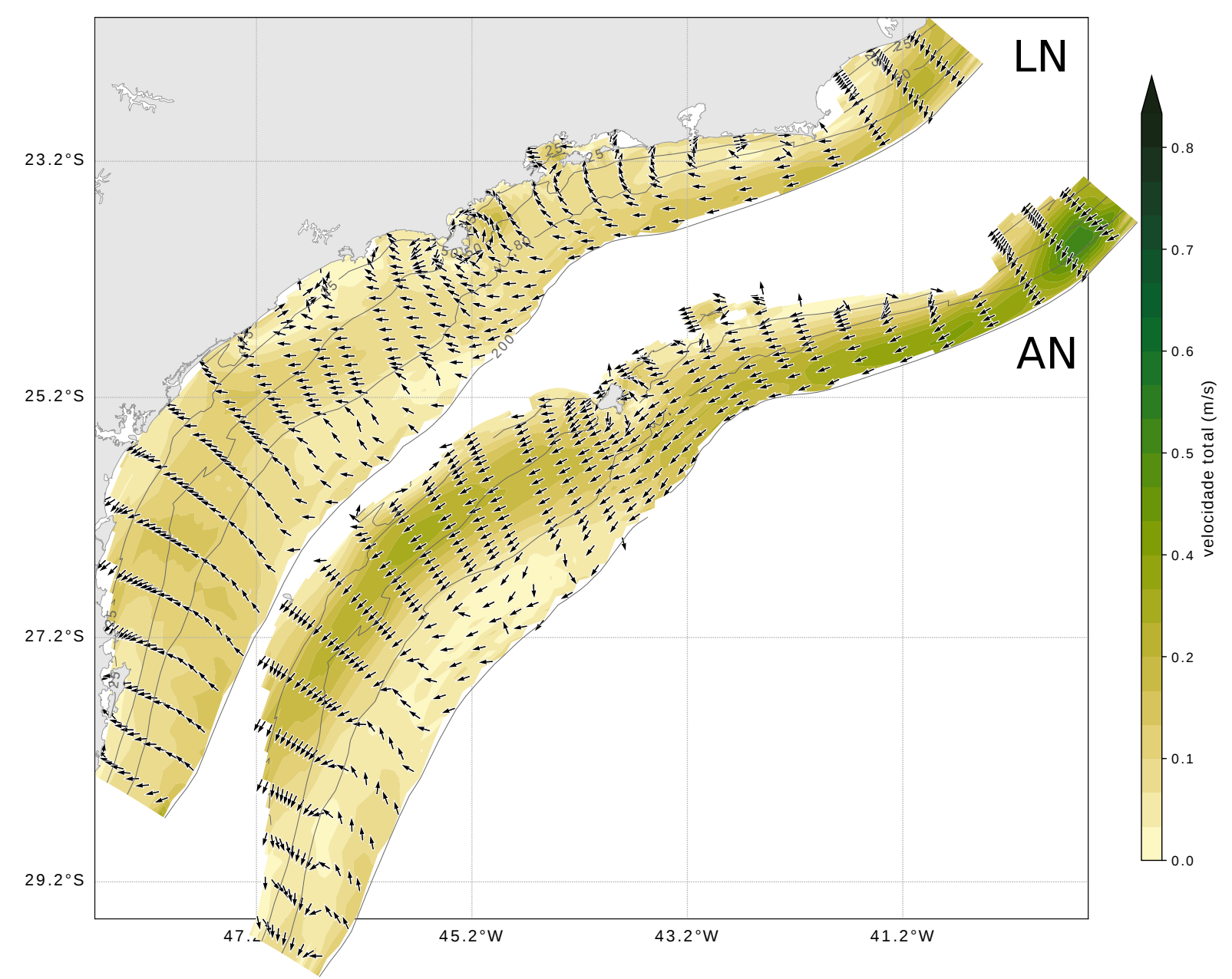

Figura 3.13: Campo horizontal de velocidade média na camada de fundo. Experimento de primavera. Anos de La Niña (LN) e de ano neutro (AN). Intensidade representada pela cor, em m s $\mathrm{s}^{-1}$, e direção representada pelos vetores normalizados.

Por último, analisando os experimentos de verão, na superfície (Figura 3.14) a veloci- 
dade máxima encontrada para o experimento de LN é de $0.54 \mathrm{~m} \mathrm{~s}^{-1}$ e a mínima é praticamente nula. A média é de $0.14 \mathrm{~m} \mathrm{~s}^{-1}$ e o desvio padrão é de $0.08 \mathrm{~m} \mathrm{~s}^{-1}$. Os valores mais intensos de velocidade encontram-se no norte da grade e, até Cananéia, a direção predominante da corrente é de SW. Ao sul de Cananéia, é possível perceber a corrente escoando para W-NW, padrão visto também no outono.

No experimento de AN, a velocidade na superfície apresenta padrão bastante semelhante ao do LN, também na superfície, em relação à direção das correntes. A velocidade máxima é de $0.62 \mathrm{~m} \mathrm{~s}^{-1}$, a mínima é praticamente nula, a média é $0.13 \mathrm{~m} \mathrm{~s}^{-1}$ e o desvio padrão é de $0.08 \mathrm{~m} \mathrm{~s}^{-1}$.

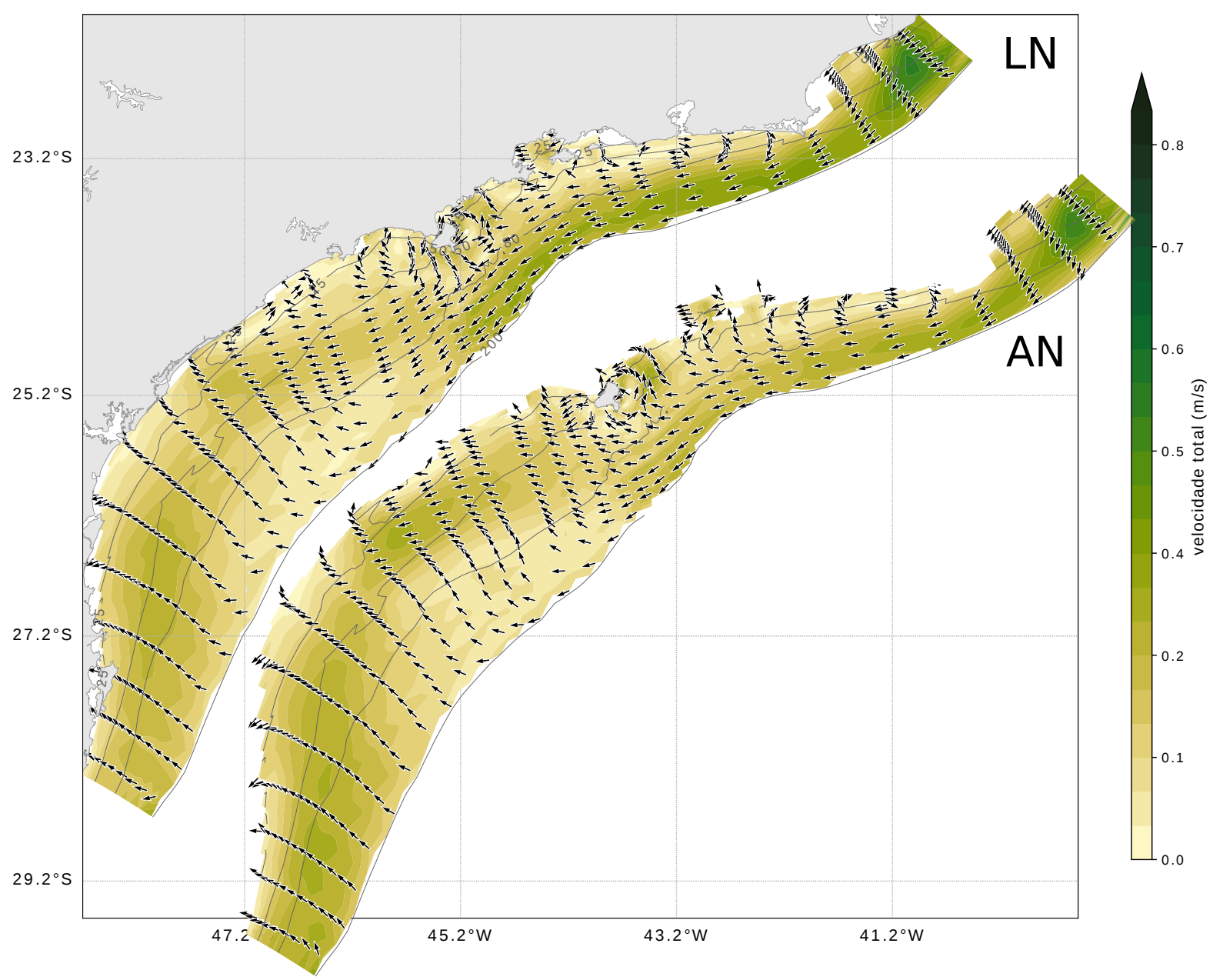

Figura 3.14: Campo horizontal de velocidade média na camada de superfície. Experimento de verão. Anos de La Niña (LN) e de ano neutro (AN). Intensidade representada pela cor, em $\mathrm{m} \mathrm{s}^{-1}$, e direção representada pelos vetores normalizados.

Já no fundo (Figura 3.15), no experimento de LN, durante o verão, a velocidade máxima 
encontrada é de $0.22 \mathrm{~m} \mathrm{~s}^{-1}$ e a mínima é praticamente nula. A média é de $0.04 \mathrm{~m} \mathrm{~s}^{-1} \mathrm{e}$ o desvio padrão é de $0.03 \mathrm{~m} \mathrm{~s}^{-1}$. Ao sul de São Sebastião, a direção predominante é de SW, enquando ao norte de São Sebastião a corrente é de NE na PCM e de SW na PCI.

Durante o AN, as correntes do fundo também seguem padrão semelhando ao encontrado no fundo no LN, no que diz respeito à direção da corrente. A velocidade máxima encontrada é de $0.18 \mathrm{~m} \mathrm{~s}^{-1}$ e a mínima é praticamente nula. A velocidade média é de 0.04 $m s^{-1}$ e o desvio padrão é de $0.02 \mathrm{~m} \mathrm{~s}^{-1}$.

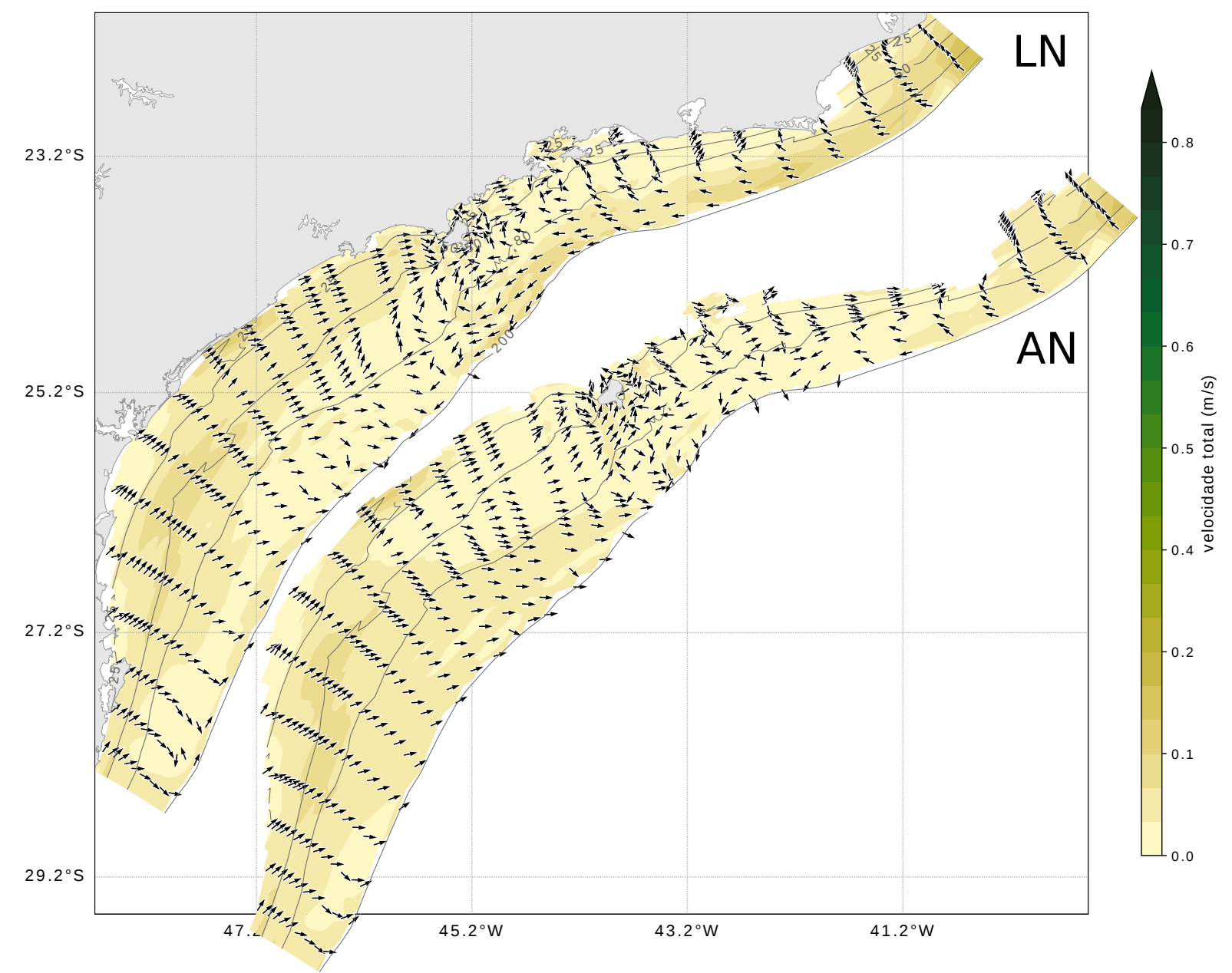

Figura 3.15: Campo horizontal de velocidade média na camada de fundo. Experimento de verão. Anos de La Niña (LN) e de ano neutro (AN). Intensidade representada pela cor, em $\mathrm{m} \mathrm{s}^{-1}$, e direção representada pelos vetores normalizados.

A diferença apresentada entre os dois exprimentos de verão, $\mathrm{AN}$ e $\mathrm{LN}$, foi muito pequena. A direção das correntes e a intensidade são bastante semelhantes. Este comportamento assemelha-se àquele encontrado por Coelho (2008), com escoamento predomi- 
nante para $\mathrm{S} / \mathrm{SW}$ em praticamente toda a região. Neste experimento o autor forçou o modelo com vento e baroclinicidade. Ruffato (2011) também encontrou correntes predominantes de S/SW no experimento em que usou como forçante os campos climatológicos de TS, vento, e maré.

\section{Resposta das correntes à entrada de frente fria}

Nesta sessão, o campo horizontal de corrente foi analisado antes, durante e depois da passagem de FF, tanto para superfície quanto para o fundo, com o intuito de observar a resposta das correntes à passagem destes sistemas, principais responsáveis pelas alterações sinóticas dos campos.

A escolha das FF analisadas foi feita com base no esquema teórico de Stech e Lorenzzetti (1992), representado na Figura 1.3 e, também, explicado por Castro (1985). No momento pré frontal, há ocorrência de ventos de NW; durante a passagem do sistema frontal, o vento é de SW; já no momento pós frontal, o vento é de NE.

Apenas algumas das FF analisadas serão mostradas aqui. Começando por uma FF que ocorreu em outubro de 2010 (FF1). Para a identificação desta frente, foi considerado um campo de vento com direção NW ao sul de Cananéia, sendo considerado como o período pré frontal (Figura 3.16), no dia 23/09/2010.

Já a entrada da FF foi considerada pela entrada dos ventos de quadrante sul, no dia 25/09/2010, dois dias após o período pré frontal (Figura 3.17). Apesar de não ter avançado por toda a PCSP, este período foi escolhido pela semelhança ao modelo teórico de Stech e Lorenzzetti (1992).

No dia seguinte, 26/09/2010, já estava definido o período pós frontal, com vento de direção NE (Figura 3.18).

Escolhido o período, então foi calculado o campo horizontal instantâneo de correntes para cada um dos três dias, tanto para a superfície (esquerda) quanto para o fundo (direita) (Figura 3.19). 


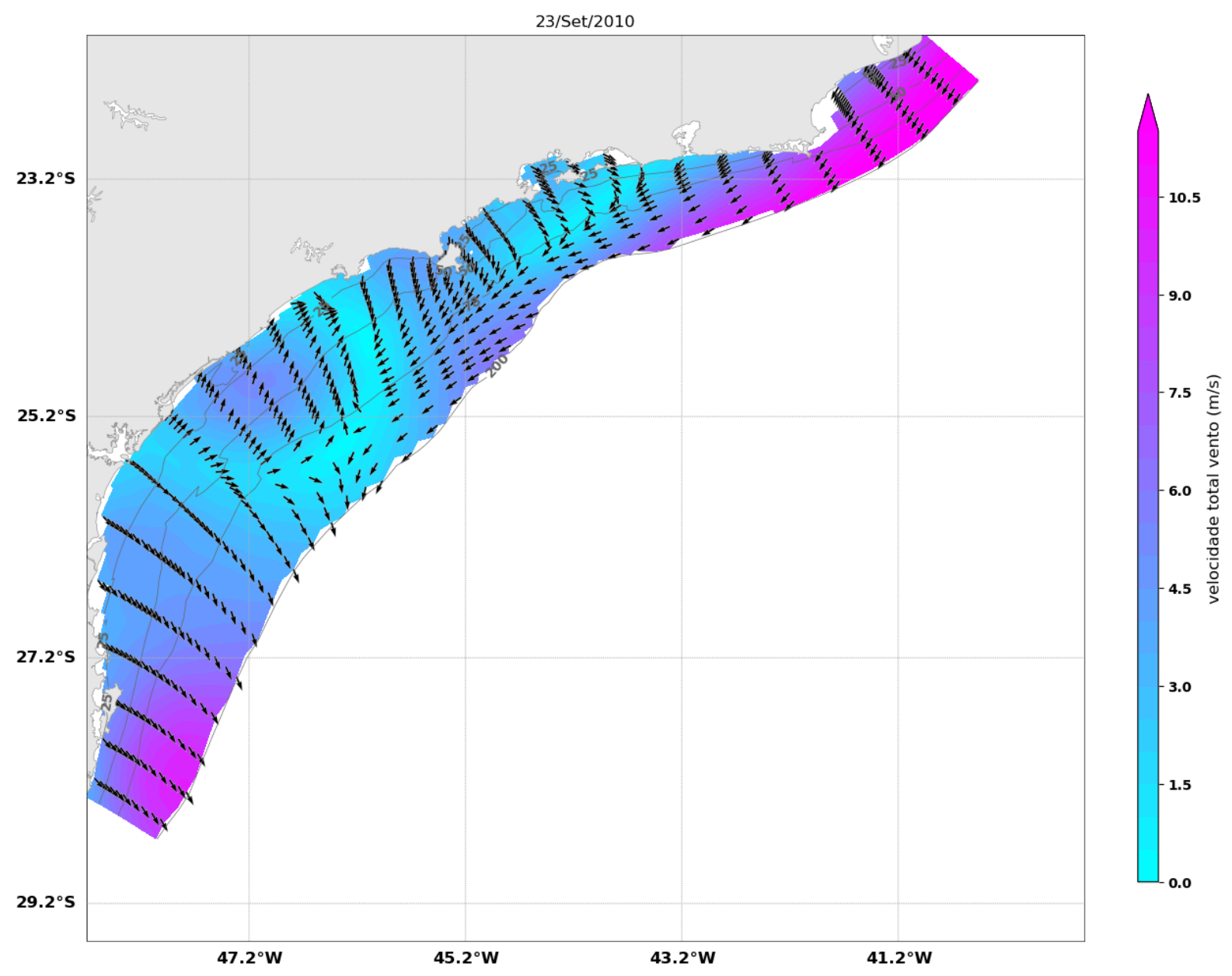

Figura 3.16: Vento a 10 m da superfície no dia 23/09/2010. Experimento de primavera, no ano de La Niña. Período Pré Frontal. Intensidade representada pela cor, em $\mathrm{m} \mathrm{s}^{-1}$, e direção representada pelos vetores normalizados. 


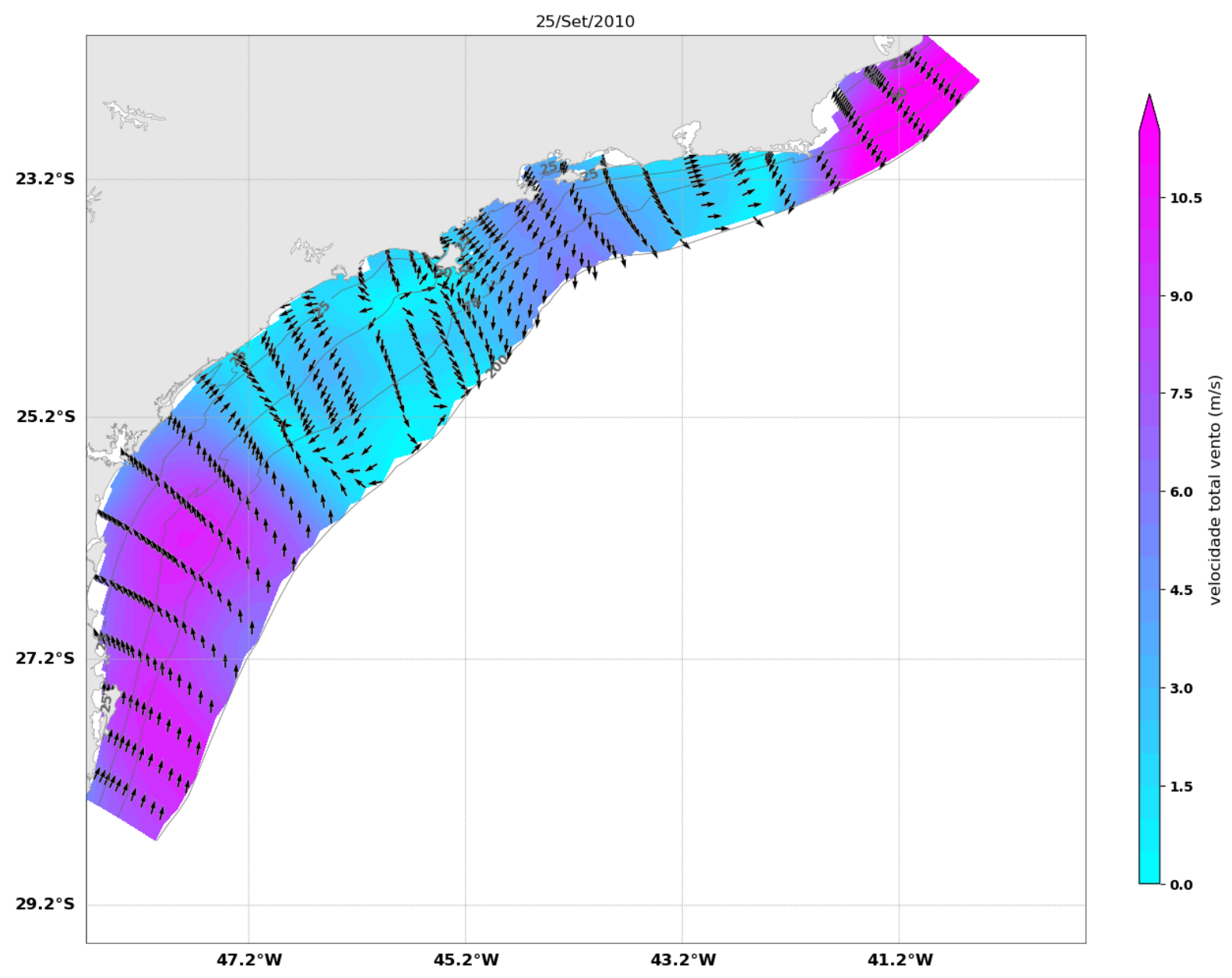

Figura 3.17: Vento a 10 m da superfície no dia 25/09/2010. Experimento de primavera, no ano de La Niña. Frente Fria. Intensidade representada pela cor, em $\mathrm{m} \mathrm{s}^{-1}$, e direção representada pelos vetores normalizados. 


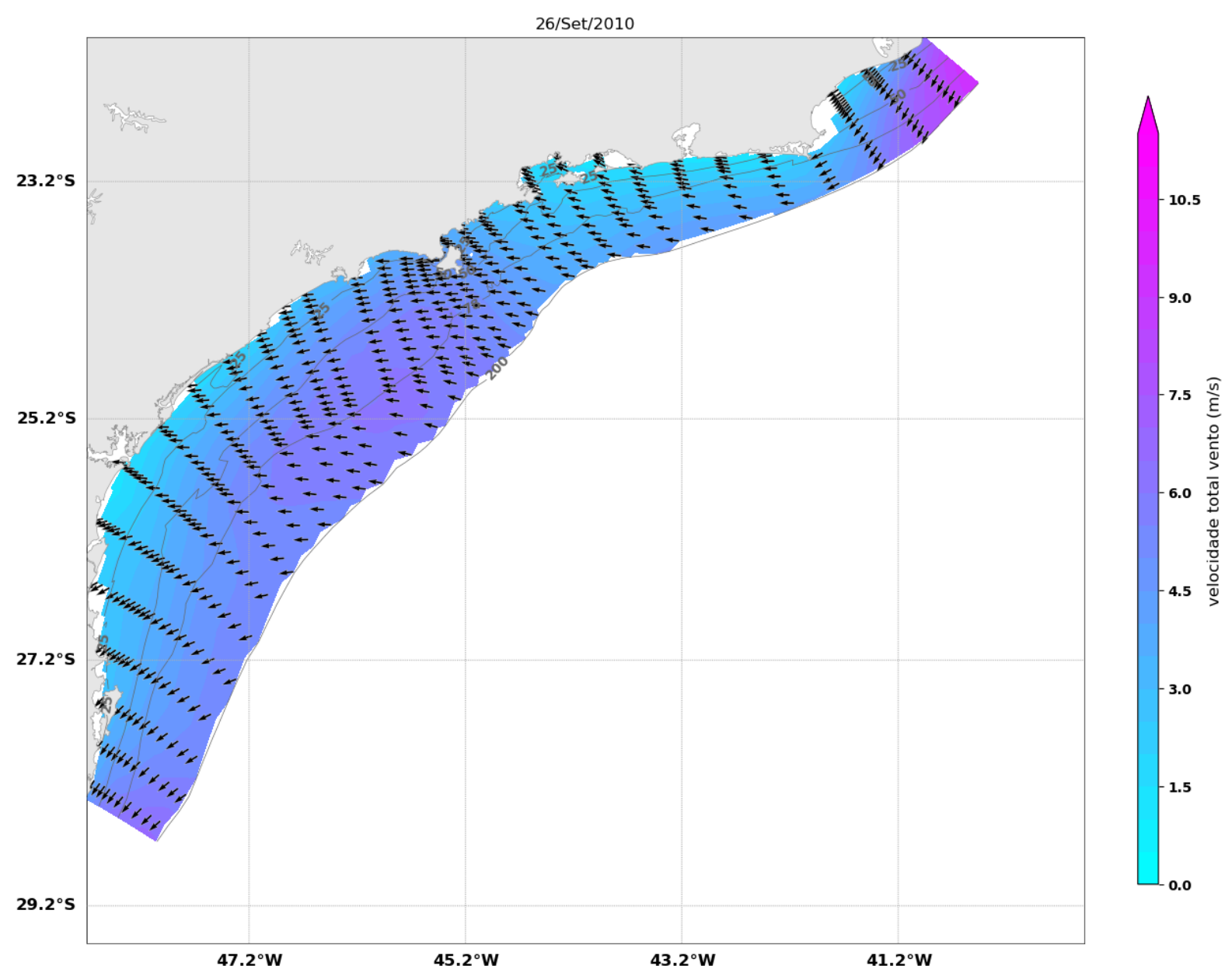

Figura 3.18: Vento a 10 m da superfície, no dia 26/09/2010. Experimento de primavera, no ano de La Niña. Pós Frente Fria. Intensidade representada pela cor, em $\mathrm{m} \mathrm{s}^{-1}$, e direção representada pelos vetores normalizados.

Analisando em ordem alfabética, tem-se que a velocidade máxima encontrada em (A), que representa a situação pré FF, na camada superficial no dia 23/09/2010, é de 0.49 $m \mathrm{~s}^{-1}$, a velocidade mínima é praticamente nula, a velocidade média é de $0.10 \mathrm{~m} \mathrm{~s}^{-1}$ e o desvio padrão é de $0.08 \mathrm{~ms}^{-1}$. Já a figura (B), que também representa o dia 23/09/2010, mas no fundo, apresenta velocidade máxima de $0.25 \mathrm{~m} \mathrm{~s}^{-1}$, velocidade mínima praticamente nula, velocidade média de $0.05 \mathrm{~m} \mathrm{~s}^{-1}$ e desvio padrão de $0.03 \mathrm{~m} \mathrm{~s}^{-1}$. Comparando as velocidades de superfície e fundo no momento pré FF, tanto a velocidade máxima quanto a velocidade média são maiores na superfície. Ambas são quase 2 vezes maior na superfície que no fundo. A figura (C) refere-se ao período da FF, na camada superficial, no dia 25/09/2010. A velocidade máxima encontrada é de $1.34 \mathrm{~m} \mathrm{~s}^{-1}$, a velocidade mínima é praticamente nula, a velocidade média é de $0.21 \mathrm{~m} \mathrm{~s}^{-1}$ e o desvio padrão é de $0.14 \mathrm{~m} \mathrm{~s}^{-1}$. Na figura (D), também para a FF, é retratado o fundo. A velocidade máxima 
encontrada é de $0.57 \mathrm{~m} \mathrm{~s}^{-1}$, e a mínima é praticamente nula. A velocidade média é de $0.12 \mathrm{~m} \mathrm{~s}^{-1}$ e o desvio padrão é de $0.07 \mathrm{~m} \mathrm{~s}^{-1}$. Comparando as velocidade superfície e fundo durante a passagem da FF, tanto a velocidade máxima quanto a velocidade média são maiores na superfície. A velocidade máxima de fundo representa $42 \%$ do valor da velocidade máxima de superfície. Já a velocidade média de fundo representa 57\% do valor da velocidade média de superfície. A figura (E) representa o momento pós FF, no dia 26/09/2010, na superfície. A velocidade máxima é de $0.74 \mathrm{~m} \mathrm{~s}^{-1}$, a velocidade mínima é praticamente nula, a velocidade média é de $0.19 \mathrm{~m} \mathrm{~s}^{-1}$ e o desvio padrão é de $0.11 \mathrm{~m} \mathrm{~s}^{-1}$. Já a figura (F), que também representa o momento pós FF, representa o fundo, com velocidade máxima de $0.37 \mathrm{~m} \mathrm{~s}^{-1}$, mínima quase nula, média de $0.12 \mathrm{~m} \mathrm{~s}^{-1}$ e desvio padrão de $0.06 \mathrm{~m} \mathrm{~s}^{-1}$. Comparando as velocidade superfície e fundo durante o momento pós FF, tanto a velocidade máxima quanto a velocidade média são maiores na superfície. A velocidade máxima de fundo é exatamente a metade da velocidade máxima de superfície, enquanto a velocidade média de fundo representa $63 \%$ do valor da velocidade média de superfície.

Comparativamente, a maior velocidade máxima do campo foi encontrada durante a passagem da FF, na superfície, onde também foi encontrada a maior velocidade média. No fundo, o maior valor de velocidade encontrado também foi durante a passagem da FF. Em relação à média, durante e após a passagem da FF são encontrados os maiores valores de velocidade, sendo mais que o dobro da velocidade média encontrada no fundo no momento pré FF. 
(A)

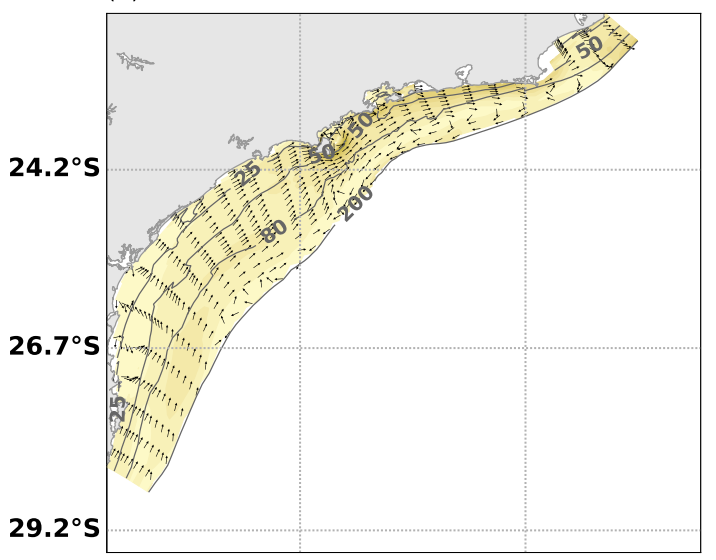

(C)

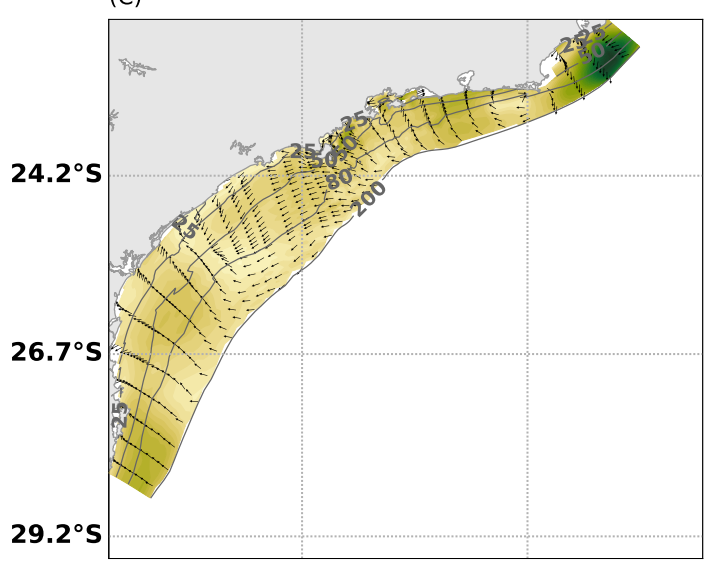

(E)

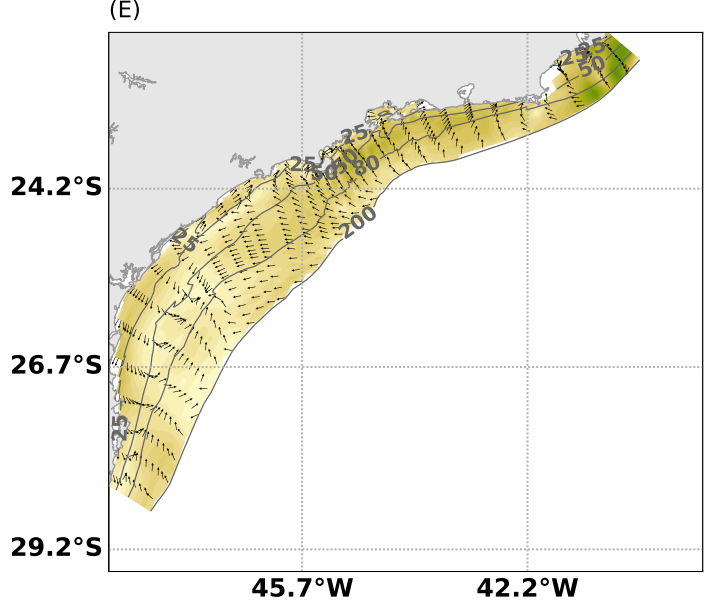

(B)

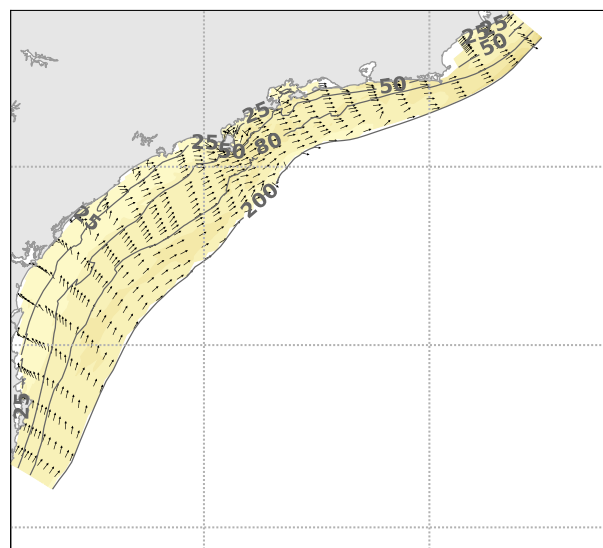

(D)

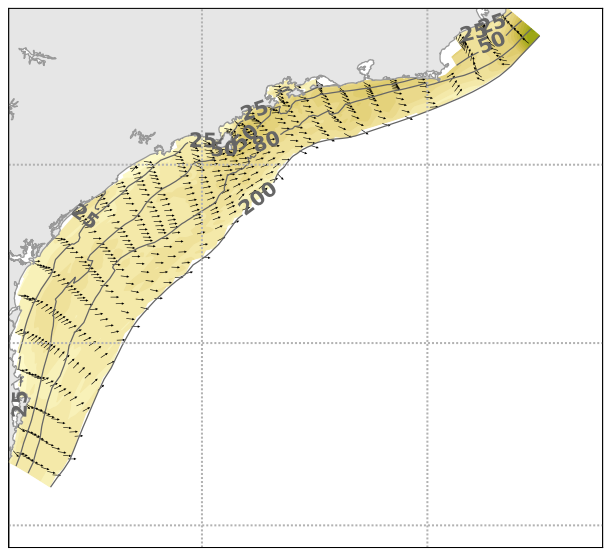

(F)

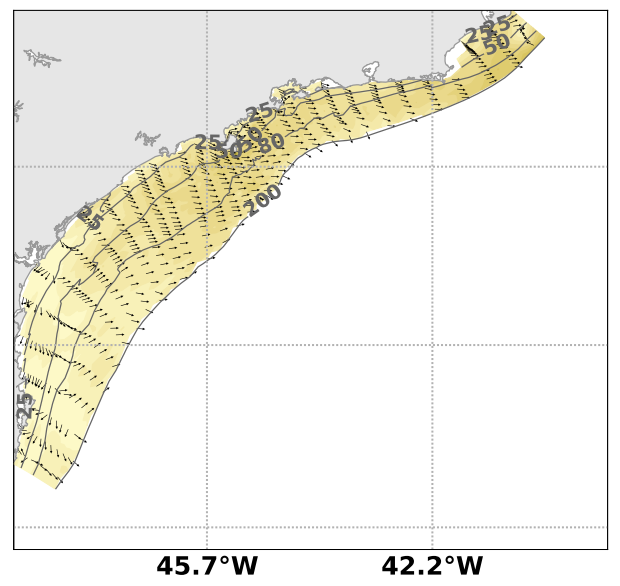

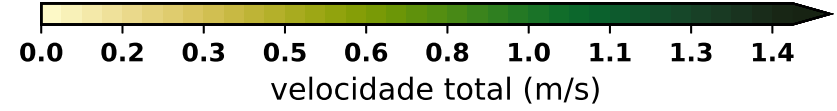

Figura 3.19: Campo instantâneo de corrente. Experimento de primavera, no ano de LN. Intensidade representada pela cor, em $\mathrm{m} \mathrm{s}^{-1}$, e direção representada pelos vetores normalizados. Figuras $(A),(C)$ e $(E)$ representam a superficie; $(B),(D) e(F)$ representam o fundo. Figuras $(A) e$ (B) são do dia 23/09/2010,0 (C) e (D) são do dia 25/09/2010 e (E) e (F) são do dia 26/09/2010. 
Conforme dito anteriormente, a frente escolhida para esta análise deve-se ao fato de apresentar comportamento semelhante ao modelo teórico de frente fria. No entanto, é uma frente que dura menos de um dia e vai apenas até Cananéia, aproximadamente. O valor máximo de vento nesta frente é de $15.09 \mathrm{~m} \mathrm{~s}^{-1}$.

Na superfície, é possível ver que a FF não teve força o suficiente para total reversão do padrão da circulação, no entanto, no entorno de Cananéia, há mudança do sentido da corrente que está vindo de NE e passa a escoar para oeste. Passada a FF, o escoamento começa a voltar para o sentido de NE. Já no fundo, percebe-se que no momento da FF há dominância de correntes para NE, o que se mantem após a passagem da frente.

Para comparar o comportamento desta frente com outra mais intensa (FF2), foram escolhidos os dias 30/05/2010 como pré frontal, 01/06/2010 (Figura 3.20) como FF e 03/06/2010 como pós FF. Este período foi escolhido com base na semelhança ao modelo teórico de FF para a região. A difereça deste caso com o anterior está na intensidade dos ventos, que chega a $15.53 \mathrm{~m} \mathrm{~s}^{-1}$ na FF, percorrendo toda a grade, conforme pode ser visto na Figura 3.20, pelos ventos de SW presentes em todo o campo.

Analisando a Figura 3.21, tem-se que em (A), período pré frontal, no dia 30/05/2010, na superfície, a velocidade máxima é de $0.97 \mathrm{~m} \mathrm{~s}^{-1}$ e a velocidade mínima é praticamente nula. A velocidade média do campo é de $0.29 \mathrm{~m} \mathrm{~s}^{-1}$ e o desvio padrão do campo, nesta data, é de $0.13 \mathrm{~m} \mathrm{~s}^{-1}$. Já na figura (B), que representa o fundo no mesmo período, a velocidade máxima encontrada é de $0.29 \mathrm{~m} \mathrm{~s}^{-1}$, a velocidade mínima é quase zero, a velocidade média é de $0.07 \mathrm{~m} \mathrm{~s}^{-1}$ e o desvio padrão é de $0.04 \mathrm{~m} \mathrm{~s}^{-1}$.

Comparando as velocidades de superfície e fundo no momento pré FF, tanto a velocidade máxima quanto a velocidade média são maiores na superfície, sendo que a velocidade máxima de fundo representa $30 \%$ da velocidade máxima de superfície, e a velocidade média de fundo representa $24 \%$ do valor da velocidade média de superfície. A figura (C) representa o perído da FF, no dia 01/06/2010, na superfície, com velocidade máxima de $2.31 \mathrm{~m} \mathrm{~s}^{-1}$ e velocidade mínima de $0.01 \mathrm{~m} \mathrm{~s}^{-1}$. A velocidade média é de $0.76 \mathrm{~m} \mathrm{~s}^{-1}$ enquanto o desvio padrão é de $0.41 \mathrm{~m} \mathrm{~s}^{-1}$. A figura (D) representa o mesmo período, porém para o campo de fundo, com velocidade máxima de $0.97 \mathrm{~m} \mathrm{~s}^{-1}$ e velocidade mínima praticamente nula $\mathrm{m} \mathrm{s}^{-1}$. A média é de $0.31 \mathrm{~m} \mathrm{~s}^{-1}$ e o desvio padrão é de $0.16 \mathrm{~m} \mathrm{~s}^{-1}$. 


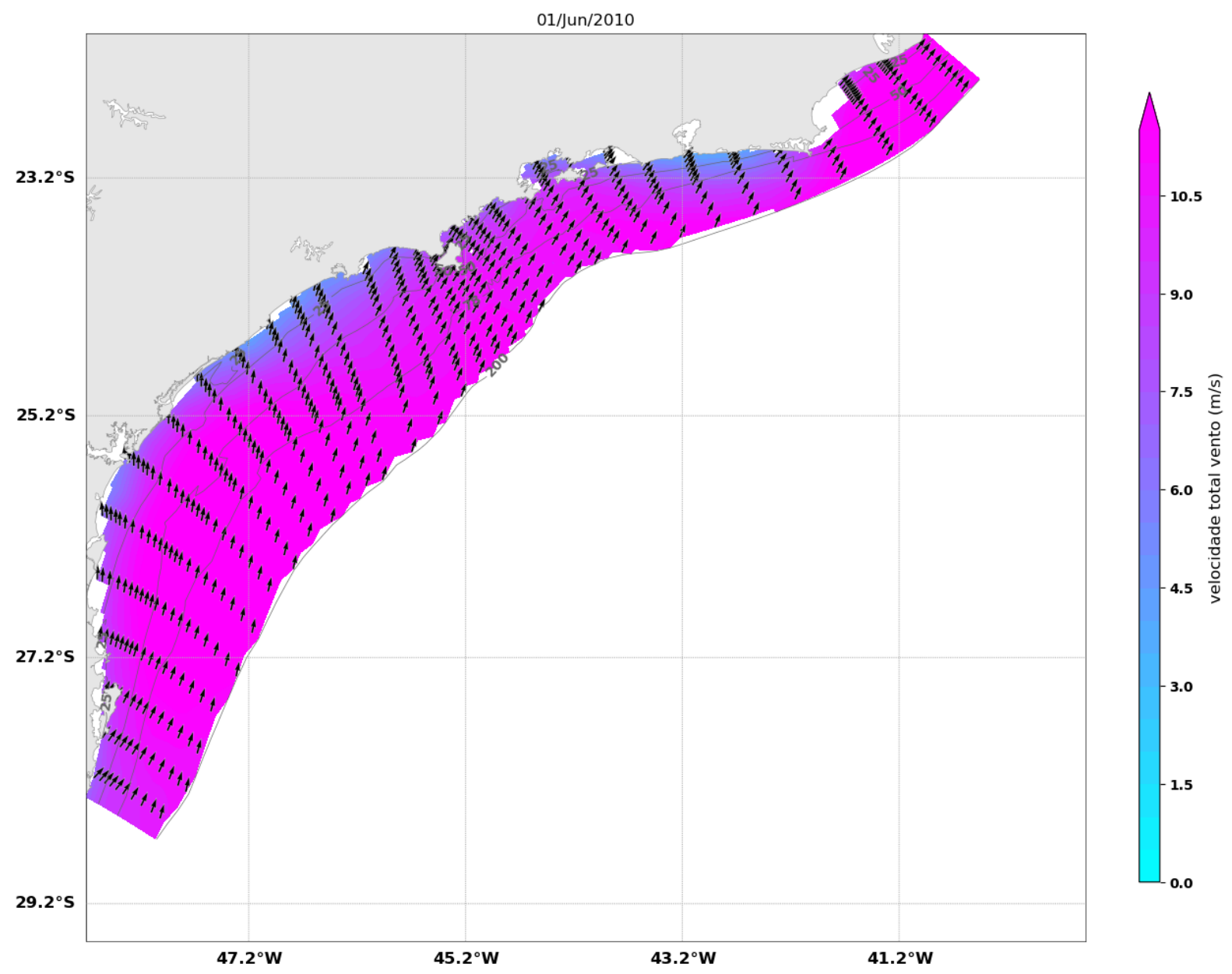

Figura 3.20: Vento a $10 \mathrm{~m}$ da superfície no dia 01/06/2010. Experimento de outono, ano de La Niña. Passagem de frente fria. Intensidade representada pela cor, em $\mathrm{m} \mathrm{s}^{-1}$, e direção representada pelos vetores normalizados.

Comparando as velocidade superfície e fundo durante a passagem da FF, tanto a velocidade máxima quanto a velocidade média são maiores na superfície. A velocidade máxima de fundo representa $42 \%$ do valor da velocidade máxima de superfície. Já a velocidade média de fundo representa $41 \%$ do valor da velocidade média de superfície. As figuras (E) e (F) representam o momento pós frontal, no dia 03/06/2010, para superfície e fundo, respectivamente. A figura (E) apresenta velocidade máxima de $1.02 \mathrm{~m} \mathrm{~s}^{-1}$ e mínima praticamente nula $m \mathrm{~s}^{-1}$. A média e o desvio padrão são, respectivamente, $0.36 \mathrm{~m} \mathrm{~s}^{-1}$ e 0.17 $m \mathrm{~s}^{-1}$. Já a figura (F) apresenta velocidade máxima de $0.39 \mathrm{~m} \mathrm{~s}^{-1}$ e mínima praticamente nula $\mathrm{m} \mathrm{s}^{-1}$. A média é $0.11 \mathrm{~m} \mathrm{~s}^{-1}$ e o desvio padrão é de $0.06 \mathrm{~m} \mathrm{~s}^{-1}$. 
(A)

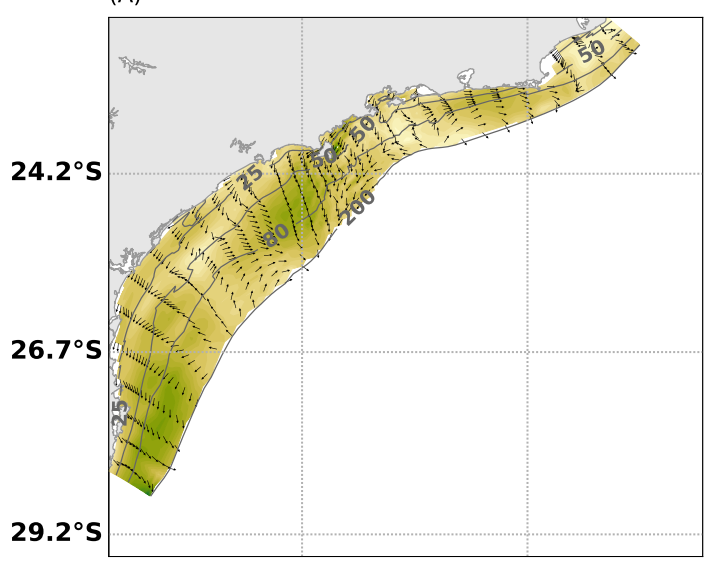

(C)

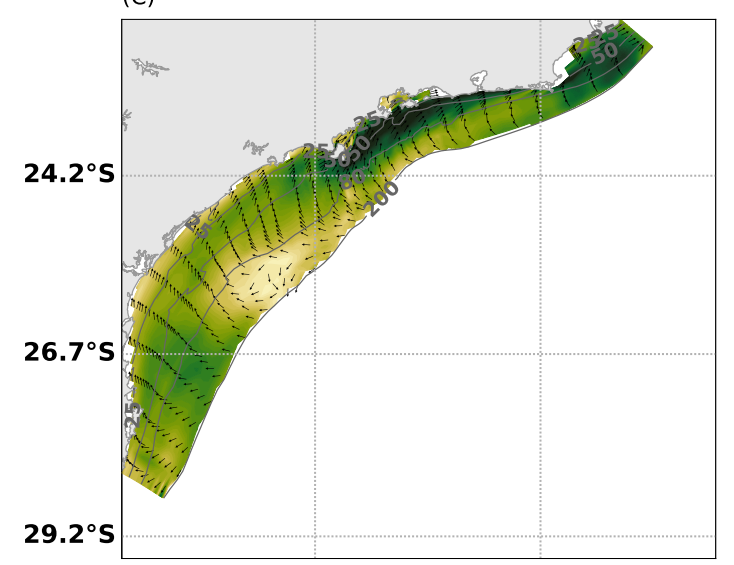

(E)

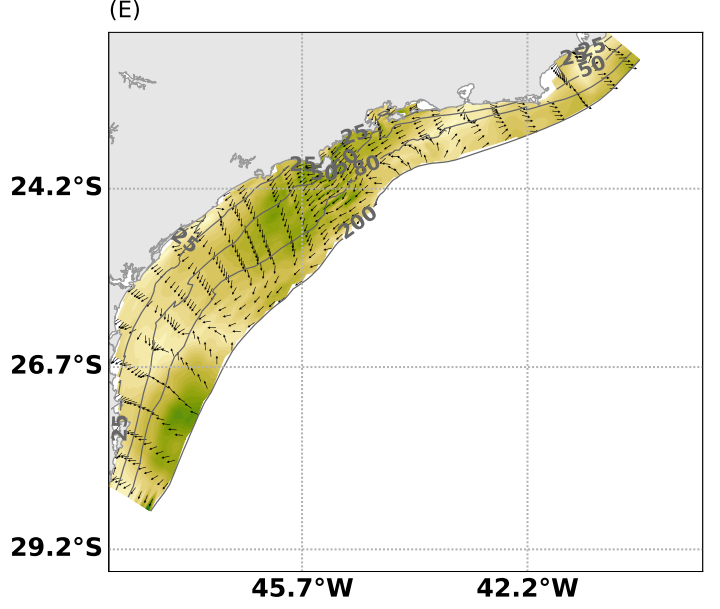

(B)

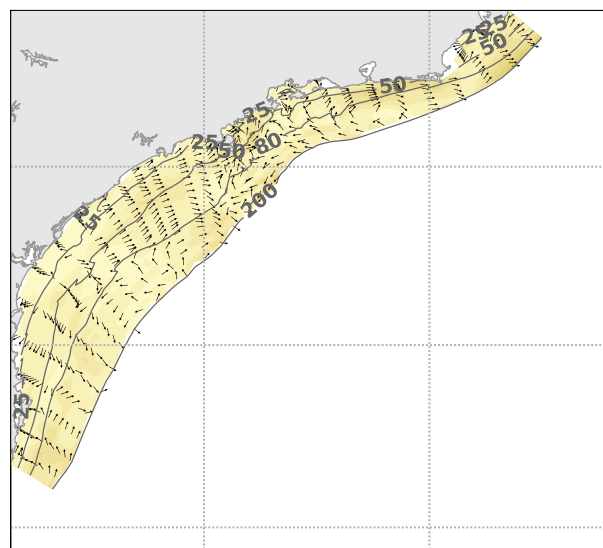

(D)

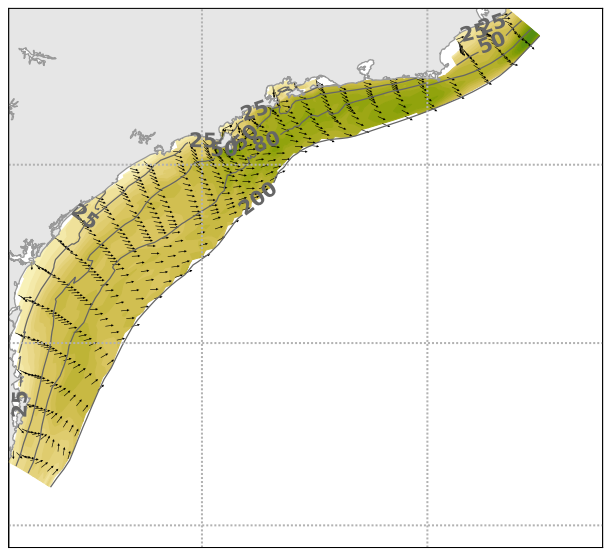

(F)

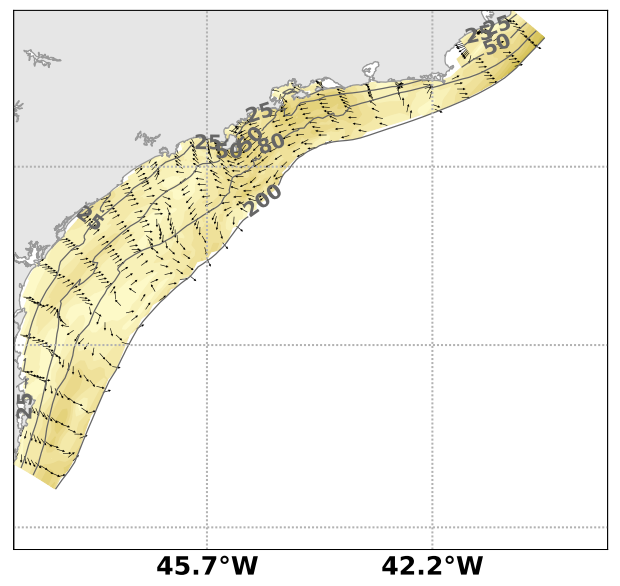

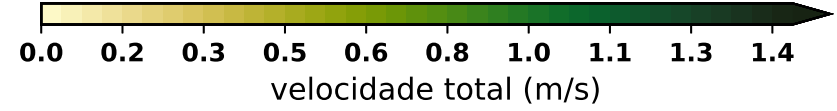

Figura 3.21: Campo instantâneo de corrente. Experimento de outono, ano de LN. Intensidade representada pela cor, em $\mathrm{m} \mathrm{s}^{-1}$, e direção representada pelos vetores normalizados. Figuras (A), $(C)$ e $(E)$ representam a superfície; $(B),(D)$ e $(F)$ representam o fundo. Figuras $(A)$ e $(B)$ são do dia 30/05/2010, (C) e (D) são do dia 01/06/2010 e (E) e (F) são do dia 03/06/2010. 
Comparando as velocidade superfície e fundo durante o momento pós FF, tanto a velocidade máxima quanto a velocidade média são maiores na superfície. A velocidade máxima de fundo representa $38 \%$ da velocidade máxima de superfície, enquanto a velocidade média de fundo representa $30 \%$ do valor da velocidade média de superfície.

Durante o período pré frontal, na superfície, não há um sentido bem definido de correntes. Na altura de Cananéia há entrada de águas vindas da PCE, que bifurcam para o sul e para o norte. Esta água que vai para o norte escoa de SW e, na altura de Santos, converge com correntes vindas de NE, gerando uma circulação com sentido offshore. Isso mostra dois giros espelhados, um anticiclônico ao sul de Cananéia, e um ciclônico entre Cananéia e Santos. Ainda na superfície, durante a passagem da FF, há intensificação das correntes, sendo os maiores valores encontrados entre São Sebastião e Ubatuba. Nesta região, há correntes vindas de SE da PCE, invertendo para NE ao se aproximar da PCI, caracterizando um escoamento ciclônico. Valores de correntes mais intensos a leste da ilha de São Sebastião também foram encontrados por Kirinus et al. (2018) e por Fortes (2019), e ao norte da ilha, Stech (1990) também encontrou intensificação das correntes. Ao sul de São Sebastião, correntes vindas de NE, da PCE, entram na PCM e na PCI, invertendo o sentido e indo em direção à NE. Principalmente na PCI, este sentido está bem definido, e as correntes seguem a direção das isóbatas, o que se repete no campo inteiro, nesta profundidade. Passados dois dias, já no momento pós FF, as correntes que predominam são de SW, com exceção da região ao norte do Rio de Janeiro, onde as correntes predominantes são de NE. Ao sul de Santos, há ocorrência de velocidades para offshore, que entre a isobata de 80 e 200 m invertem para SW. Já no fundo, tanto no cenário pré frontal, FF e pós FF, as velocidades são menos intensas. Na figura (B), assim como na (A), o sentido da corrente não está bem definido. Entre Santos e Cananéia, há entrada de águas da PCE e, tanto no sul quanto no norte da grade, há correntes para NE. Na figura (D), no entanto, o campo está bem definido para NE, com velocidades mais intensas ao norte de São Sebastião. Uma parte das correntes vindas do sul da Ilha de São Sebastião entra no canal, e outra parte contorna a ilha por fora. Na figura (F), desde o sul da Ilha de São Sebastião até o Rio de Janeiro a corrente vem de NE. Já ao sul de Santos, a corrente está indo para NE. Tanto na superfície quanto no fundo, as velocidades mais intensas são encontradas durante a passagem da FF.

Comparando os dois casos FF1 e FF2, tem-se que em, ambas situações, o campo médio 
de velocidade é mais intenso durante a FF. Em relação à velocidade máxima encontrada no campo, no FF1 foi antes da passagem da frente, e no FF2 foi depois da passagem. No FF2, a diferença entre as velocidades de superfície e fundo são maiores do que no FF1

Um terceiro caso (FF3) para o inverno do AN (Figura 3.22) será demonstrado a seguir. Assim como nos casos anteriores, o momento pré frontal possui ventos de NW no sul do campo. A FF é descrita quando há entrada de ventos vindos de $\mathrm{SW}$, e o momento pós frontal ocorre quando o campo tem os ventos invertidos para SW. O valor máximo de vento encontrado no cenário de FF é de $10.90 \mathrm{~m} \mathrm{~s}^{-1}$, sendo menor do que no FF1 e FF2. No entanto, o comportamento se assemelha ao do FF2 por avançar ao longo de todo o campo.

Analisando a Figura 3.22, tem-se que em (A), que representa o momento pré frontal no dia 04/08/2010, na superfície, a velocidade máxima encontrada é de $0.92 \mathrm{~m} \mathrm{~s}^{-1}$, a velocidade mínima é praticamente nula, a média é de $0.14 \mathrm{~m} \mathrm{~s}^{-1}$ e o desvio padrão, no campo, é de $0.20 \mathrm{~m} \mathrm{~s}^{-1}$. A figura (B) representa o mesmo período, porém para o fundo. A velocidade máxima encontrada neste cenário é de $0.04 \mathrm{~m} \mathrm{~s}^{-1}$ e a mínima praticamente nula. A média é de $0.05 \mathrm{~ms}^{-1}$ e o desvio padrão é de $0.04 \mathrm{~m} \mathrm{~s}^{-1}$. Comparando as velocidades de superfície e fundo no momento pré FF, tanto a velocidade máxima quanto a velocidade média são maiores na superfície, sendo que a velocidade máxima de fundo representa $46 \%$ da velocidade máxima de superfície, e a velocidade média de fundo representa $25 \%$ do valor da velocidade média de superfície. Passando para o momento da FF, no dia 06/08/2012, a figura (C) representa a superífcie, onde a velocidade máxima é de $0.95 \mathrm{~m} \mathrm{~s}^{-1}$, a velocidade mínima é praticamente nula, a média é de $0.28 \mathrm{~m} \mathrm{~s}^{-1}$ e o desvio padrão no campo é de $0.01 \mathrm{~m} \mathrm{~s}^{-1}$. Já no fundo (D), a velocidade máxima é de $0.42 \mathrm{~m} \mathrm{~s}^{-1}$, a mínima é praticamente nula, a média é $0.15 \mathrm{~m} \mathrm{~s}^{-1}$ e o desvio padrão é de $0.07 \mathrm{~m} \mathrm{~s}^{-1}$. Comparando as velocidade superfície e fundo durante a passagem da FF, tanto a velocidade máxima quanto a velocidade média são maiores na superfície. A velocidade máxima de fundo representa $44 \%$ do valor da velocidade máxima de superfície. Já a velocidade média de fundo representa $53 \%$ do valor da velocidade média de superfície. 
(A)

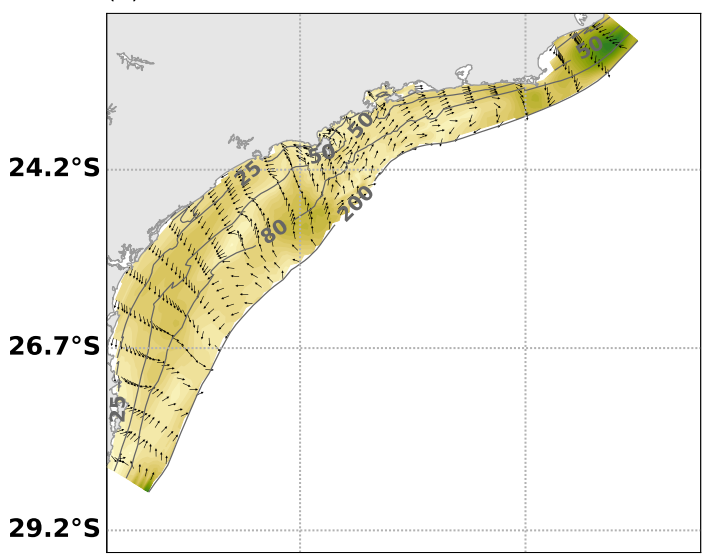

(C)

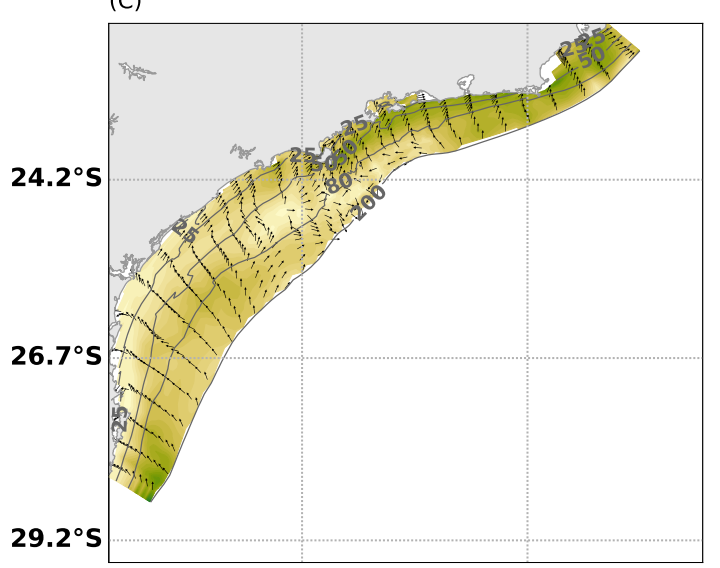

(E)

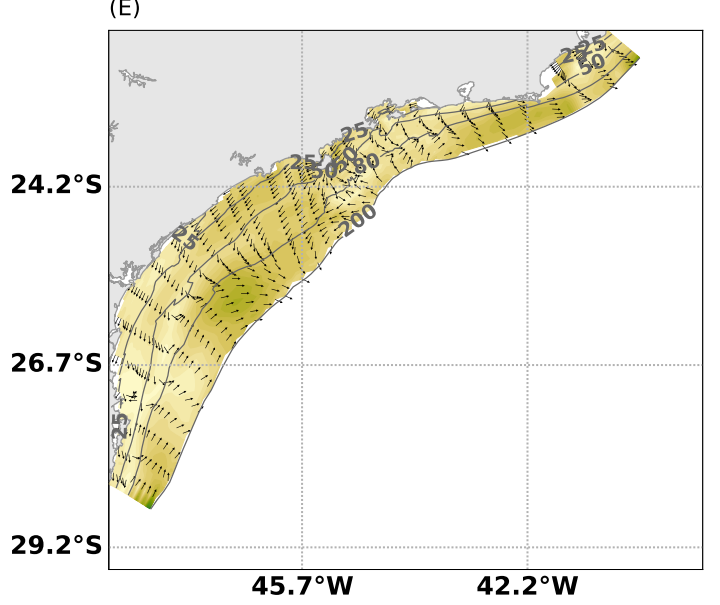

(B)

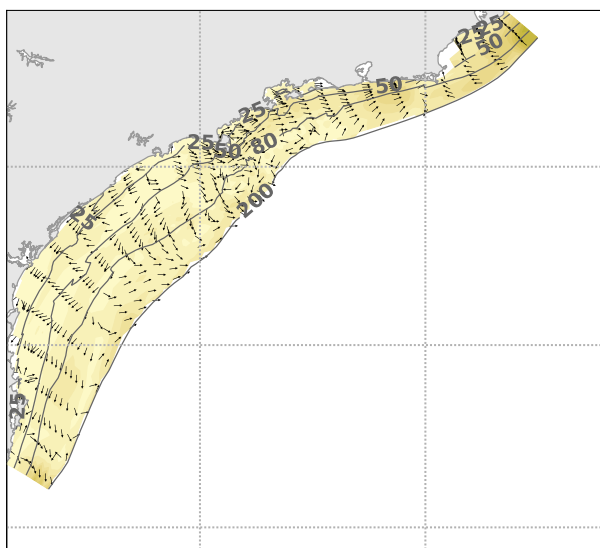

(D)

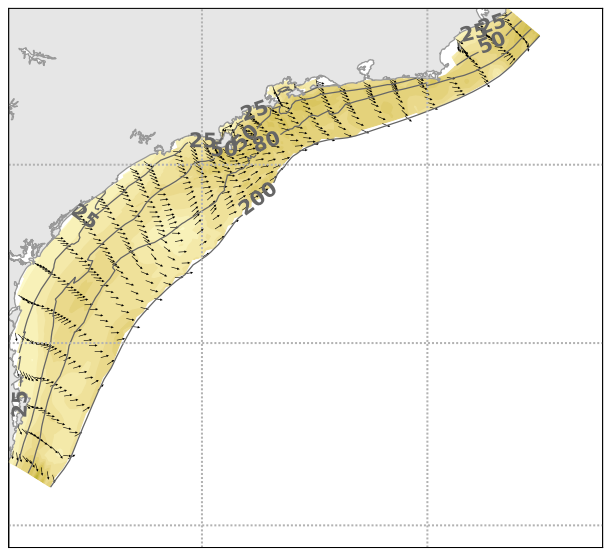

(F)

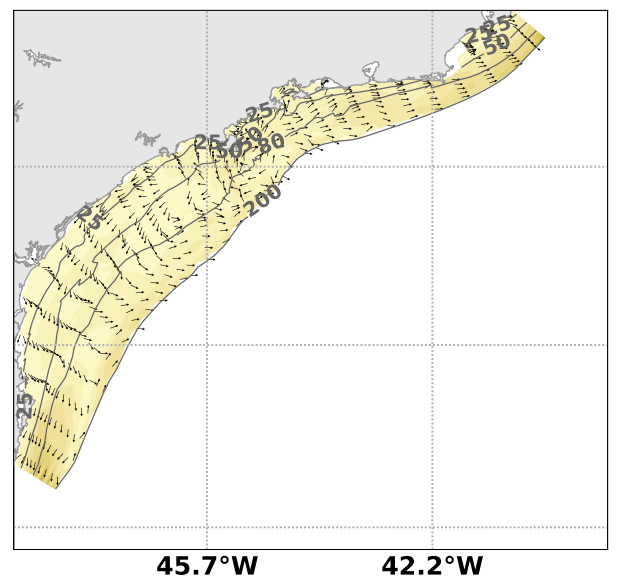

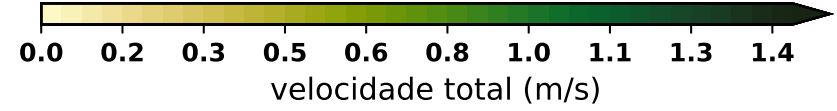

Figura 3.22: Campo instantâneo de corrente. Experimento de inverno, no AN. Intensidade representada pela cor, em $\mathrm{m} \mathrm{s}^{-1}$, e direção representada pelos vetores normalizados. Figuras (A), $(C)$ e $(E)$ representam a superfície; $(B),(D)$ e $(F)$ representam o fundo. Figuras $(A)$ e $(B)$ são do dia 04/08/2012, (C) e (D) são do dia 06/08/2012 e (E) e (F) são do dia 08/08/2012. 
Por último, no momento pós FF, no dia 08/08/2012, na superfície (E), a velocidade máxima encontrada foi de $0.90 \mathrm{~m} \mathrm{~s}^{-1}$, a mínima praticamente nula, a média $0.20 \mathrm{~m} \mathrm{~s}^{-1}$ e o desvio padrão no campo de $0.09 \mathrm{~m} \mathrm{~s}^{-1}$. Neste cenário, ocorre uma converência de correntes vindas se SW com correntes vindas de NE entre as isóbatas de 80 e 100 m. Neste encontro de correntes, ocorre uma resultante em direção à PCE. No fundo, neste cenário (F), a velocidade máxima encontrada foi de $0.50 \mathrm{~m} \mathrm{~s}^{-1}$, com mínima praticamente nula, média de $0.05 \mathrm{~m} \mathrm{~s}^{-1}$ e desvio padrão de $0.03 \mathrm{~m} \mathrm{~s}^{-1}$. Comparando as velocidade superfície e fundo durante o momento pós FF, tanto a velocidade máxima quanto a velocidade média são maiores na superfície. A velocidade máxima de fundo representa 57\% da velocidade máxima de superfície, enquanto a velocidade média de fundo representa $25 \%$ do valor da velocidade média de superfície.

Para melhor comparar os reusltados obtidos na análise da resposta das correntes à passagem de frentes frias, os valores de velocidade foram agrupados na Tabela 3.1. Nos três casos (FF1, FF2 e FF3), a maior velocidade média para o campo é no momento da passagem da FF, tanto na superfície quanto no fundo. O FF3 foi o que apresentou o menor máximo de velocidade, e foi também o que foi forçado pelo menor máximo de velocidade de vento $\left(10.90 \mathrm{~m} \mathrm{~s}^{-1}\right)$. Além disso, foi o caso em que a velocidade menos variou nos cenários de pré FF, FF e pós FF. A maior velocidade de vento utilizada foi no FF2, durante a passagem da FF, com velocidade máxima de $15.53 \mathrm{~m} \mathrm{~s}^{-1}$, e média de $9.30 \mathrm{~m} \mathrm{~s}^{-1}$. Foi neste caso em que houve o maior aumento da velocidade da corrente. É importante lembrar que quando a velocidade do vento é maior do que $12 \mathrm{~m} \mathrm{~s}^{-1}$, o cálculo de arrasto do vento é modificado, conforme Equação 2.26, levando a um aumento mais efetivo da velocidade das correntes oceânicas. Além do FF2, o FF1 também apresenta velocidade de vento maior que $12 \mathrm{~m} \mathrm{~s}^{-1}$ : a máxima é de $15.09 \mathrm{~m} \mathrm{~s}^{-1}$, já a média é de $4.57 \mathrm{~m} \mathrm{~s}^{-1}$. A média baixa tanto pois, no encontro dos ventos de SW e de NW (Figura 3.17) a velocidade quase zera. 
Tabela 3.1: Velocidades de corrente em $\mathrm{m} \mathrm{s}^{-1}$, obtidas para os experimentos forçados pela passagem de frentes frias $(F F)$. Máx, é a velocidade máxima no campo, Min é a velocidade mínima no campo, Média é a velocidade média do campo em um determinado instante, Std é o desvio padrão da média, sup é a superfície, FF1 é o primeiro caso de FF (outono/2010), FF2 é o segundo caso de FF (junho/2010) e FF3 é o terceiro caso de FF (agosto/2012).

\begin{tabular}{|c|c|c|c|c|c|c|c|c|c|}
\hline \multirow{2}{*}{ Cenário } & \multirow{2}{*}{ Caso } & \multicolumn{2}{|c|}{ Máx } & \multicolumn{2}{c|}{ Min } & \multicolumn{2}{c|}{ Média } & \multicolumn{3}{c|}{ Std } \\
\cline { 3 - 10 } & & sup. & fundo & sup. & fundo & sup. & fundo & sup. & fundo \\
\hline \multirow{3}{*}{ Pré FF } & FF1 & 0.49 & 0.25 & 0.00 & 0.00 & 0.10 & 0.05 & 0.08 & 0.03 \\
& FF2 & 0.97 & 0.29 & 0.00 & 0.00 & 0.29 & 0.07 & 0.13 & 0.04 \\
& FF3 & 0.92 & 0.42 & 0.00 & 0.00 & 0.20 & 0.05 & 0.10 & 0.04 \\
\hline \multirow{3}{*}{ FF } & FF1 & 1.34 & 0.57 & 0.00 & 0.00 & 0.21 & 0.12 & 0.14 & 0.71 \\
& FF2 & 2.31 & 0.97 & 0.01 & 0.00 & 0.76 & 0.31 & 0.41 & 0.16 \\
& FF3 & 0.95 & 0.42 & 0.00 & 0.00 & 0.28 & 0.15 & 0.15 & 0.07 \\
\hline \multirow{3}{*}{ Pós FF } & FF1 & 0.74 & 0.37 & 0.00 & 0.00 & 0.19 & 0.12 & 0.11 & 0.06 \\
& FF2 & 1.02 & 0.39 & 0.00 & 0.00 & 0.36 & 0.11 & 0.17 & 0.06 \\
& FF3 & 0.90 & 0.51 & 0.00 & 0.00 & 0.20 & 0.05 & 0.09 & 0.03 \\
\hline
\end{tabular}




\section{Transpote paralelo à costa}

Três séries temporais do transporte de volume paralelo à costa foram calculadas para cada uma das três sessões transversais, localizadas em Cananéia, Santos e Ubatuba, entre a costa e $100 \mathrm{~m}$ de profundidade, integradas em $x$ e em $z$ (direções quase-perpendicular à costa e vertical, respectivamente). Estas séries temporais referem-se ao transporte total, transporte barotrópico e transporte baroclínico, os quais foram calculados em Sverdrup (Sv). Os ventos zonal e meridional também foram analisados, porém as figuras não serão exibidas aqui. Nos oito experimentos, o maior valor da média do transporte quadrado (RMS) total, barotrópico e baroclínico ocorre em Santos.

Começando pelo outono do experimento LN (Figura 3.23), o primeiro pico de transporte encontrado é no começo de abril, com o valor máximo em Santos. Já na metade de abril, houve inversão do sentido do transporte nas três regiões, com inversão também dos ventos. O maior pico de transporte encontrado é na metade de maio, com valores negativos. A maior intensidade do transporte ocorre novamente em Santos.
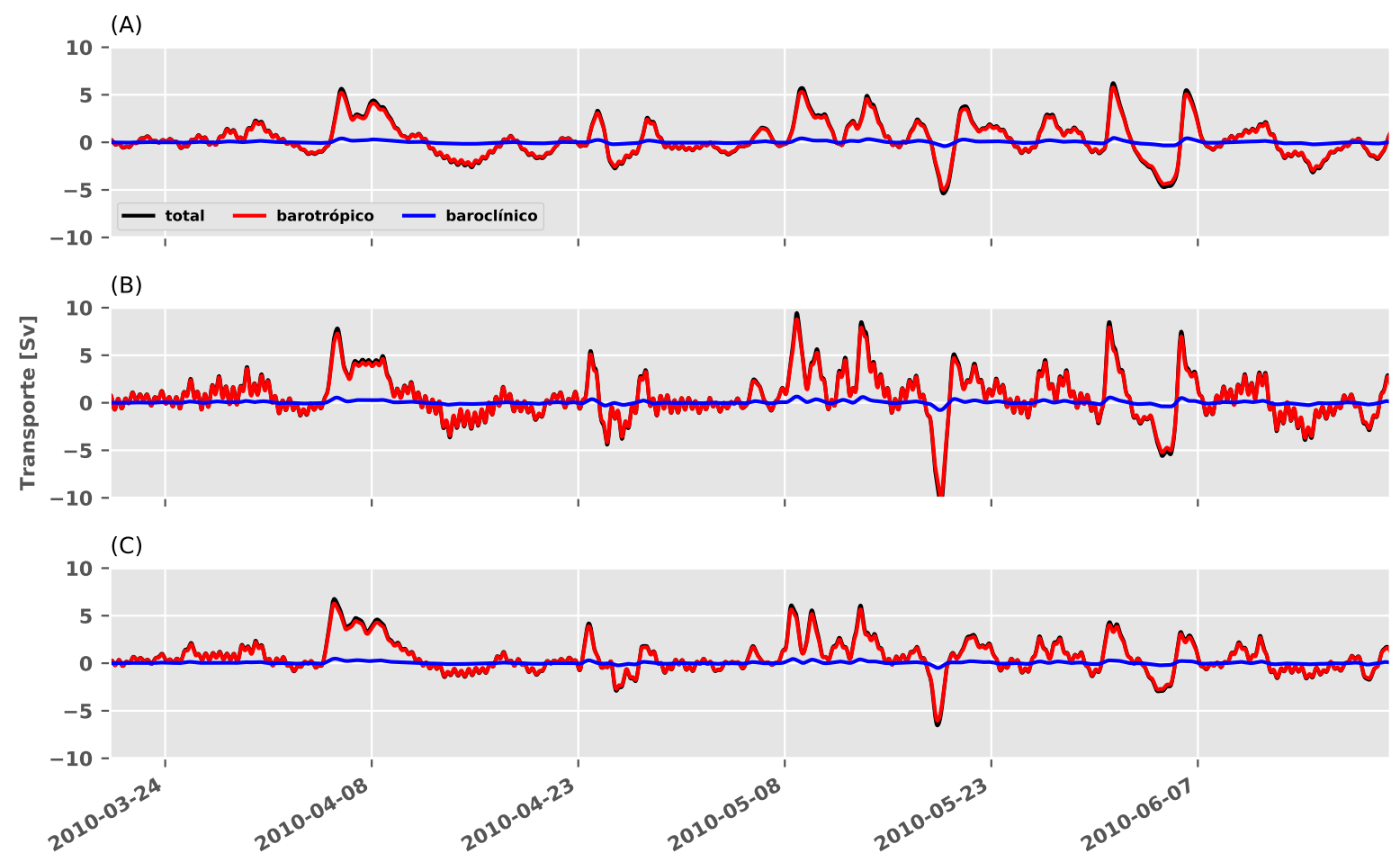

Figura 3.23: Transporte de volume paralelo à costa em Sv. Em preto o transporte total, em vermelho o transporte barotrópico e em azul o transporte baroclínico. (A) Ubatuba; (B) Santos; (C) Cananéia. Experimento de outono, ano de La Nña. 
Olhando para o experimento AN, de outono, (Figura 3.24), é possível ver um pico no transporte no fim de março. Este pico ocorre com maior intensidade em Santos, seguido por Ubatuba e, por último, Cananéia. Neste mesmo período ocorre maior intensidade em ambas componentes do vento. Seguindo na série temporal, outro pico, menos intenso que o anterior, ocorre na metade de abril. Novamente, o maior valor encontrado para o transporte é em Santos e o maior pico de vento meridional também é em Cananéia, enquanto o maior pico de vento zonal é em Ubatuba. No fim de março, houveram algumas variações no sentido do transporte, acompanhadas pela variação no sentido do vento.

Comparando os dois experimentos, é possível perceber que no LN houve maior variação do transporte e picos mais intensos. Em ambos experimentos o padrão do transporte acompanhou o padrão de vento. Ambos apresentaram as menores intensidades em Ubatuba, tanto para vento quanto para transporte; no entanto, o trasporte foi maior no LN, nas três sessões.
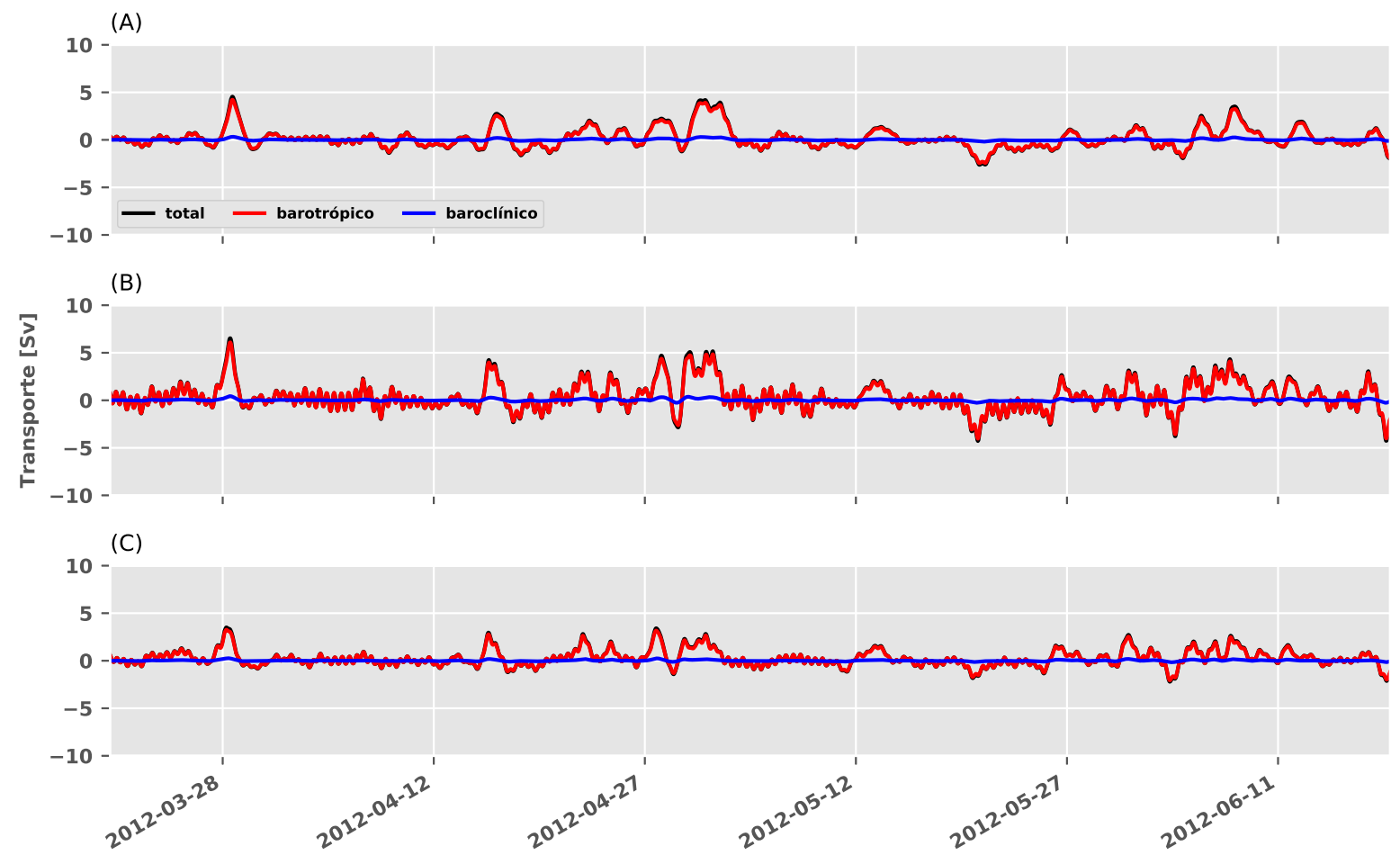

Figura 3.24: Transporte de volume paralelo à costa em Sv. Transporte total, barotrópico e baroclínico em preto, vermelho e azul, respectivamente. (A) Ubatuba; (B) Santos; (C) Cananéia. Experimento de outono, no ano neutro.

No inverno, no experimento LN (Figura 3.25), o transporte ocorreu de acordo com o sentido do vento. Um exemplo é no começo de agosto, em que dois picos de transporte 
ocorrem simultaneamente a dois picos do vento meridional. Entre 5 e 20 de agosto, houve uma sequência de picos positivo/negativo/positivo do transporte, e também de ambas componentes do vento, sendo que nos três picos os maiores valores do transporte ocorreram, em módulo, foram em Santos.
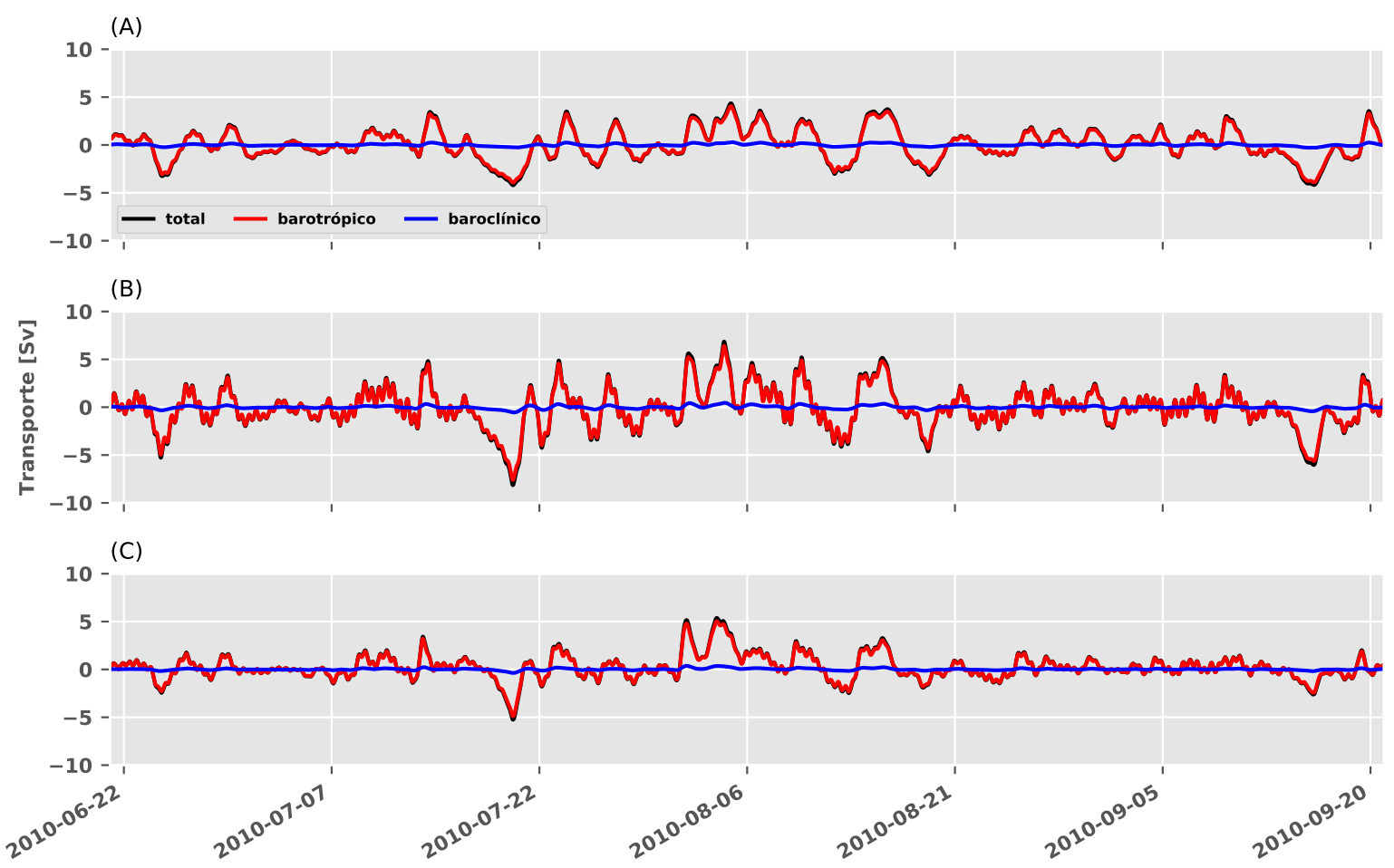

Figura 3.25: Transporte de volume paralelo à costa em Sv. Transporte total, barotrópico e baroclínico em preto, vermelho e azul, respectivamente. (A) Ubatuba; (B) Santos; (C) Cananéia. Experimento de inverno, no ano de La Niña.

Já no AN, no inverno, (Figura 3.26), é possível ver um pico no começo de julho, em que o transporte em Santos é muito maior que os outros dois. Em ambas componentes da velocidade é possível ver este pico. No entorno do dia 19 de agosto, o transporte se comporta com valores negativos, e nesse mesmo período, ambas as componentes do vento são negativas. De forma geral, o transporte acompanha o comportamento do vento.

É possível ver que no experimento de $\mathrm{LN}$, durante o inverno, os picos de transporte ocorreram principalmente antes de 20 de julho e depois de 20 de agosto, enquanto no experimento de AN os maiores picos ocorrem desde do fim de julho até o fim de agosto. Em geral, os maiores valores do transporte do volume paralelo à costa ocorreram no AN. 

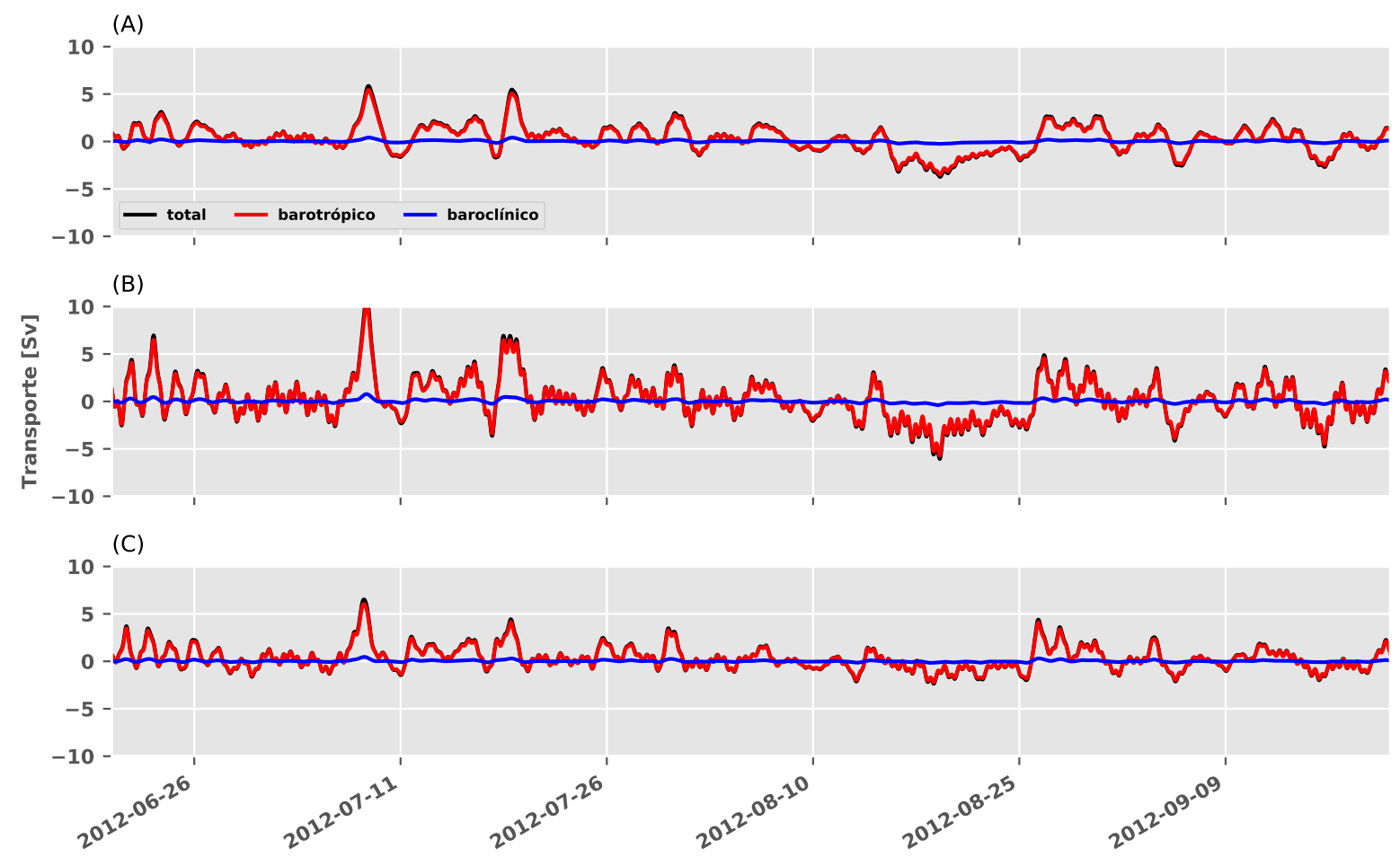

Figura 3.26: Transporte de volume paralelo à costa em Sv. Transporte total, barotrópico e baroclínico em preto, vermelho e azul, respectivamente. (A) Ubatuba; (B) Santos; (C) Cananéia. Experimento de inverno, no ano neutro.

No experimento AN, durante a primavera, no começo da série temporal ocorre o maior pico de transporte no período, sendo o maior valor em Santos, seguido de Ubatuba e, por último, Cananéia (Figura 3.28). Em relação ao vento, o maior valor encontrado, em ambas as componentes da velocidade, foi em Santos.

No experimento de primavera de LN (Figura 3.27), é possível ver, de forma geral, o transporte oscilando no entorno do zero, com a ocorrência de alguns picos, os quais são coincidentes com picos de vento. No começo de maio, há um pico de transporte em que a maior intensidade ocorre em Santos. Em seguida, ocorreu a inversão do transporte, simultaneamente à inversão dos ventos. Outro pico ocorre por volta do dia 18/10/2010, com valor máximo de transporte em Santos, de vento meridional em Cananéia e de vento zonal em Ubatuba. 

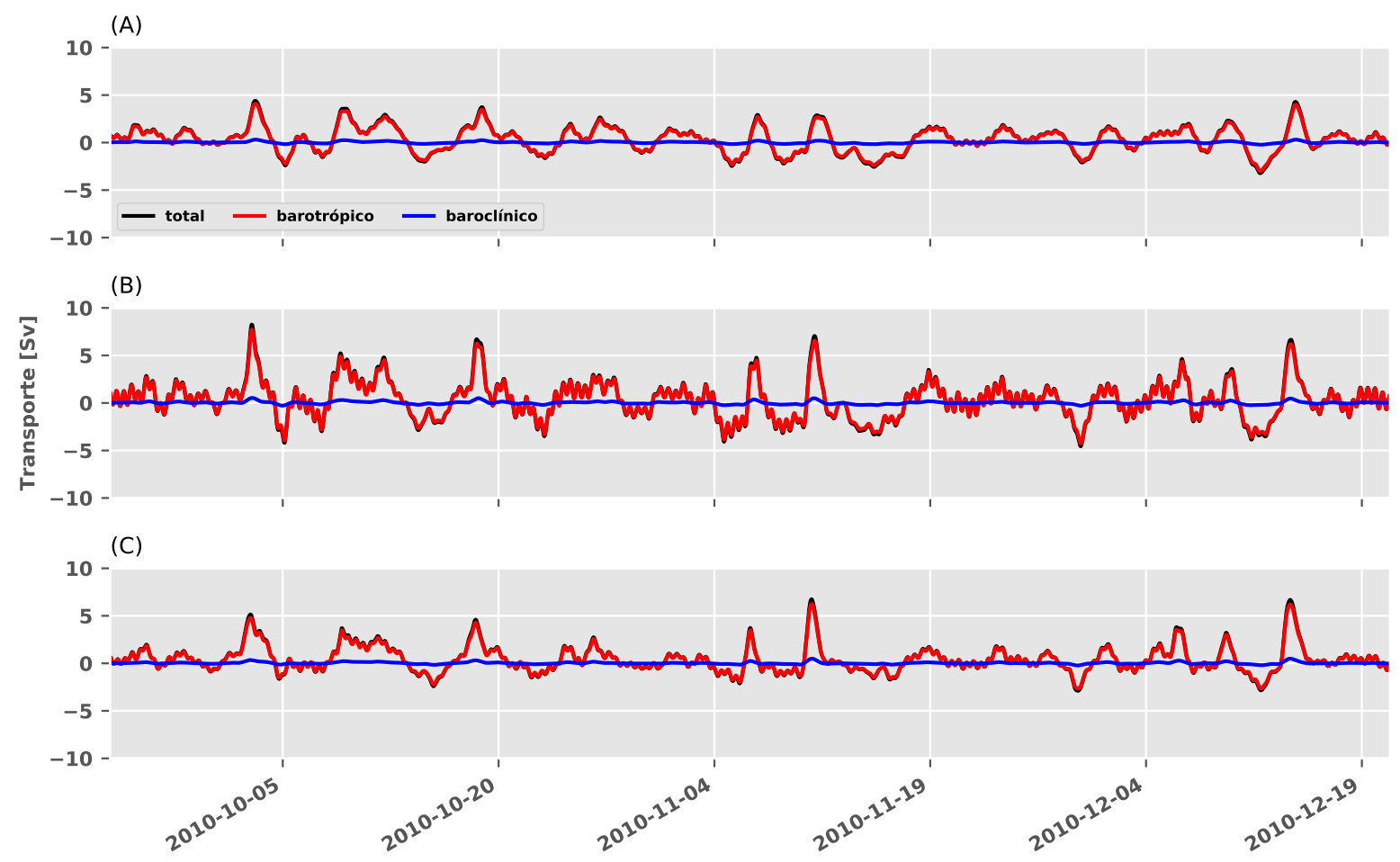

Figura 3.27: Transporte de volume paralelo à costa em Sv. Transporte total, barotrópico e baroclínico em preto, vermelho e azul, respectivamente. (A) Ubatuba; (B) Santos; (C) Cananéia. Experimento de primavera, no ano de La Niña.

Outros picos menores ocorrem ao longo do tempo, porém com menor intensidade, mas também acompanhados pelo comportamento do vento. Um exemplo é na metade de novembro, quando ocorre um pico no transporte, com valor máximo em Santos, e o vento também aumenta, porém com valor máximo em Cananéia, na componente meridional, e valor máximo em Ubatuba, na componente zonal.

No LN ocorrem mais picos com valor a cima de $5 \mathrm{~Sv}$ do que no AN. Neste segundo, estes valores mais altos ocorrem apenas no começo da série.

No experimento LN (Figura 3.29), durante o verão, por volta do dia 18 de fevereiro,um pico intenso ocorre, com maior intensidade em Cananéia e Ubatuba. Este pico é acompanhado por um pico de velocidade meridional, mais intenso em Cananéia. Por volta do dia 18 de março ocorre outro pico com maiores valores em Cananéia e Ubatuba. 

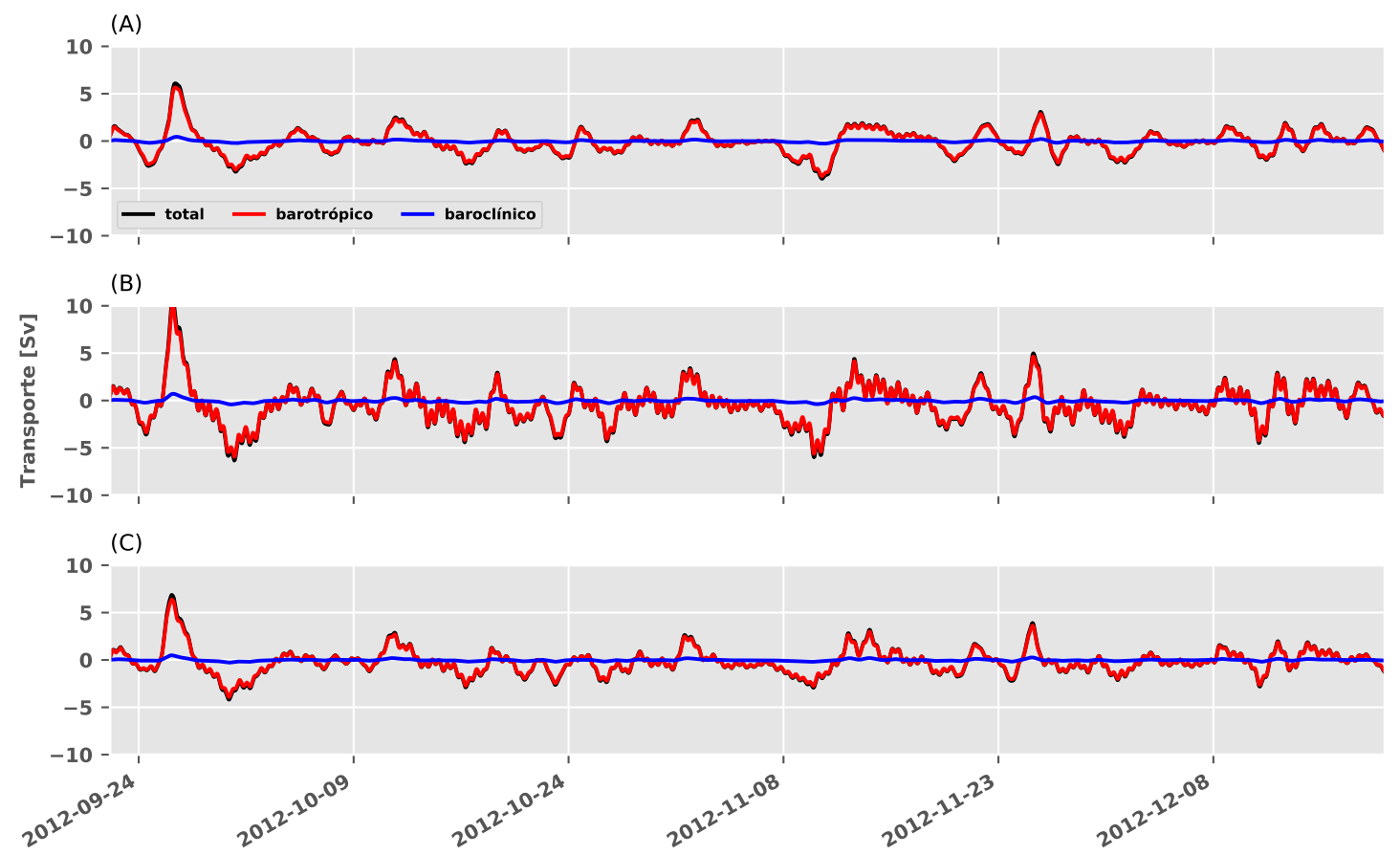

Figura 3.28: Transporte de volume paralelo à costa em Sv. Transporte total, barotrópico e baroclínico em preto, vermelho e azul, respectivamente. (A) Ubatuba; (B) Santos; (C) Cananéia. Experimento de primavera, no ano neutro.

No experimento de verão de AN (Figura 3.30), analisando o pico que ocorre no começo de janeiro, é possível ver que o maior valor de transporte integrado ocorre em Santos, ultrapassando 5 Sv. Já o vento apresenta maior velocidade em Cananéia, na componente meridional, e em Ubatuba, na componente zonal. Em seguida ocorre um pico negativo, em 5/01/2013, em que novamente o valor máximo encontrado é em Santos. A maior intensidade de vento meridional ocorre em Cananéia, enquanto a maior intensidade de vento zonal ocorre em Santos. 

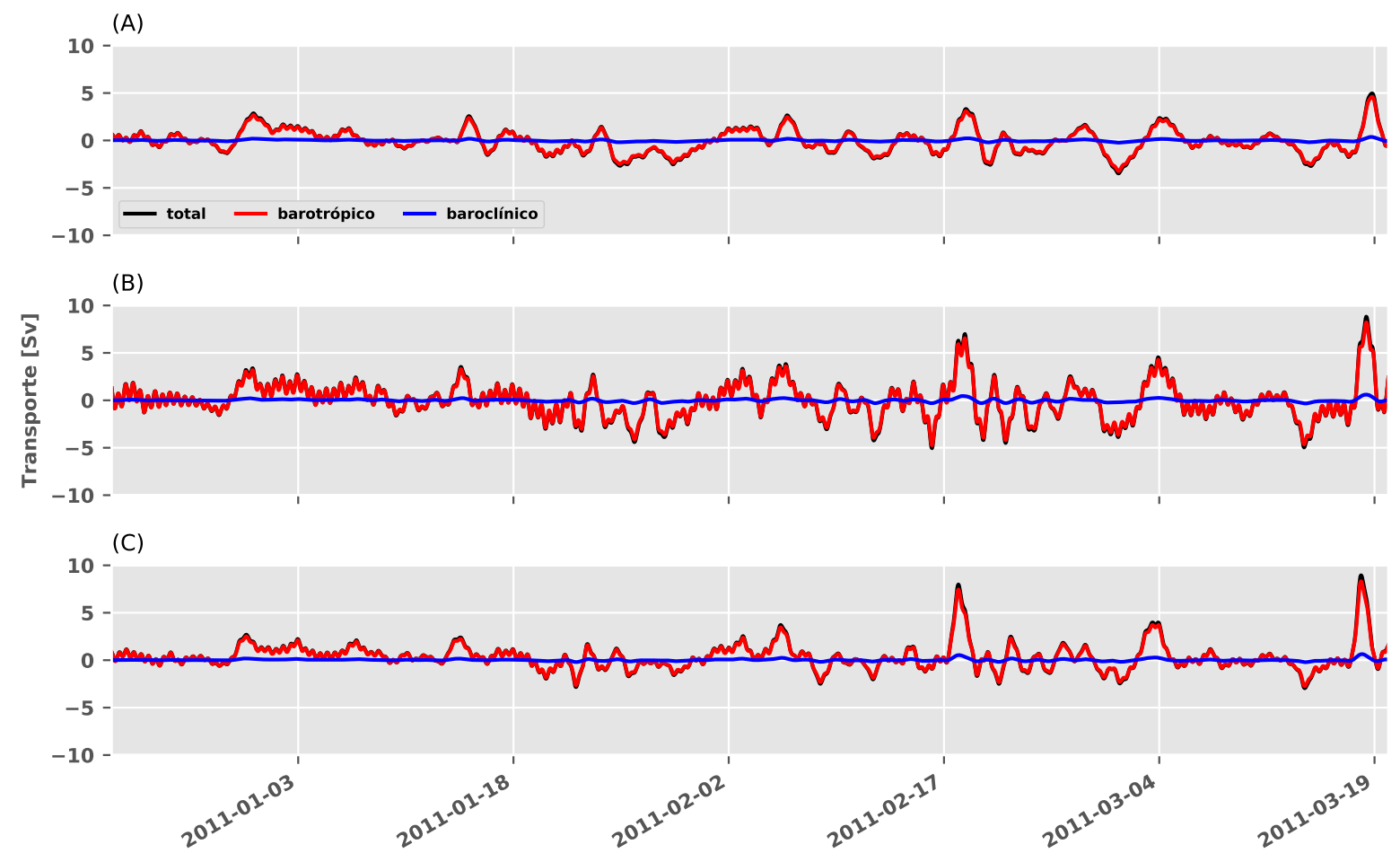

Figura 3.29: Transporte de volume paralelo à costa em Sv. Transporte total, barotrópico e baroclínico em preto, vermelho e azul, respectivamente. (A) Ubatuba; (B) Santos; (C) Cananéia. Experimento de verão, no ano de La Niña.

Comparando os valores de RMS obtidos para todos os experimentoes (Tabela 3.2), percebe-se que os maiores valores de transporte ocorrem em Santos. Ao comparar a mesma estação nos dois anos diferentes, é possível ver que a maior variação ocorre no outono, sendo os maiores valores encontrados no LN. A maior diferença neste caso ocorre em Santos, onde o transporte é 2.7 vezes maior que o transporte na mesma região no AN. Foi neste experimento que os maiores valores de transporte foram encontrados, tanto transporte total, transporte barotrópico e transporte baroclínico. 

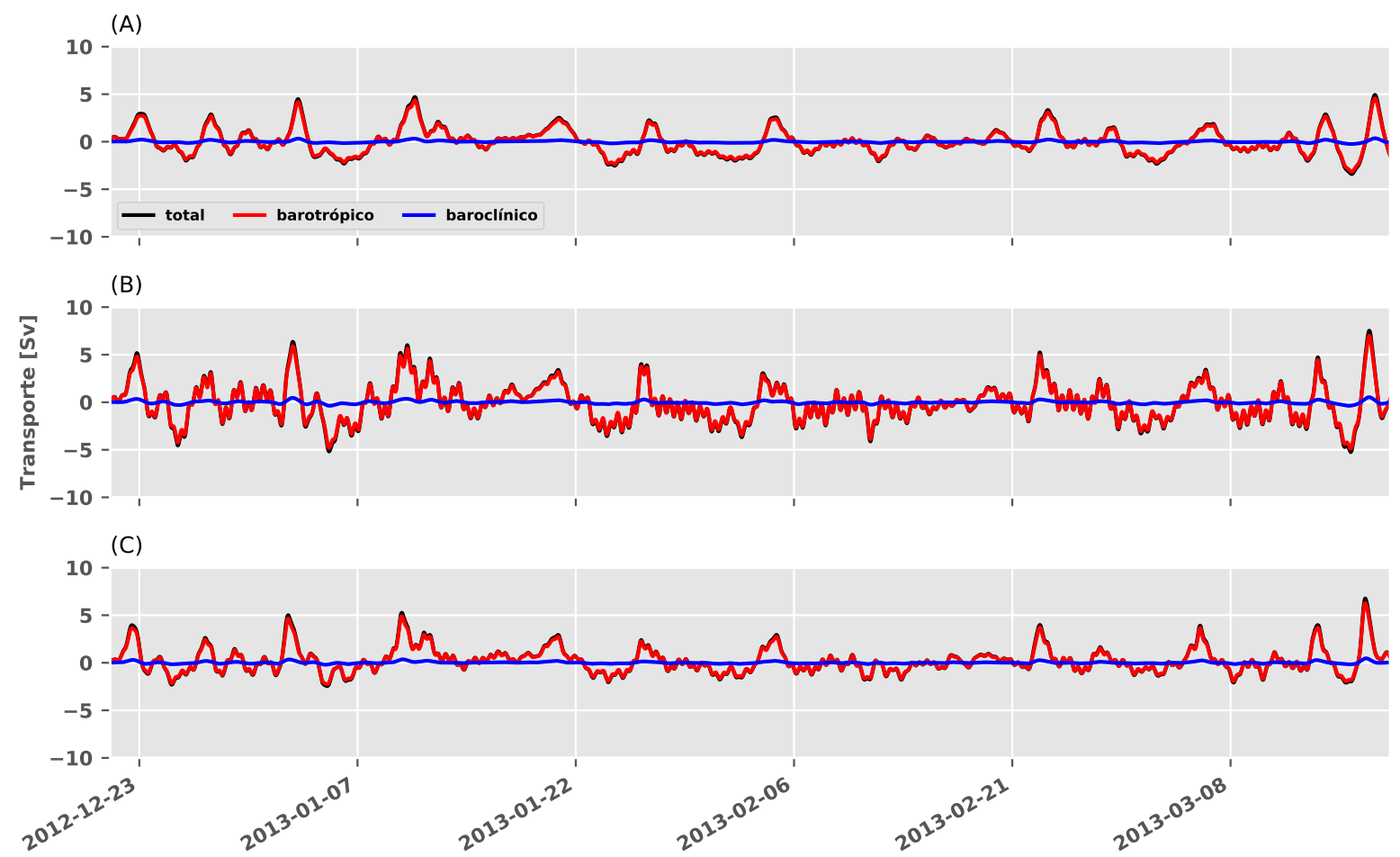

Figura 3.30: Transporte de volume paralelo à costa em SV. Transporte total, barotrópico e baroclínico em preto, vermelho e azul, respectivamente. (A) Ubatuba; (B) Santos; (C) Cananéia. Experimento de verão, no ano neutro.

Em um experimento de inverno, barotrópico, Castro (1985) encontra valores de transporte maiores no norte $(2.60 \mathrm{~Sv})$ da PCSE do que no sul da região $(0.70 \mathrm{~Sv})$. Este mesmo padrão foi encontrado para os transportes barotrópicos de inverno de AN e LN deste trabalho. Os valores encontrado são de $2.38 \mathrm{~Sv}$ para o norte da PCSE, e 1.55 Sv para o sul da PCSE, no LN. Já no AN, os valores encontrados para norte e sul foram, respectivamente, $2.00 \mathrm{~Sv}$ e $1.51 \mathrm{~Sv}$. 
Tabela 3.2: Média do transporte de volume paralelo à costa em Sv. Transporte total, barotrópico (BT) e baroclínico (BC). Radial Cananéia é indicada por sul, Radial Santos é indicada por centro e Radial Ubatuba é indicada por norte. LN representa o ano de La Niña, e AN representa o Ano Neutro.

\begin{tabular}{|c|c|c|c|c|c|c|c|c|c|}
\hline \multirow{2}{*}{ Período } & \multicolumn{3}{|c|}{ Transporte total } & \multicolumn{3}{|c|}{ Transporte BT } & \multicolumn{3}{|c|}{ Transporte BC } \\
\hline & norte & centro & sul & norte & centro & sul & norte & centro & sul \\
\hline Outono (LN) & 3.72 & 6.40 & 3.36 & 3.21 & 5.58 & 2.91 & 0.02 & 0.03 & 0.02 \\
\hline Inverno (LN) & 2.75 & 4.57 & 1.79 & 2.38 & 3.98 & 1.55 & 0.01 & 0.02 & 0.01 \\
\hline Primavera $(\mathrm{LN})$ & 1.98 & 4.22 & 2.25 & 1.72 & 3.69 & 1.95 & 0.01 & 0.02 & 0.01 \\
\hline Verão (LN) & 1.58 & 3.66 & 2.20 & 1.37 & 3.19 & 1.90 & 0.01 & 0.02 & 0.01 \\
\hline Outono (AN) & 1.27 & 2.37 & 0.85 & 1.10 & 2.07 & 0.74 & 0.01 & 0.01 & 0.00 \\
\hline Inverno (AN) & 2.28 & 4.82 & 1.75 & 2.00 & 4.19 & 1.51 & 0.01 & 0.02 & 0.01 \\
\hline Primavera (AN) & 1.79 & 4.46 & 1.91 & 1.55 & 3.89 & 1.65 & 0.01 & 0.02 & 0.01 \\
\hline Verão (AN) & 1.89 & 3.95 & 1.93 & 1.63 & 3.44 & 1.67 & 0.01 & 0.02 & 0.01 \\
\hline
\end{tabular}

A média anual dos transportes de volume através das 3 sessões, confirma que na radial de Santos ocorrem os maiores valores, seguidos por Ubatuba e Cananéia, em ordem decrescente (Figura 3.31). Este padrão pode estar associado a transportes transversais às isóbatas indo em direção à costa, entre Cananéia e Santos, e transportes transversais às isóbatas indo em direção ao oceano profundo entre Santos e Ubatuba. Além disso, pode estar associado ao padrão ciclônico encontrado na região.

No ano LN, o transporte em Santos é cerca de 53\% maior do que Ubatuba. No AN, essa liderança é cerca de 46\%. Em todas as situações dessa média anual, o transporte barotrópico varia entre $86 \%$ e $87 \%$ do transporte total, com ligeiro predomínio do AN sobre LN em Ubatuba e em Santos, e ligeiro domínio do ano de LN sobre AN em Cananéia. 

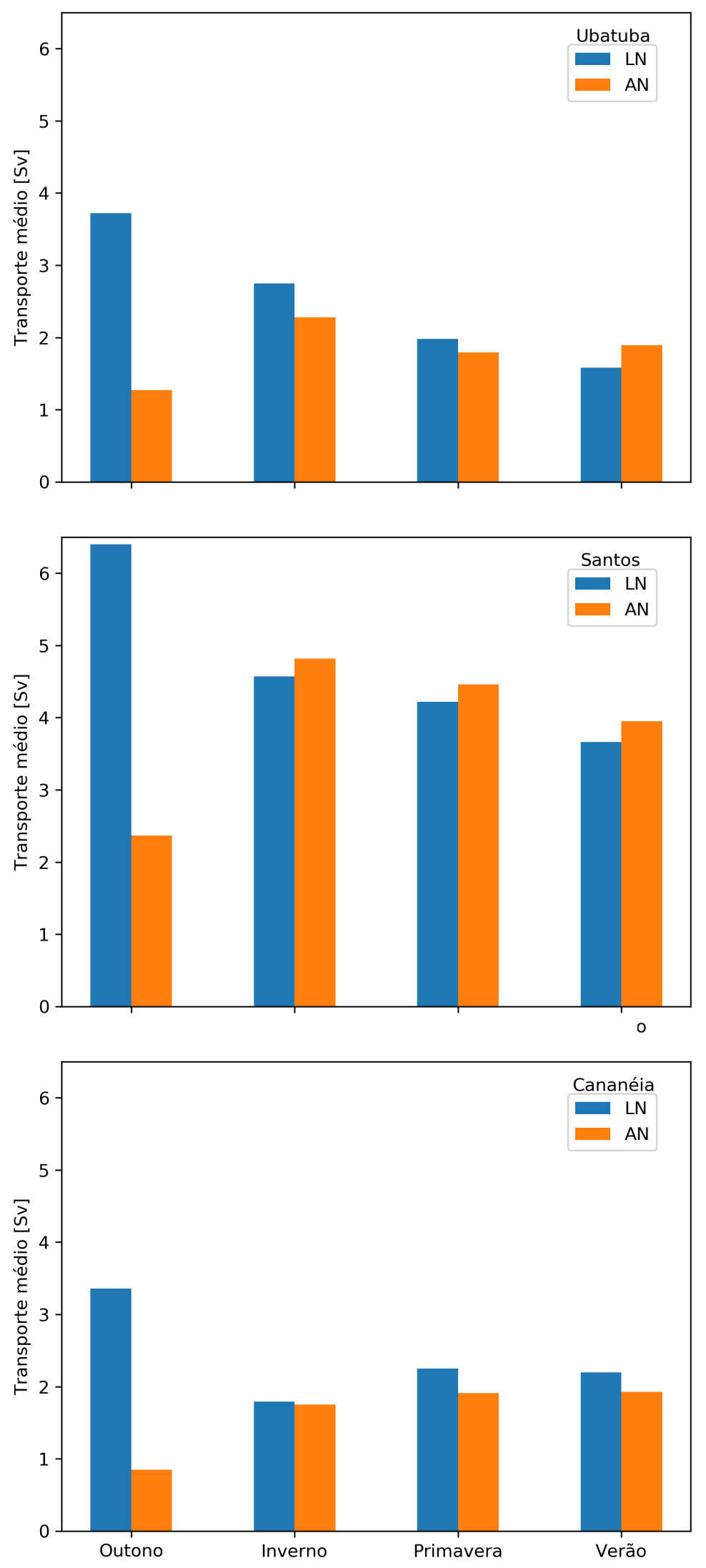

Figura 3.31: Transporte de volume médio paralelo à costa (Sv). Em azul, experimento de La Niña e em laranja, Ano Neutro, para Ubatuba, Santos e Cananéia, para as 4 estações do ano. 


\section{Nível médio do mar}

O nível médio do mar foi calculado para as mesmas radiais em que o transporte foi calculado: Ubatuba, Cananéia e Santos. A sua evolução temporal está representada ao longo de toda a sessão transversal. Sabe-se que a elevação (diminuição) do nível do mar está associada aos ventos vindos do quadrante sul (norte), devido ao transporte de Ekman. Em todos os experimentos foi possível perceber que as oscilações do nível médio do mar (NMM) ocorrem quase em fase nas três radiais.

Começando pelo outono, é possível ver que em ambos experimentos ocorrem oscilações do nível médio do mar tanto positivas quanto negativas. No entanto, no AN (Figura 3.32) a variação do NMM negativa apresenta valores maiores. Já no LN (Figura 3.33), é possível ver que as oscilações negativas apresentam-se mais expressivas. Esta maior ocorrência de oscilações positivas no LN pode estar associada com ventos do quadrante sul mais intensos, causando maior empilhamento de água na costa.
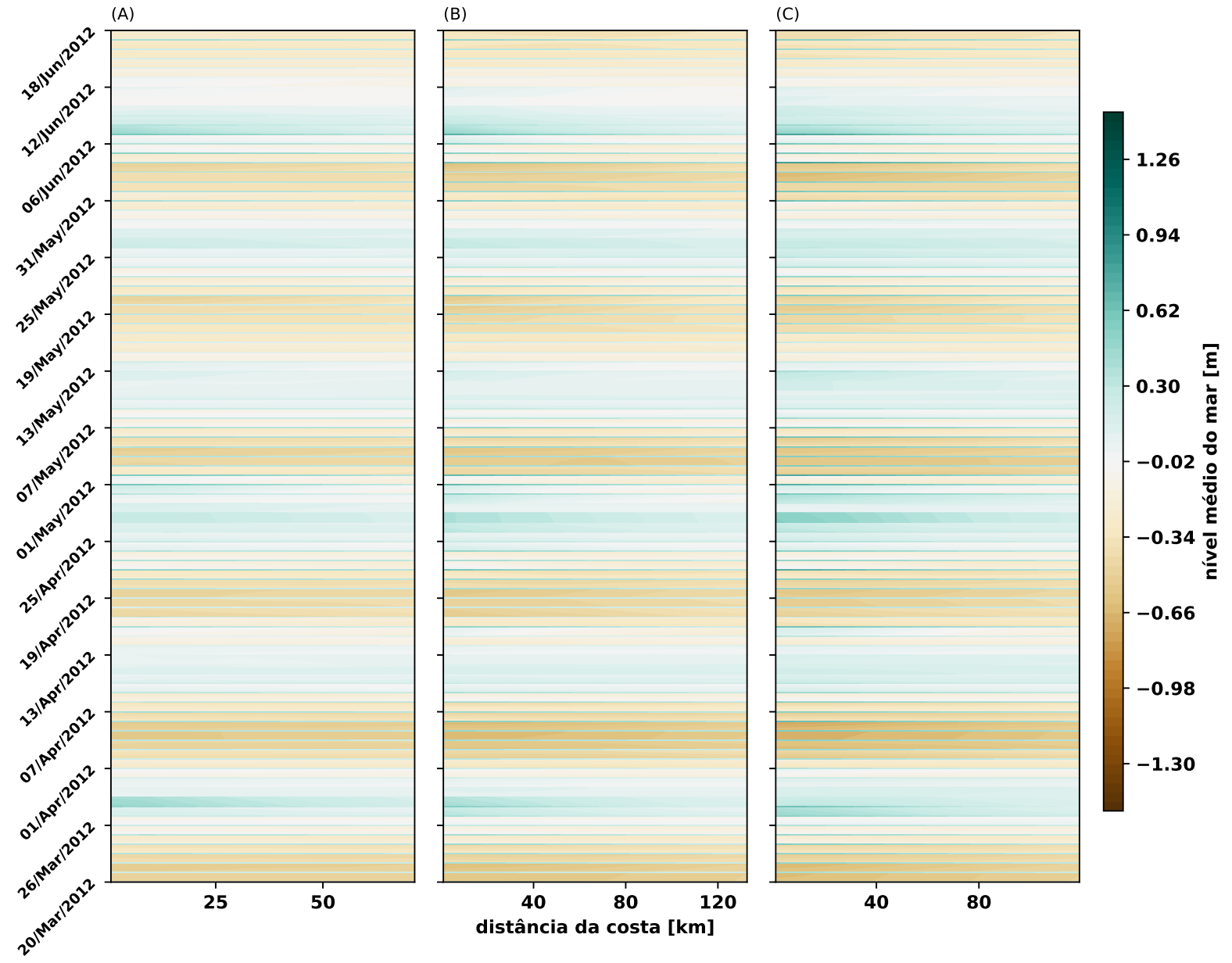
Figura 3.32: Nível médio do mar em metros. (A) radial de Ubatuba até isóbata de 100 m; (B) radial de Santos até isóbata de $100 \mathrm{~m} ;(\mathrm{C})$ radial de Cananéia até isóbata de $100 \mathrm{~m}$. Experimento de outono, no ano neutro.

Para entender por que no ano de LN as oscilações são positivas, o NMM foi analisado apenas referente à maré (Figura 3.34) e sem sua influência (Figura 3.35). É possível ver que quando a maré é desconsiderada, o NMM é sempre positivo, além disso, os maiores valores encontrados são mais próximos à costa, indicando a presença de ventos do quadrante sul, que propiciam que o transporte e Ekman empilhe água próximo à costa. Do dia 05/04/2010 ao dia 09/04/2010 os ventos estavam de SW, o que propicia aumento do nível do mar pelo transporte de Ekman, estando de acordo com pico de altura positiva do NMM visto neste mesmo período.
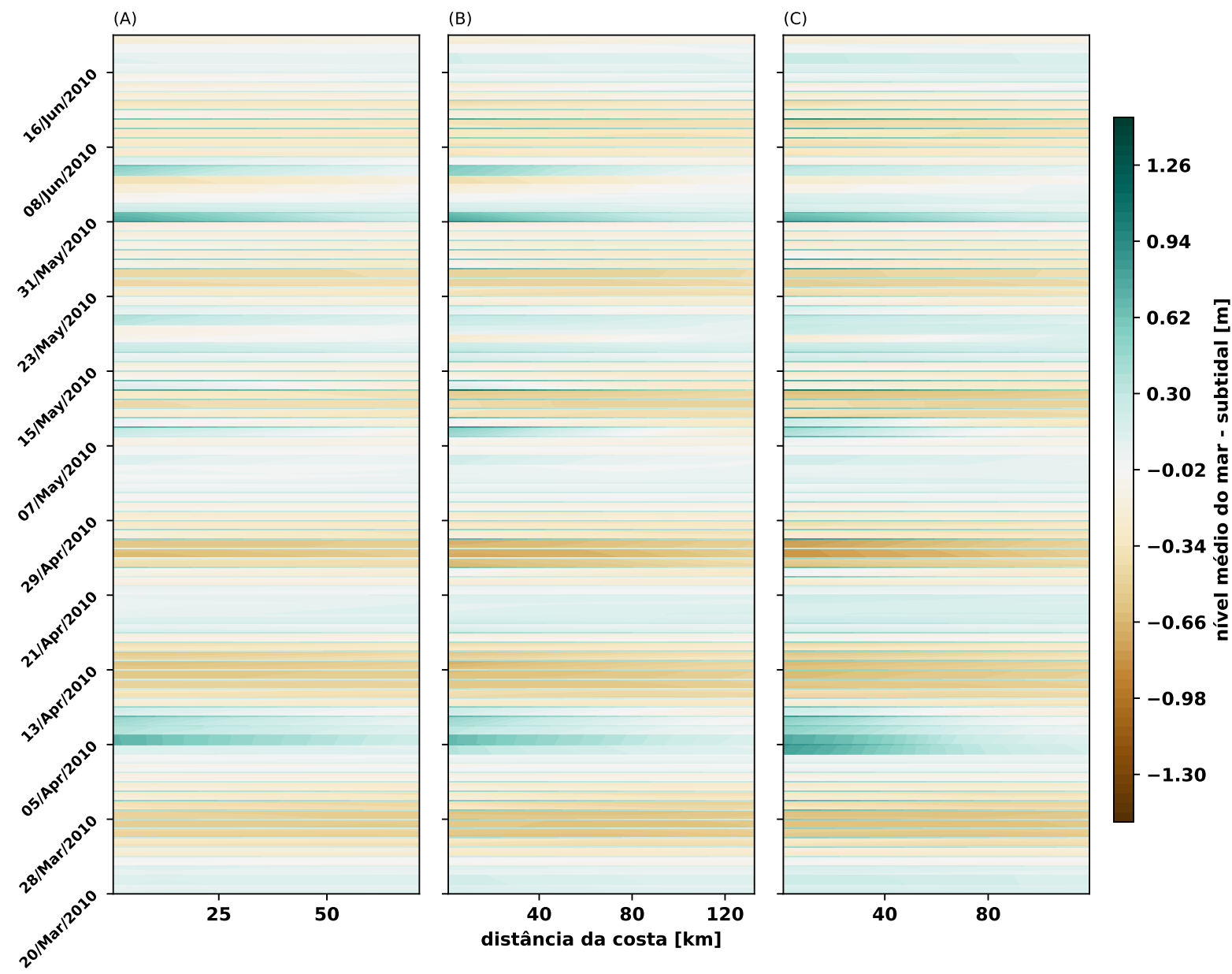

Figura 3.33: Nível médio do mar em metros. (A) radial de Ubatuba até isóbata de 100 m; (B) radial de Santos até isóbata de $100 \mathrm{~m}$; (C) radial de Cananéia até isóbata de $100 \mathrm{~m}$. Experimento de outono, no ano de La Niña. 

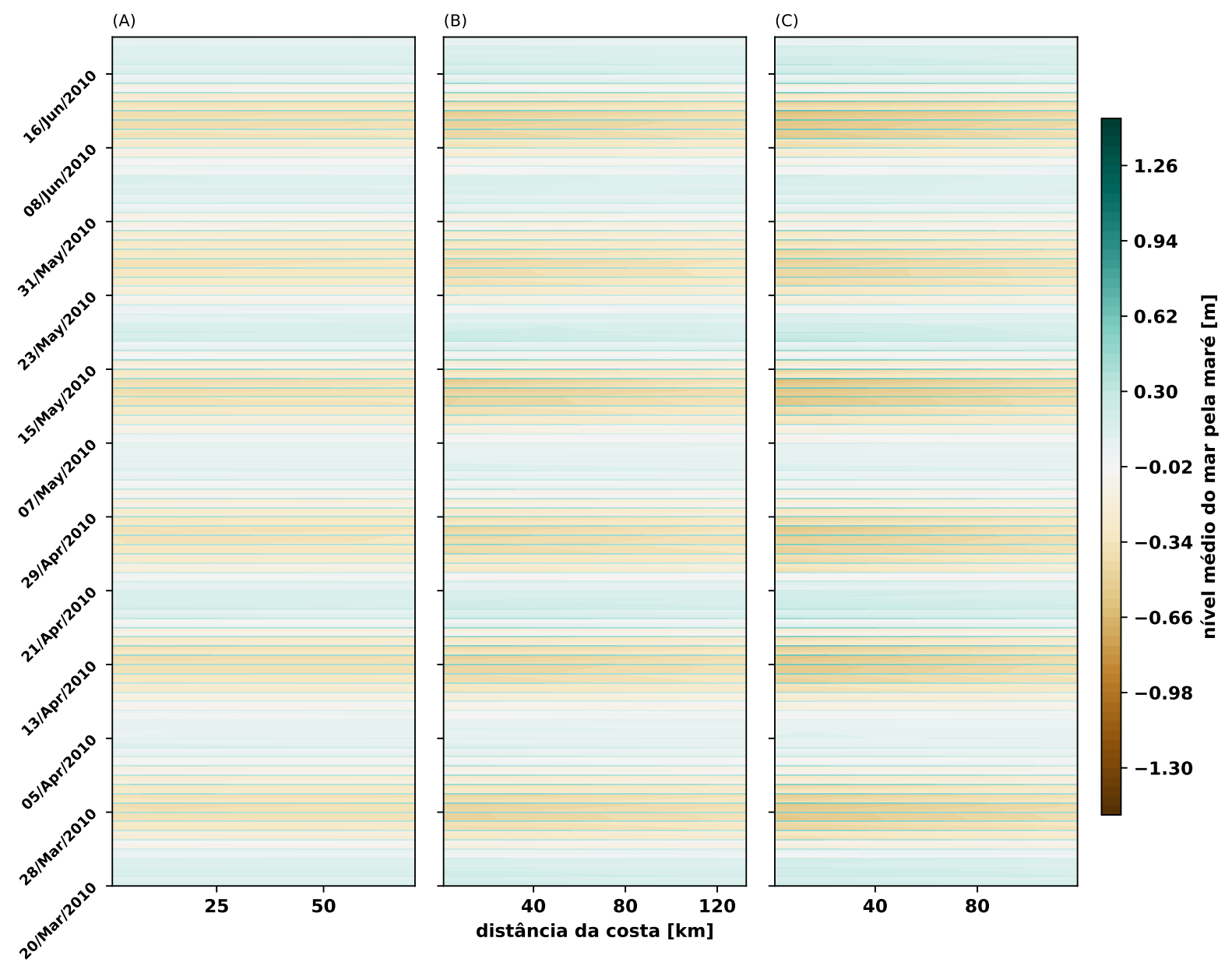

Figura 3.34: Nível médio do mar, referente à maré, em metros. (A) radial de Ubatuba até isóbata de 100 m; (B) radial de Santos até isóbata de 100 m; (C) radial de Cananéia até isóbata de 100 m. Experimento de outono, ano de La Niña.

Já ao analisar a maré de forma isolada (Figura 3.34), há valores positivos e negativos, sendo os negativos maiores em módulo. Em Ubatuba, a amplitudo da maré é menor do que em Santos e Cananéia. 

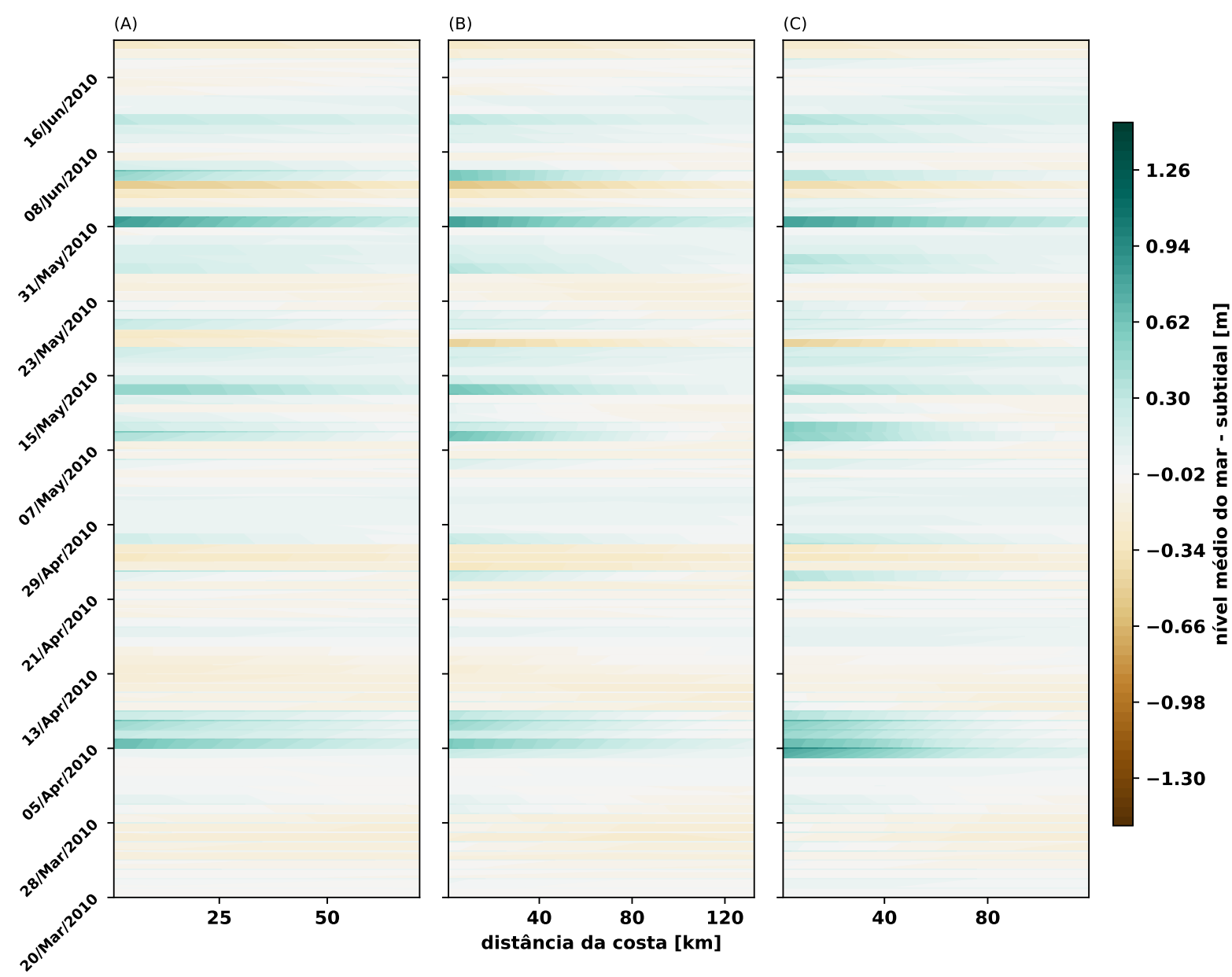

Figura 3.35: Nivel médio do mar, sem maré, em metros. (A) radial de Ubatuba até isóbata de 100 m; (B) radial de Santos até isóbata de 100 m; isóbata de 100 m; (C) radial de Cananéia até isóbata de 100 m. Experimento de outono, ano de La Niña.

No inverno as oscilações do nível do mar apresentam-se menores do que no outono, sendo que a elevação positiva, possível resultado de ventos de quadrante sul, é predominante. Os dois experimentos de inverno apresentam-se bastante semelhantes, no entanto, no AN (Figura 3.36), aparecem dois rebaixamentos do nível do mar, o que não é visto no LN (Figura 3.37).

A importância relativa da maré no NMM atua de forma semelhante tanto no experimento da AN quanto no experimento de LN, portanto será apresentado apenas um dos casos (LN) para exemplificar como ocorre este processo.

Nesta estação, a resposta do nível do mar ao vento atua contra a resposta do nível do mar ao sentido da maré, que tem maiores valores, em módulo, abaixo de zero (Figura 3.38), provocando aumento do nível do mar (Figura 3.39). Como a resultante é positiva (Figura 3.37), pode-se dizer que o vento acaba barrando o efeito de rebaixamento do NMM. 
É possível ver que quando não há influência da maré, as amplitudes são maiores quanto mais próximo à costa, indicanto o empilhamento/retirada da água na costa.
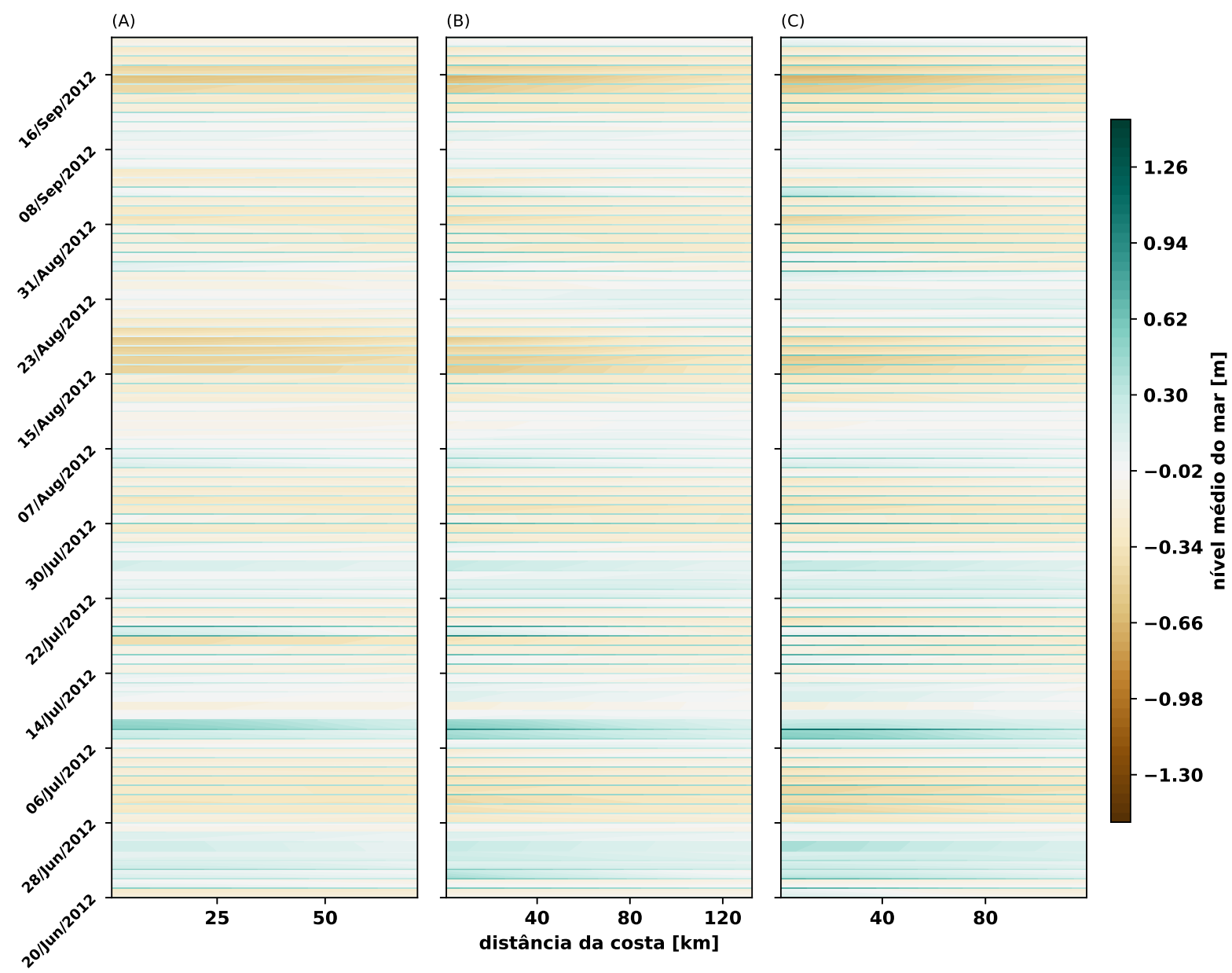

Figura 3.36: Nivel médio do mar em metros. (A) radial de Ubatuba até isóbata de $100 \mathrm{~m}$; (B) radial de Santos até isóbata de $100 \mathrm{~m}$; (C) radial de Cananéia até isóbata de $100 \mathrm{~m}$. Experimento de inverno, no ano neutro.

Em Ubatuba, assim como no outono, a maré apresenta menor amplitude em relação a Santos e Cananéia. Já em relação à situação sem maré, é possível ver que no fim do inverno há um pequeno decaimento do nível do mar que ocorre mais proeminente em Ubatuba, depois em Santos e nem chega a aparecer em Cananéia. Isso pode estar associado a ventos do quadrante norte que não tiveram força suficiente para chegar até o sul da PCSP. Já em relação à elevação da superfície, em Ubatuba, são encotrado os menores valores, indicando a entrada de ventos do quadrante sul por Cananéia, os quais vão enfraquecendo até chegar em Ubatuba. 

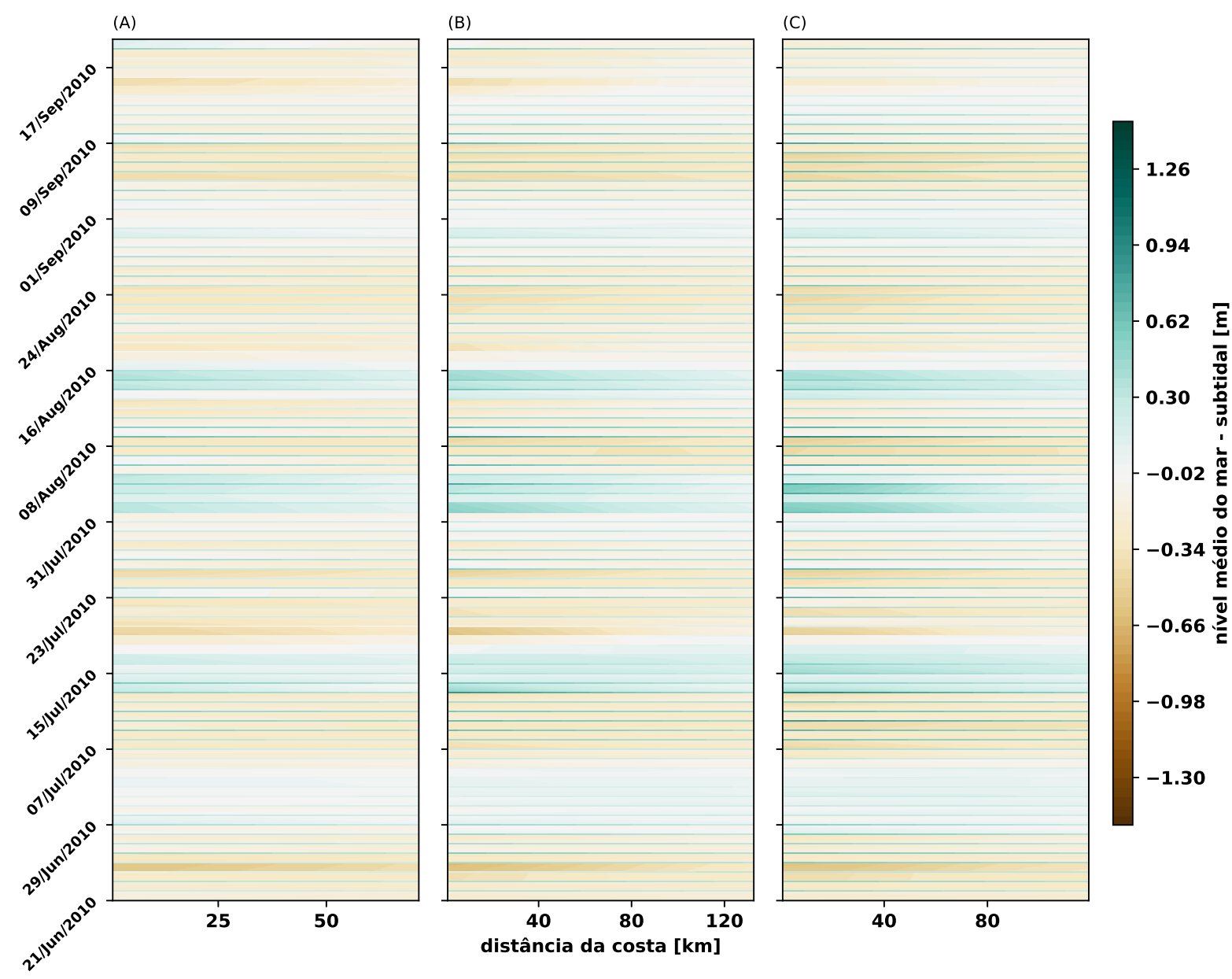

Figura 3.37: Nível médio do mar em metros. (A) radial de Ubatuba até isóbata de 100 m; (B) radial de Santos até isóbata de $100 \mathrm{~m}$; (C) radial de Cananéia até isóbata de $100 \mathrm{~m}$. Experimento de inverno, ano de La Niña. 

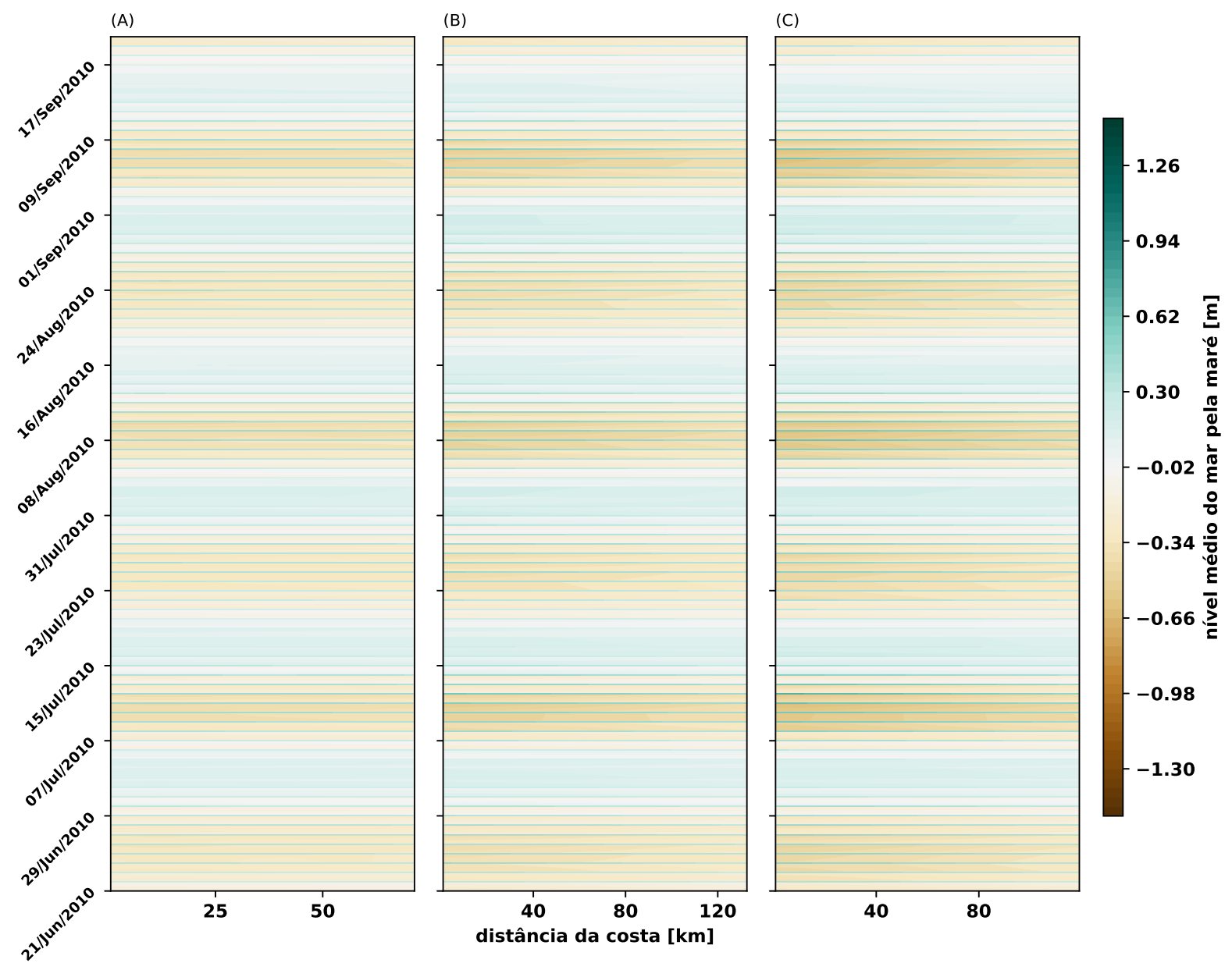

Figura 3.38: Nível médio do mar, referente à maré, em metros. (A) radial de Ubatuba até isóbata de 100 m; (B) radial de Santos até isóbata de 100 m; (C) radial de Cananéia até isóbata de 100 m. Experimento de inverno, ano de La Niña. 

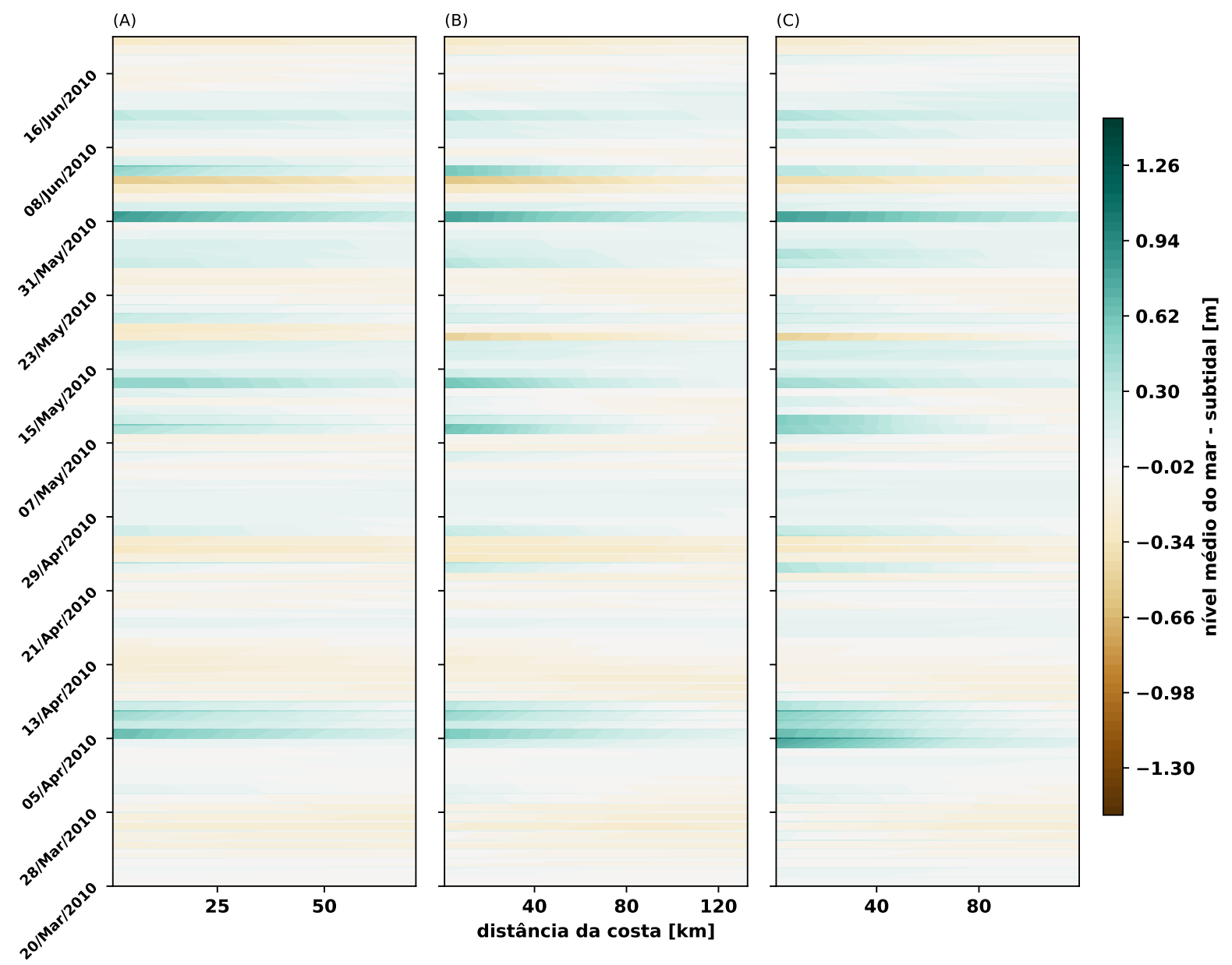

Figura 3.39: Nivel médio do mar, sem maré, em metros. (A) radial de Ubatuba até isóbata de 100 m; (B) radial de Santos até isóbata de 100 m; isóbata de 100 m; (C) radial de Cananéia até isóbata de $100 \mathrm{~m}$. Experimento de inverno, ano de La Niña. 
Os experimentos de primavera, tanto AN (Figura 3.40) quanto LN (Figura 3.41), apresentam padrões bastante semelhantes quanto à variação do NMM no decorrer do tempo. As oscilações negativas ao redor da média são mais frequentes e mais intensas. Entre os dois experimentos, é possível ver que a ondulação possui frequência bastante similar. O rebaixamento do NMM pode ser explicado por predominância de ventos do quadrante nordeste.
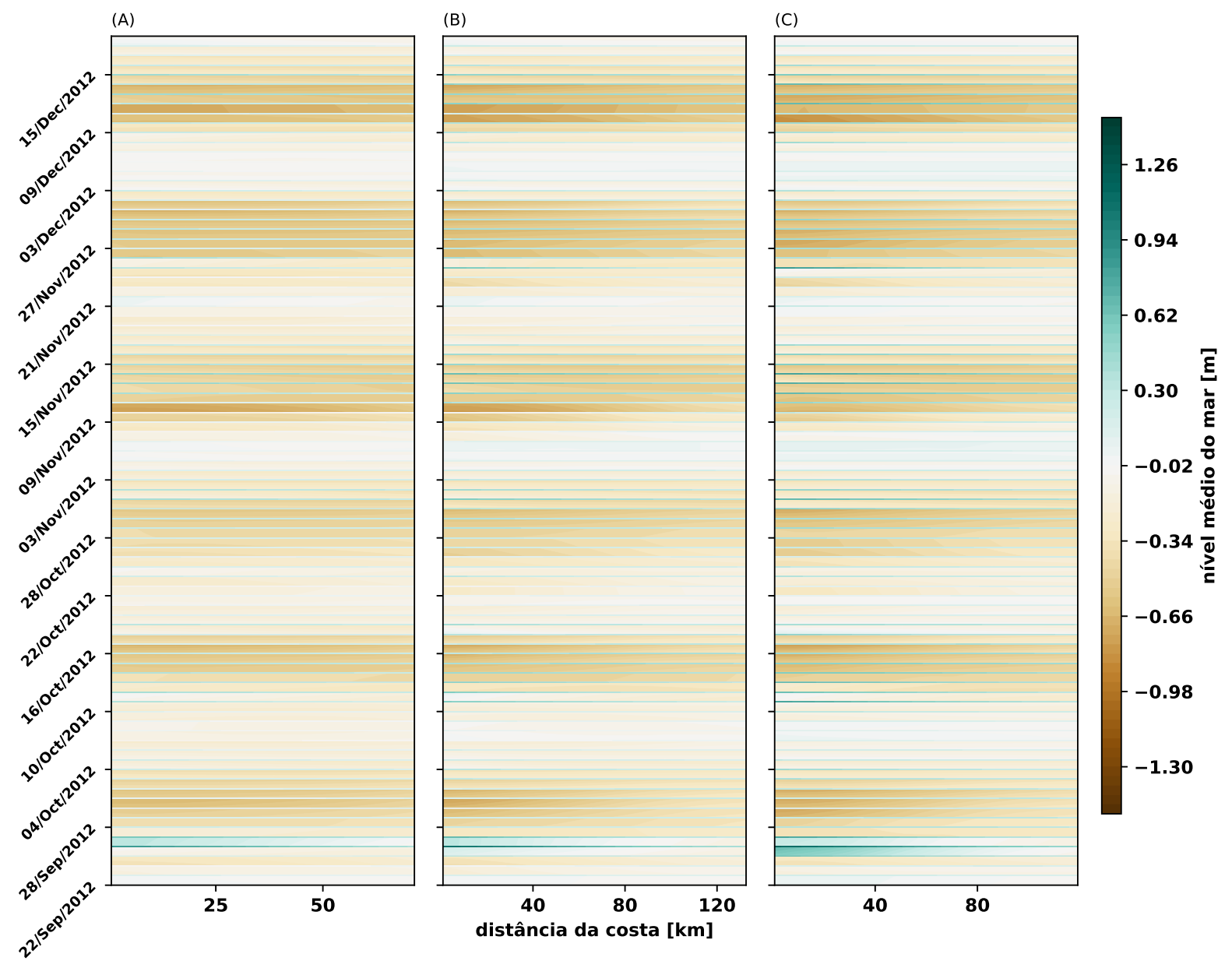

Figura 3.40: Nivel médio do mar em metros. (A) radial de Ubatuba até isóbata de $100 \mathrm{~m}$; (B) radial de Santos até isóbata de $100 \mathrm{~m}$; (C) radial de Cananéia até isóbata de $100 \mathrm{~m}$. Experimento de primavera, no ano neutro. 

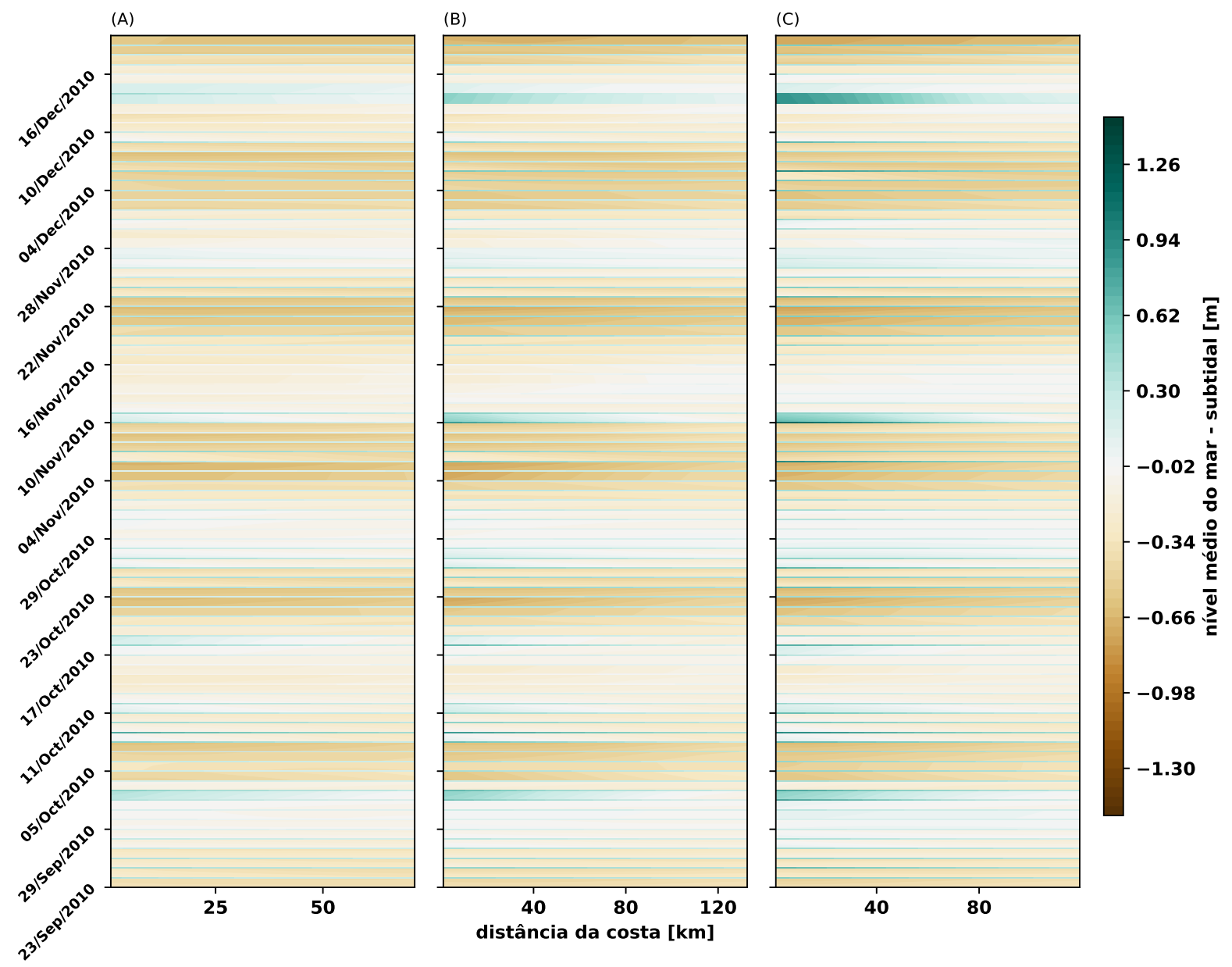

Figura 3.41: Nível médio do mar em metros. (A) radial de Ubatuba até isóbata de $100 \mathrm{~m}$; (B) radial de Santos até isóbata de $100 \mathrm{~m}$; (C) radial de Cananéia até isóbata de $100 \mathrm{~m}$. Experimento de primavera, no ano de La Niña. 
Em ambos experimentos, a maré foi dominante em relação ao vento sobre o NMM, portanto serão mostradas apenas as figuras referentes ao $\mathrm{LN}$ como forma de exemplificar. $\mathrm{Na}$ Figura 3.42 é possível perceber o mesmo padrão de oscilação da Figura 3.41, indicando a importância relativa da maré sobre o NMM. Já na Figura 3.43 não há influência da maré, e é possível ver que os valores de oscilação são bastante baixos, sendo Ubatuba a região onde há menor oscilação do NMM quando não se considera a maré. Já Cananéia apresenta as maiores elevações quando a maré é desconsiderada, o que pode estar relacionado à maior susceptibilidade aos ventos de SW.
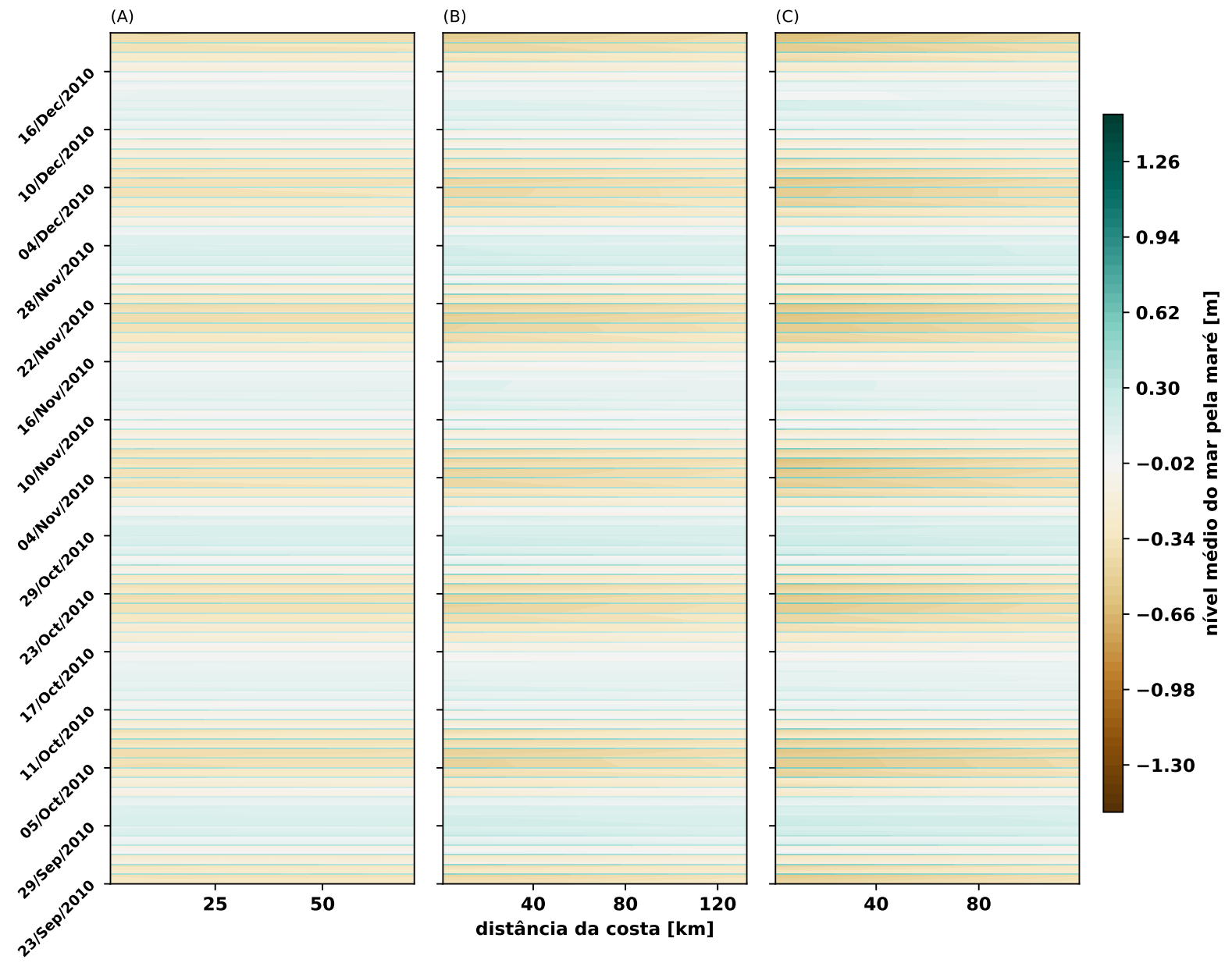

Figura 3.42: Nível médio do mar, referente à maré, em metros. (A) radial de Ubatuba até isóbata de $100 \mathrm{~m} ;$ (B) radial de Santos até isóbata de $100 \mathrm{~m}$; (C) radial de Cananéia até isóbata de 100 m. Experimento de primavera, no ano de La Niña. 

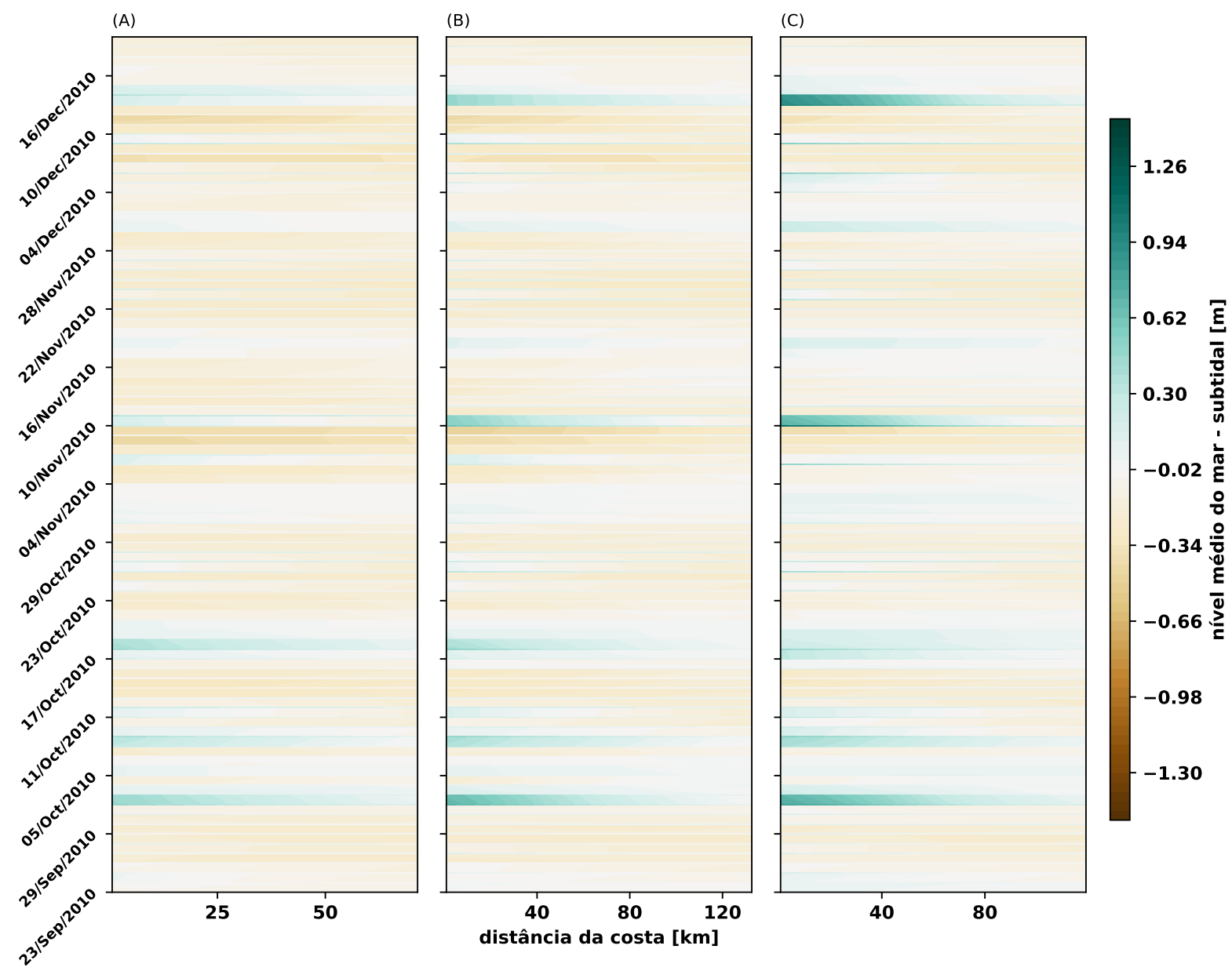

Figura 3.43: Nivel médio do mar, sem maré, em metros. (A) radial de Ubatuba até isóbata de 100 m; (B) radial de Santos até isóbata de 100 m; isóbata de 100 m; (C) radial de Cananéia até isóbata de 100 m. Experimento de primavera, no ano de La Niña.

O verão, assim como a primavera, destaca-se pela ocorrência de rebaixamento do nível médio tanto no experimento AN (Figura 3.44) quanto no experimento LN (Figura 3.41). Ambos os experimentos apresentam a mesma frequência na oscilação do NMM, ocorrendo 6 rebaixamentos ao longo da estação. No LN, é possível ver que em Cananéia ocorrem pequenas elevações do nível, podendo ser a resposta a ventos vindos de sul, que, nessa época do ano, não apresentam força suficiente para seguir em direção ao norte na PCSE.

A análise da importância da maré será apresentada apenas para o ano LN, pois em ambos os experimentos o comportamento é muito semelhante. Começando para a Figura 3.46 que representa a resposta do NMM à maré, é possível ver que o padrão apresentado é o mesmo encontrado na Figura 3.45, indicando predominância da maré.

Já ao olhar a Figura 3.47, é possível ver comportamentos diferentes nas três radiais. 
Em Ubatuba, o nível do mar apresenta o mesmo padrão da maré, porém com amplitudes menores. Desta forma, elas se somam e aumentam o rebaixamento do nível. Já em Cananéia, ocorrem alguns eventos de elevação do nível do mar, possivelmente associados a passagem de FF. Um exemplo pode ser visto no dia 18/02/2011, em que é possível ver a elevação do NMM e, ao analisar o campo de ventos, percebe-se a entrada de ventos de SW, o que propicia o empilhamento de água na costa devido ao transporte de Ekman. Ainda assim, nas três sessões fica evidencia a importância relativa da maré para o NMM.
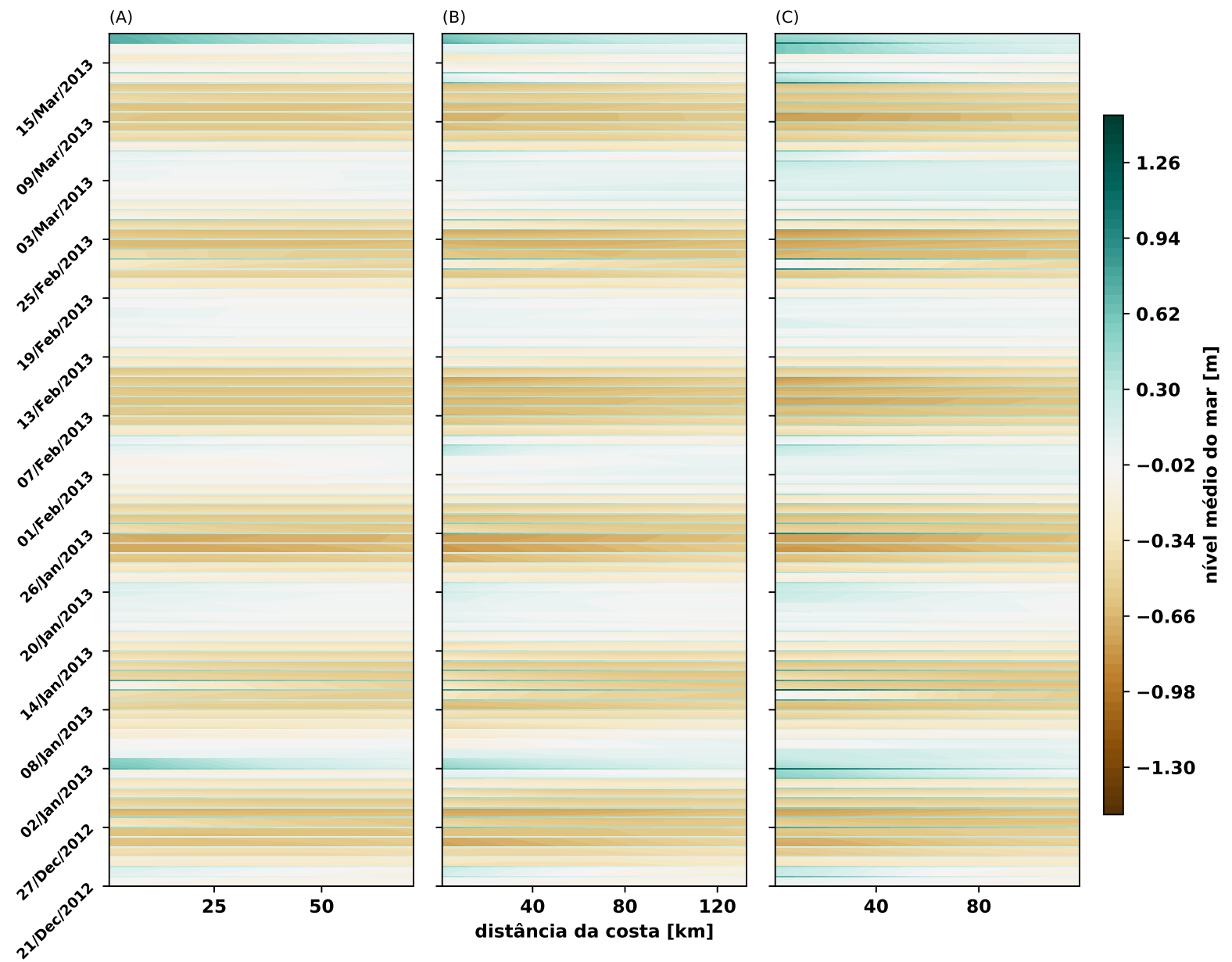

Figura 3.44: Nivel médio do mar em metros. (A) radial de Ubatuba até isóbata de $100 \mathrm{~m}$; (B) radial de Santos até isóbata de $100 \mathrm{~m}$; (C) radial de Cananéia até isóbata de $100 \mathrm{~m}$. Experimento de verão, no ano neutro. 

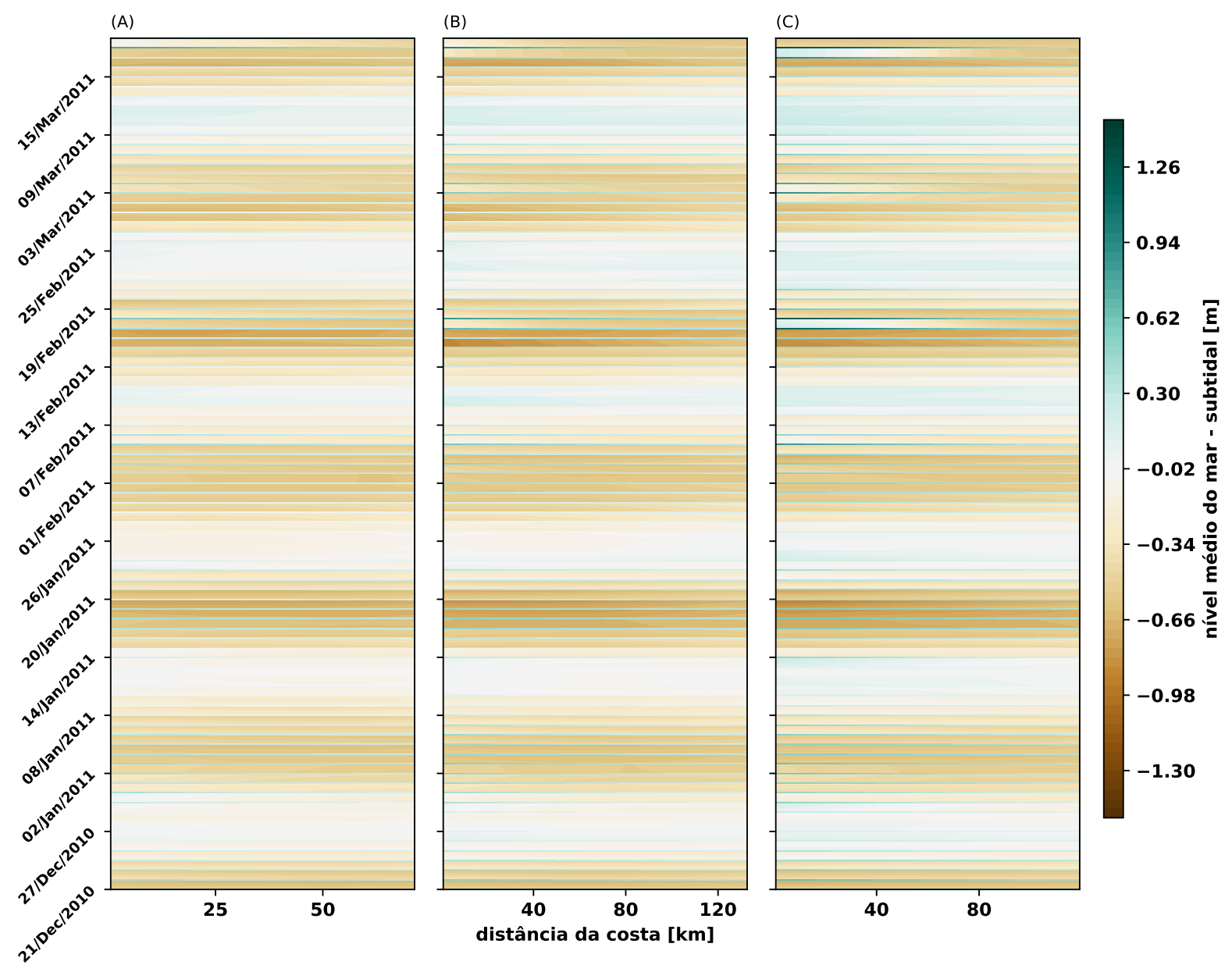

Figura 3.45: Nivel médio do mar em metros. (A) radial de Ubatuba até isóbata de $100 \mathrm{~m}$; (B) radial de Santos até isóbata de $100 \mathrm{~m}$; (C) radial de Cananéia até isóbata de $100 \mathrm{~m}$. Experimento de verão no ano de La Niña. 

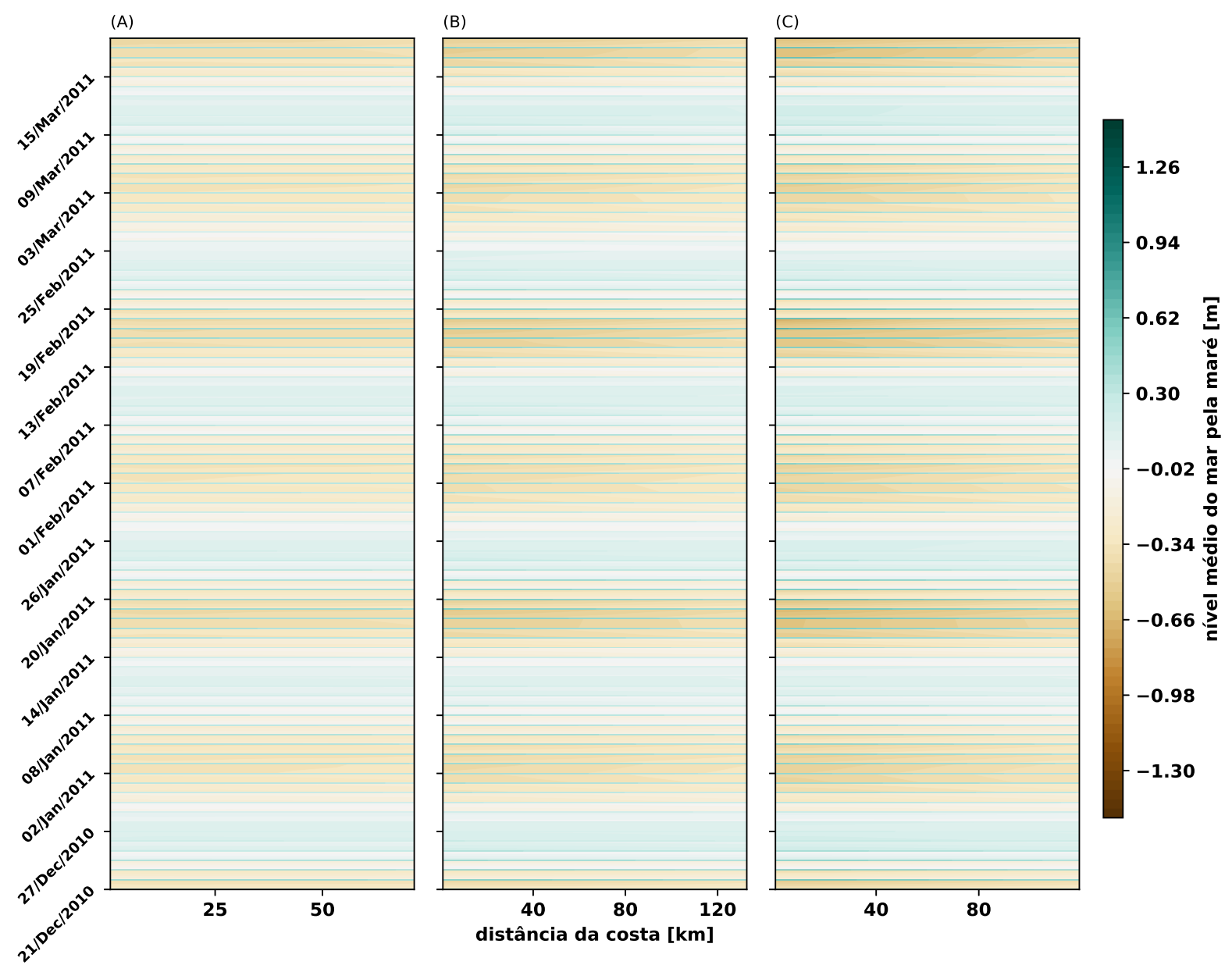

Figura 3.46: Nível médio do mar, referente à maré, em metros. (A) radial de Ubatuba até isóbata de 100 m; (B) radial de Santos até isóbata de 100 m; (C) radial de Cananéia até isóbata de 100 m. Experimento de verão no ano de La Niña. 

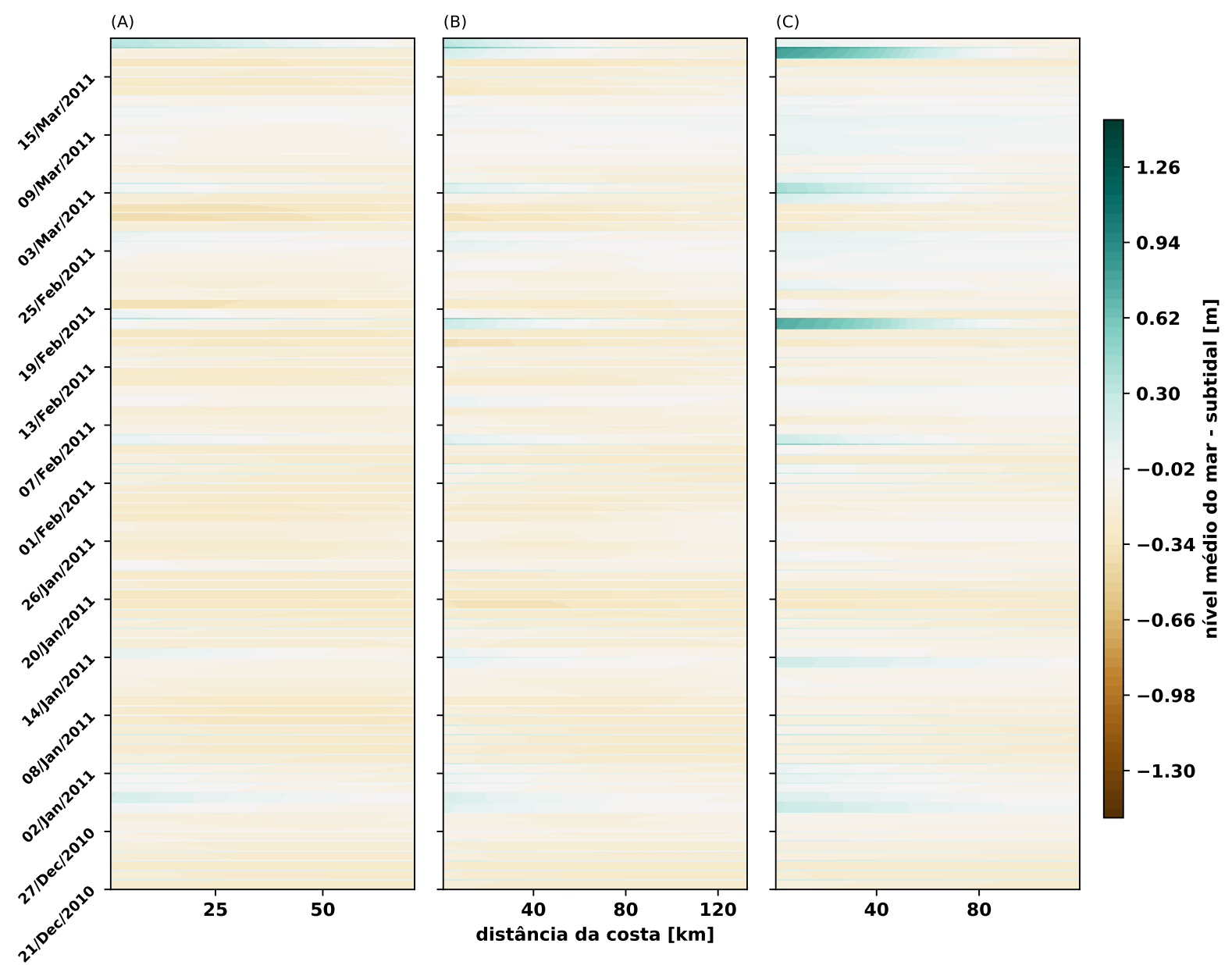

Figura 3.47: Nível médio do mar, sem maré, em metros. (A) radial de Ubatuba até isóbata de $100 \mathrm{~m}$; (B) radial de Santos até isóbata de 100 m; isóbata de 100 m; (C) radial de Cananéia até isóbata de 100 m. Experimento de verão no ano de La Niña.

Ao comparar as quatro estações, percebe-se padões bem definidos em cada uma, quanto ao NMM, e pouca variação de um ano para o outro, sendo o outono a estação que apresenta maior diferença. Esta estação é a estação que apresenta a maior amplitude do nível do mar. Já o inverno, é a estação que apresenta maior homogeneidade ao longo do ano, com predominância de NMM maior do que zero. A primavera e o verão apresentam predomnínio de valores negativos do NMM, sendo que no verão estes valores são maiores. 


\section{Capítulo 4}

\section{Conclusões}

- Os resultados do modelo, para a velocidade paralela à costa, apresentaram bons valores de skill quando comparados aos valores encontrados na literatura.

- Em relação aos campos de temperatura e salinidade, no outono a PCI é verticalmente homogênea, já a PC apresenta estratificação. No inverno o campo é verticalmente homogêneo, mas há variação no campo horizontal; na primavera a PCI é verticalmente homogênea e a PCM é estratificada, assim como no outono, já o verão é a estação que apresenta maior estratificação com a profundidade.

- Os padrões de TS estão de acordo com aqueles apresentados por Castro e Miranda (1998) e por Castro (1996), mostrando a representatividade da climatologia utilizada no presente trabalho.

- Em relação ao campo horizontal de velocidade, no outono houve variação tanto da magnitude quando da direção da velocidade da corrente com a profundidade, tanto no AN quanto no LN; no inverno não há diferenças importantes entre os anos de $\mathrm{AN}$ e LN. Em ambos casos, a velocidade na PCI e na PCM apresentam sentidos opostos na superfície, e entre costa e a isóbata de 80 m o sentido da corrente na superfície é oposto ao sentido da corrente no fundo; na primavera também não foi observada variação importante entre os anos de AN e LN, e os campos de velocidade de fundo e superfície apresentam sentidos opostos; e no verão também há pouca variação entre os anos de AN e LN, sendo que os resultados encontrados assemelham-se àqueles apresentados por Coelho (2008) e Ruffato (2011).

- Comparando os três casos de passagem de frentes frias (FF1, FF2 e FF3), é possível 
ver que em ambas situações o campo médio de velocidade é mais intenso durante a passagem de FF, tanto na superfície quanto no fundo.

- Quando a FF é mais intensa, há maior cisalhamento de velocidade na vertical.

- Nas quatro estações do ano, tanto para o AN quanto para LN, a maior média do transporte ocorreu em Santos.

- A variação do transporte entre os experimentos de AN e LN só é visível no outono, sendo os maiores valores encontrados no LN.

- O padrão de transporte encontrado para o inverno está de acordo com aquele encontrado por Castro (1985).

- O transporte barotrópico é predominante na componente paralela à costa.

- Em relação ao NMM, os padrões são bem definidos em cada experimento, e não há muita variação com o aumento da latitude. Há pouca variação entre o $\mathrm{AN}$ e LN, sendo as maiores diferenças encontradas no outono. No verão e na primavera a maré é dominante, já no outono e no inverno o vento também mostra importância relativa semelhante à maré.

- Os menores valores de amplitude de maré foram encontrados na sessão de Ubatuba.

Os resultados apresentados neste trabalho não mostram padrões bem definidos de variação nos campos horizontais de velocidade entre o ano neutro e o ano de La Niña, não sendo possível concluir se este evento atomosférico é capaz de gerar alterações nos padrões de circulação horizontal na PCSP. As principais diferenças encontradas referem-se às variações sazonais, as quais apresentam padrões bem definidos.

Em relação ao transporte de volume, as médias anuais nos experimentos de LN foram maiores na três radiais, tanto para o transporte total, tranporte barotrópico e transporte baroclínico.

Como sugestões para trabalhos futuros, é necessário analisar um número maior de AN e LN para poder assegurar a influência destes padrões atmosféricos na circulação oceânica. Além disso, o outono de 2010 foi apresentou sempre as maiores 
diferenças entre os experimentos de LN e AN em relação aos outros experimentos, portanto seria interessante aprofundar as análises para este período. 


\section{Referências}

Blumberg, A. F., F. Asce, N. Georgas, e M. Asce (2008). Quantifying Uncertainty in Estuarine and Coastal Ocean Circulation Modeling. Journal of Hydraulic Engineering 134(4), 403-415.

Blumberg, A. F., L. A. Khan, e J. P. St. John (1999). Three-Dimensional Hydrodynamic Model of New York Harbor Region. Journal of Hydraulic Engineering 125(8), 799-816.

Blumberg, A. F. e G. L. Mellor (1987). A description o f a three-dimensional coastal ocean circulation model.

Brink, K. H. (2005). Coastal physical processes overview. The Sea. The Global Coastal Ocean: Multiscale Interdisciplinary Processes 13, 37-59.

Campos, E. J. D., C. A. D. Lentini, J. L. Miller, e A. R. Piola (1999). Interannual variability of the sea surface temperature in the South Brazil Bight. Geophysical Research Letters 26(14), 2061-2064.

Campos, E. J. D., J. A. Lorenzzetti, M. R. Stevenson, J. L. Stech, e R. B. Souza (1996). Penetration of waters from the Brazil-Malvinas confluence region along the South American Continental Shelf up to 23S. 68(1), 49-58.

Campos, P. C., O. O. Möller, A. R. Piola, e E. D. Palma (2013). Seasonal variability and coastal upwelling near Cape Santa Marta (Brazil). Journal of Geophysical Research: Oceans 118(3), 1420-1433.

Campos, R. M., R. Camargo, e J. Harari (2010). Caracterização De Eventos Extremos Do Nível Do Mar Em Santos E Sua Correspondência Com As Reanálises Do Modelo Do Ncep No Sudoeste Do Atlântico Sul. Revista Brasileira de Meteorologia 25(2), 175-184.

Carvalho, J. L., C. A. Schettini, e T. M. Ribas (2010). Estrutura termohalina 
do litoral centro-norte catarinense. Brazilian Journal of Aquatic Science and Technology 2(1), 181.

Castro, B. M. (1985). Subtidal response to wind forcing in the South Brazil Bight during winter. Phd dissertation, University of Miami.

Castro, B. M. (1990). Wind driven currents in the channel of São Sebastião: winter, 1979. Boletim do Instituto Oceanográfico 38(2), 111-132.

Castro, B. M. (1996). Correntes e massas de água da plataforma continental norte de São PauloNo Title. Livre-docente, Universidade de Sao Paulo.

Castro, B. M. (2014). Summer/winter stratification variability in the central part of the South Brazil Bight. Continental Shelf Research 89, 15-23.

Castro, B. M. e T. N. Lee (1995). Wind-forced sea level variability on the southeast Brazilian shelf. Journal of Geophysical Research 100(C8), 16,04516,056 .

Castro, B. M., J. A. Lorenzzetti, I. C. da Silveira, e L. B. Miranda (2006). Estrutura termohalina e circulacao na regiao entre o Cabo de Sao Tomé (RJ) eo Chu1 (RS). In O ambiente oceanográfico da plataforma continental e do talude na região sudeste-sul do Brasil, pp. 11-120. EDUSP.

Castro, B. M. e L. B. Miranda (1998). Physical oceanography of the western Atlantic continental shelf located between 4 N and 34 S. The Sea 11(1), 209251.

Cerda, C. e B. M. Castro (2013). Hydrographic climatology of South Brazil Bight shelf waters between Sao Sebastiao (24S) and Cabo Sao Tome (22S). Continental Shelf Research 89, 5-14.

Coelho, A. L. (2008). Resposta da Plataforma Continental Sudeste a ventos sazonais e sinóticos de verão: estudos numéricos. $\mathrm{Ph}$. D. thesis, Universidade de São Paulo, São Paulo.

Csanady, G. T. (1978). The Arrested Topographic Wave.

Dottori, M. e B. M. Castro (2009, aug). The response of the Sao Paulo Continental Shelf, Brazil, to synoptic winds. Ocean Dynamics 59(4), 603-614.

Duchon, C. E. (1979). Lanczos Filtering in One and Two Dimensions. Journal of Applied Meteorology 18, 1016-1022. 
Egbert, G. D., A. F. Bennett, e M. G. G. Foreman (1994). TOPEX/POSEIDON tides estimated using a global inverse model. Journal of Geophysical Rese$\operatorname{arch} 99(\mathrm{C} 12), 24821$.

Egbert, G. D. e S. Y. Erofeeva (2002). Efficient Inverse Modeling of Barotropic Ocean Tides. Journal of Atmospheric and Oceanic Technology 19, 183-204.

Filippo, A., A. R. Torres, B. Kjerfve, e A. Monat (2012). Application of Artificial Neural Network (ANN) to improve forecasting of sea level. Ocean \& Coastal Management 55, 101-110.

Fofonoff, N. P. (1962). Physical properties of sea-water. The Sea 1, 3-30.

Fontes, R. F. C. e B. M. Castro (2017). Currents on the continental shelf adjacent to the Laje de Santos (SP, Brazil). Brazilian Journal of Oceanography 65(4), 594-604.

Fortes, J. F. (2019, jan). Avaliação do potencial de energias marinhas na região de São Sebastião. Ph. D. thesis, Universidade de São Paulo, São Paulo.

Georgas, N., A. F. Blumberg, M. S. Bruno, e D. S. Runnels (2009). Marine Forecasting for the New York Urban Waters and Harbor Approaches: The Design and Automation of NYHOPS. In 3rd International Conference on Experiments/Process/System Modeling/Simulation \& Optimization, pp. 1-8.

Gill, A. E. e E. H. Schumann (1974). The Generation of Long Shelf Waves by the Wind. Journal Of Physical Oceanography 4(1), 83-90.

Gregorio, H. P. (2014). Oscilações subinerciais na plataforma continental sudeste: estudos numéricos. Ph. D. thesis, Universidade de Sao Paulo.

Harari, J. e R. Camargo (1994). Simulação da propagação das nove principais componentes de maré na plataforma sudeste Brasileira através de modelo numérico hidrodinámico. Brazilian Journal of Oceanography 42(1-2), 3554.

Harari, J. e R. Camargo (1998). Modelagem numérica da região costeira de Santos (SP): Circulação de maré (Numerical modeling of the coast region of Santos (SP): tidal circulation). Rev. bras. oceanogr 46(2), 135-156.

Huthnance, J. M. (1975). On trapped waves over a continental shelf. Journal of Fluid Mechanics 69(4), 689-704. 
Kirinus, E. P., P. H. Oleinik, J. Costi, e W. C. Marques (2018). Long-term simulations for ocean energy off the Brazilian coast. Energy 163, 364-382.

Kousky, V. E. (1979). Frontal influences on notheast Brazil. Monthly Weather Review 107, 1140-1153.

Large, W. G. e S. Pond (1981). Open ocena Momentum Flux Measurements in Moderate to Strong Winds. Journal of Physical Oceanography 11, 324-336.

Liberto, T., B. A. Colle, N. Georgas, A. F. Blumberg, e A. A. Taylor (2011). Verification of a Multimodel Storm Surge Ensemble around New York City and Long Island for the Cool Season. American Meteorological Society 26, 922-939.

Loder, J. W., W. C. Boicourt, e J. H. Simpson (1998). Western Ocean Boundary Shelves. The Sea 11, 3 - 28.

Mazzini, P. L. F. (2009). Correntes Subinerciais na Plataforma Continental Interna entre Peruıbe e São Sebastião: Observações. Dissertação de mestrado, Universidade de Sao Paulo.

Mellor, G. L., C. R. Mechoso, e E. Keto (1982). A diagnostic calculation of the general circulation of the atlantic ocean. Deep Sea Research Part A, Oceanographic Research Papers 29(10), 1171-1192.

Miranda, L. B. (1982). Análise de massas de água da plataforma continental e da região oceânica adjacente: Cabo de São Tomé (RJ) a Ilha de São Sebastião $(S P)$. Tese de livre docência, Universidade de Sao Paulo.

Miranda, L. B., E. Dalle Olle, A. L. Bérgamo, L. S. Silva, e F. P. Andutta (2012). Circulation and salt intrusion in the Piaçaguera channel, Santos (SP). Brazilian Journal of Oceanography 60(1), 11-23.

Moller, O. O., P. Castaing, J. C. Salomon, e P. Lazure (2001). The Influence of Local and Non-Local Forcing Effects on the Subtidal Circulation of Patos Lagoon. Estuaries 24(2), 297.

Möller, O. O., A. R. Piola, A. C. Freitas, e E. J. D. Campos (2008). The effects of river discharge and seasonal winds on the shelf off southeastern South America. Continental Shelf Research 28(13), 1607-1624.

Morais, P. H. S. M. (2016). Hidrodinâmica da Plataforma Continental Interna 
do estado de São Paulo. Dissertação de mestrado, Universidade de Sao Paulo.

Pereira, A. F., B. M. Castro, L. Calado, e I. C. da Silveira (2007). Numerical simulation of M2 internal tides in the South Brazil Bight and their interaction with the Brazil Current. Journal of Geophysical Research: Oceans 112.

Pereira, C. S. (1989). Seasonal variability in the coastal circulation on the Brazilian continental shelf (29S-35S). Continental Shelf Research 9(3), 285-299.

Pimenta, F. M. (2001). Estudo Numérico da influencia da descarga fluvial e dos ventos sobre a dinamica da pluma do Rio da Prata, 2001. Ph. D. thesis, Universidade de Sao Paulo.

Pimenta, F. M., E. J. D. Campos, J. L. Miller, e A. R. Piola (2005). A numerical study of the Plata River plume along the southeastern South American continental shelf. Brazilian Journal of Oceanography 53, 129-146.

Piola, A. R. (1999). Continental shelf water masses off eastern South America-20 to $40 \mathrm{~S}$.

Piola, A. R., E. J. D. Campos, O. O. Möller, M. Charo, e C. Martinez (2000). Subtropical Shelf Front off eastern South America. Journal of Geophysical Research 105(C3), 6565-6578.

Piola, A. R., R. P. Matano, E. D. Palma, O. O. Möller, e E. J. D. Campos (2005). The influence of the Plata River discharge on the western South Atlantic shelf. Geophysical Research Letters 32(1), 1-4.

Reid, R. O. e B. R. Bodine (1968). Numerical Model for Storm Surges in Galveston Bay. Journal of the Waterways and Harbors Division 94(1), 33-58.

Rezende, J. H. M. (2003). Intrusões da água central do atlântico sul na plataforma continental sudeste durante o verão. $\mathrm{Ph}$. D. thesis, Universidade de Sao Paulo.

Rodrigues, M. L. G., D. Franco, e S. Sugahara (2004). Climatologia de frentes frias no litoral de Santa Catarina. Revista Brasileira de Geofisica 22(2), 135151.

Ruffato, D. G. (2011). Circulação na Plataforma Continental Interna e Média do Estado de São Paulo durante o verão: estudos numéricos. Dissertação de mestrado, Universidade de Sao Paulo. 
Saha, S., S. Moorthi, X. Wu, J. Wang, S. Nadiga, P. Tripp, D. Behringer, Y. T. Hou, H. Y. Chuang, M. Iredell, M. Ek, J. Meng, R. Yang, P. M. Malaquías, H. Van Den Dool, Q. Zhang, W. Wang, M. Chen, e E. Becker (2014). The NCEP Climate Forecast System Version 2. Journal of Climate 27, 21852208.

Satyamurty, P., C. A. Nobre, e P. L. S. Dias (1998). South America. In Meteorology of the Southern Hemisphere, pp. 119-139. Boston, MA: American Meteorological Society.

Silva, D. A. (2019). Circulação gerada por ventos anômalos na Plataforma Continental sudeste durante o verão de 2014. Ph. D. thesis, Universidade de São Paulo.

Silveira, I. C. A., A. C. K. Schmidt, E. J. D. Campos, S. S. Godoi, e Y. Ikeda (2000). A Corrente do Brasil ao Largo da Costa Leste Brasileira (The Brazil Current off the Eastern Brazilian Coast). Revisão Rev. bras. oceanogr 48(2), 171-183.

Smagorinsky, J. (1963). General circulation experiments with the primitive equations. Monthly Weather Review 91(3), 99-164.

Soares, I. e O. O. Möller (2001). Low-frequency currents and water mass spatial distribution on the southern Brazilian shelf. Continental Shelf Rese$\operatorname{arch} 21(16-17), 1785-1814$.

Stech, J. L. (1990). Um estudo comparativo da dinâmica da circulação de inverno entre as plataformas continentais das costas sudeste do Brasil e dos Estados Unidos utilizando um modelo numérico. $\mathrm{Ph}$. D. thesis, Universidade de São Paulo.

Stech, J. L. e J. A. Lorenzzetti (1992). The response of the South Brazil Bight to the passage of wintertime cold fronts. Journal of Geophysical Research 97(C6), 9507.

Sun, X., K. H. Cook, E. K. Vizy, X. Sun, K. H. Cook, e E. K. Vizy (2017). The South Atlantic Subtropical High: Climatology and Interannual Variability. Journal of Climate 30(9), 3279-3296.

Valentim, S. S., M. E. C. Bernardes, M. Dottori, e M. Cortezi (2013). Lowfrequency physical variations in the coastal zone of Ubatuba, northern coast 
of São Paulo state, Brazil. Brazilian Journal of Oceanography 61(3), 187193.

Vaz, A. C., O. O. Möller, e T. L. Almeida (2006). Análise quantitativa da descarga dos rios afluentes da Lagoa dos Patos. Atlantica 28(1), 13-23.

Wallace, J. M. e P. V. Hobbs (2006). Atmospheric Science : an Introductory Survey. Elsevier Science.

Warner, J. C., W. R. Geyer, e J. A. Lerczak (2005, may). Numerical modeling of an estuary: A comprehensive skill assessment. Journal of Geophysical Research 110(C5), C05001.

Willmott, C. J. (1981). On the validation of models. Physical Geography 2(2), 184-194.

Zembruscki, S. e H. Chaves (1979). Geomorfologia da Margem Continental Sul Brasileira e das Bacias Oceânicas Adjacentes.

Zhang, X., M. Marta-Almeida, e R. D. Hetland (2012). A high-resolution preoperational forecast model of circulation on the Texas-Louisiana continental shelf and slope A high-resolution pre-operational forecast model of circulation on the Texas-Louisiana continental shelf and slope. Journal of Operational Oceanography 5(1), 19-34. 